\title{
A MULTIPHASE MODIFIED BOOST CONVERTER WITH REDUCED INPUT CURRENT RIPPLE: COMBINED CAPACITORS
}

\author{
A Thesis \\ presented to \\ the Faculty of California Polytechnic State University, \\ San Luis Obispo
}

\begin{abstract}
In Partial Fulfillment
of the Requirements for the Degree of

Master of Science in Electrical Engineering
\end{abstract}

by

Omri Nissan

June 2018 
(C) 2018

Omri Nissan

ALL RIGHTS RESERVED 


\section{COMMITTEE MEMBERSHIP}

TITLE: A Multiphase Modified Boost Converter With Reduced Input Current Ripple: Combined Capacitors

AUTHOR: Omri Nissan

DATE SUBMITTED: June 2018

COMMITTEE CHAIR: Taufik, Ph.D.

Professor of Electrical Engineering

COMMITTEE MEMBER: Tina Smilkstein, Ph.D.

Professor of Electrical Engineering

COMMITTEE MEMBER: Ali O. Shaban, Ph.D.

Professor of Electrical Engineering 


\begin{abstract}
A Multiphase Modified Boost Converter with Reduced Input Current Ripple: Combined Capacitors

Omri Nissan

The delivery of high power and smaller footprints through a non-isolated topology demands for the use of multiphase topology in DC-DC converters. Multiphase reduces the ripple observed on both the input and output waveforms; however, it may not be enough to connect to sensitive power sources such as renewable energy sources. A single-phase modified boost converter demonstrates the ability to acquire very minimal input current ripple by addition of passive components. The expansion to multiphase topology is the next logical step for higher power application while furthering the low input current ripple benefit. In this thesis, the multiphase modified boost topology is compared with the multiphase standard boost topology to explore the benefits and trade-offs of the proposed topology. A $12 \mathrm{~V}$ input to $19 \mathrm{~V}$ output at $95 \mathrm{~W}$ output power multiphase standard and modified boost converters were designed and constructed for the thesis. Results from theoretical calculations, computer simulations, and hardware implementations were then compared to evaluate their performances. Results show that compared to the standard boost, the modified boost yields significantly less input current ripple at $2 \%$ under full load condition while maintaining output voltage ripple of 5\% and higher than $90 \%$ efficiency.
\end{abstract}

Keywords: dc/dc, boost converter, multiphase, minimum input current ripple 


\section{ACKNOWLEDGMENTS}

Through my work this year, many people expressed their support and excitement. Many non-electrical engineers wanted to know what I am writing about, which turned into 30 minutes talk of explaining what voltage is to technical folks who were fascinated with this new technology. Their curiosity helped me define my thesis better and share what I love about electrical engineering. For that I have to say thank you to all of those who listened.

My passion for power electronics came through my internships, however Professor Taufik amplified that passion. His dedications, kindness, and wonderful stories always put a smile on my face and made me appreciate the technology and life. I will always be grateful for the time we spent in the classroom and outside. You shaped my electrical engineering journey in the most positive direction ever possible and for that I will always be grateful.

And to amazing my family:

ילש הרקי החפשמ,

ב יתוא םתדרוה לומתא וליאכ הז לבא, ,ןמאי אל- Cal Poly, תונועמה דיל היינחב התנח דרופה .

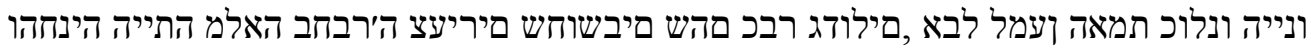

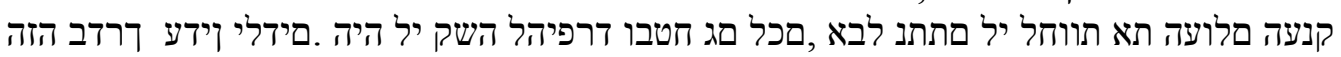

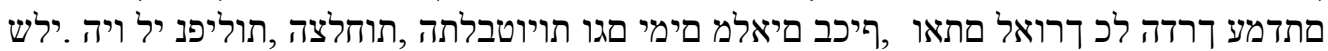

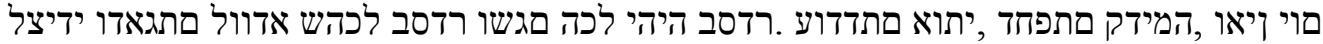

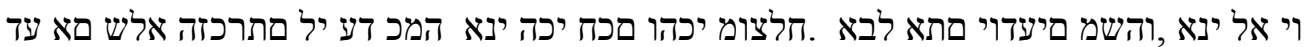

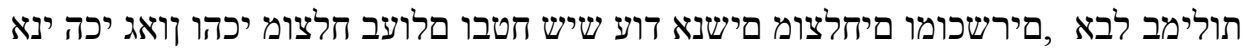

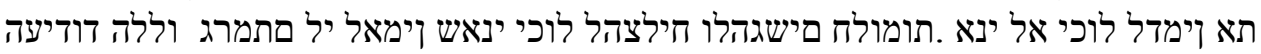

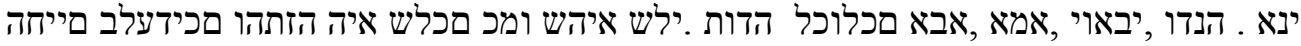
הוא.םוקיה פוס דע םכתוא ב יבאוא

דכ לכ םכתוא בהוא ינאש סכל רמול יתיצר, יב האגו קוחרמ יב תכמותש תבחרומה החפשמל לכה לע הדותו. - (לכת מכואות.

ארזע אבסלו,

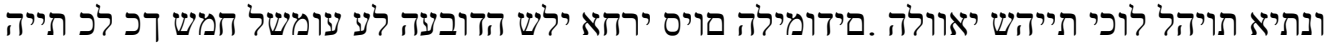

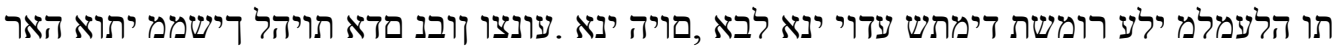
הוואגל ךל תויהל דישמהל רומשת דימשש עדוא הווקמ. 


\section{TABLE OF CONTENTS}

Page

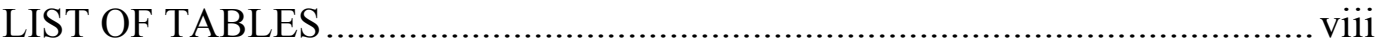

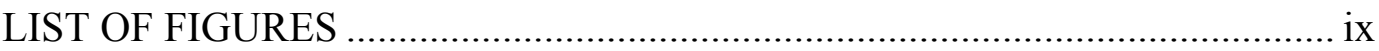

\section{CHAPTER}

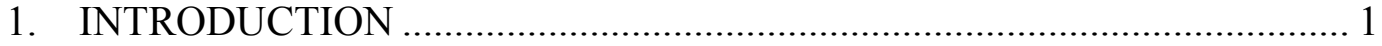

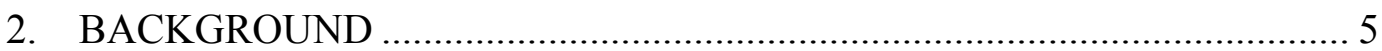

2.1 DC-to-DC Converter Characteristics ..................................................... 5

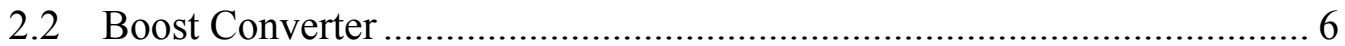

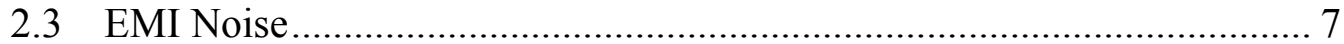

2.4 Modified Boost Converter Topology ……………………………….... 8

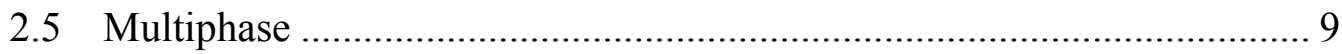

2.6 Multiphase Modified Boost Topologies ................................................. 11

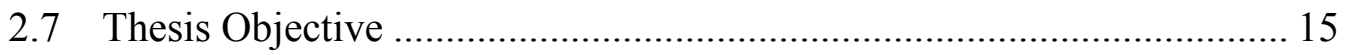

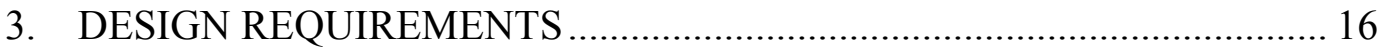

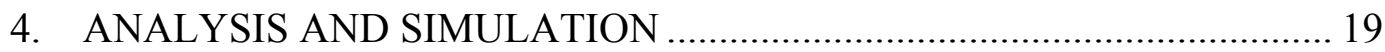

4.1 Multiphase Boost Calculations ............................................................. 20

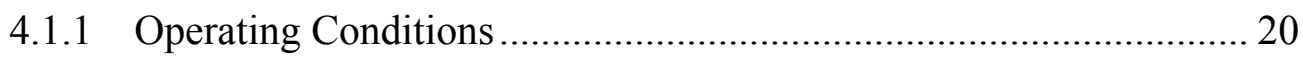

4.1.2 Inductor Calculations ...................................................................... 21

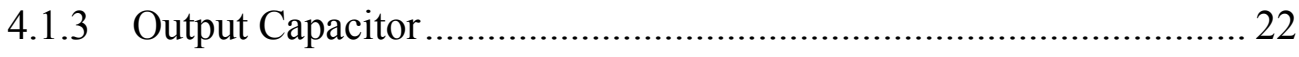

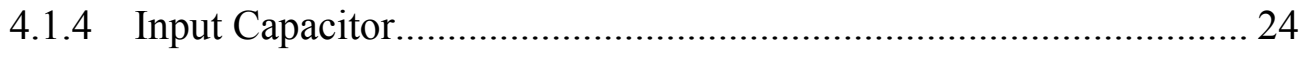

4.2 Modified Multiphase Topology ……………………........................... 25

4.2.1 State Space Representation And Analysis .......................................... 26

4.3 State Space Equations Derivations ....................................................... 27

4.3.1 State Space for State 1 ................................................................... 30

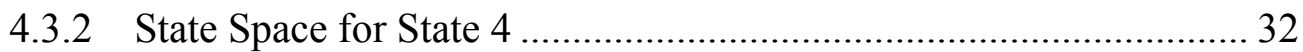

4.3.3 State Space for State Eight................................................................ 33

4.3.4 Overall System State Space .......................................................... 34

4.3.5 Averaging and DC Transfer Functions ............................................ 35

4.4 Matlab Simulation Using State Space ……………………………........ 37

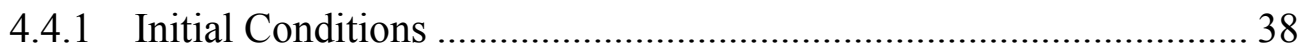

4.4.2 M-Domain State Space Transformation ……………………........... 39 


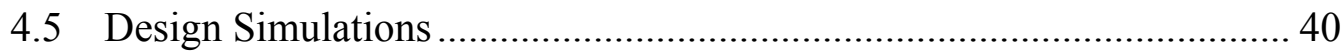

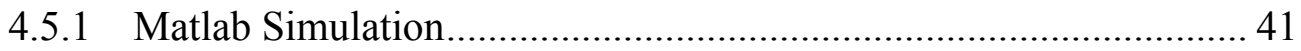

4.5.2 LTSpice Simulation Behavioral......................................................... 44

4.5.3 LTSpice Full Simulation - Using IC ............................................... 47

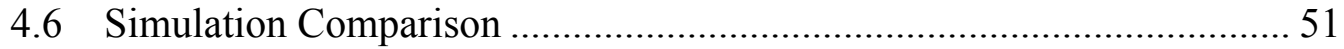

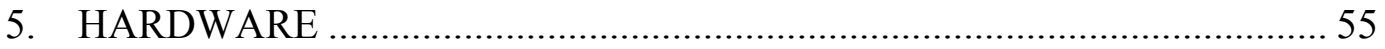

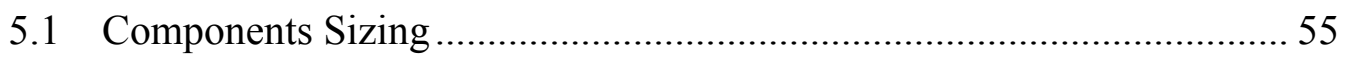

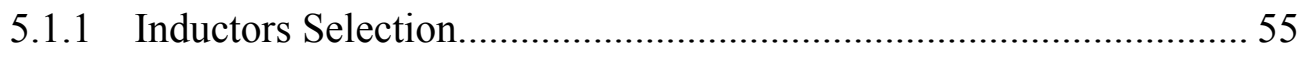

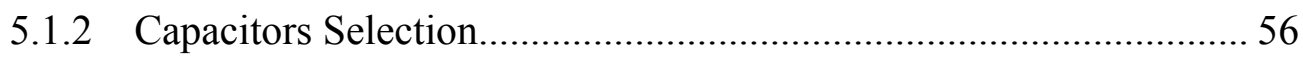

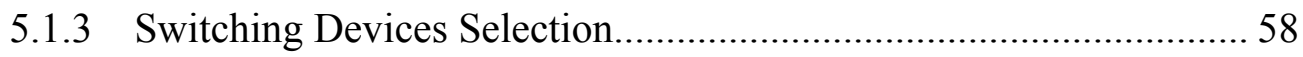

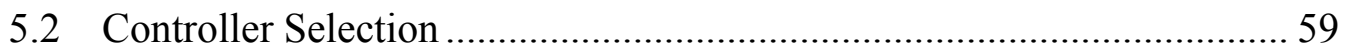

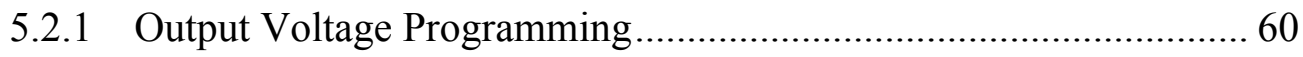

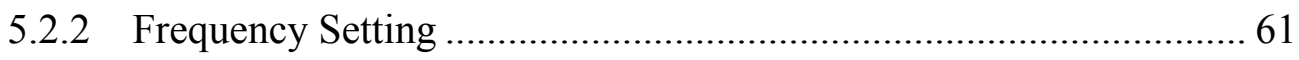

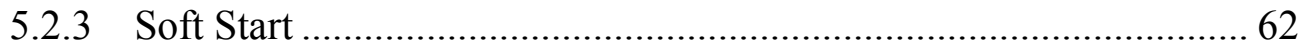

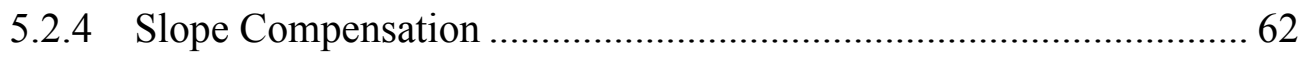

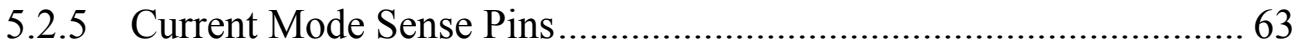

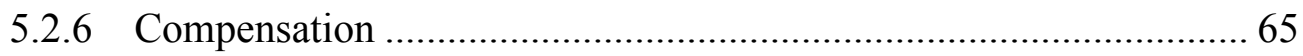

5.3 Power Dissipation ............................................................................ 70

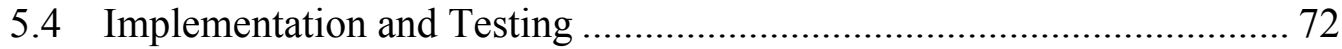

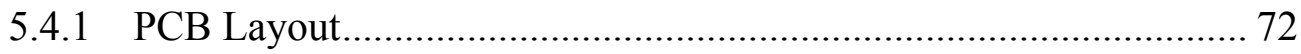

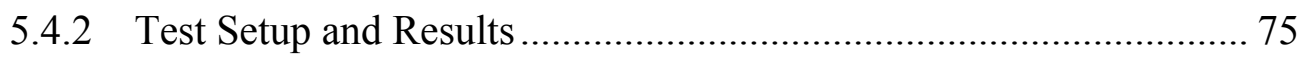

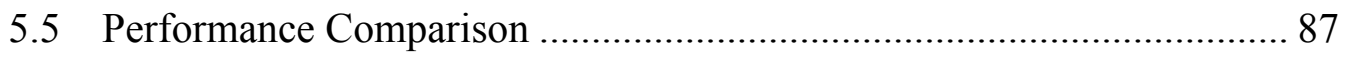

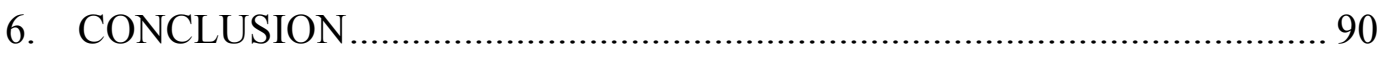

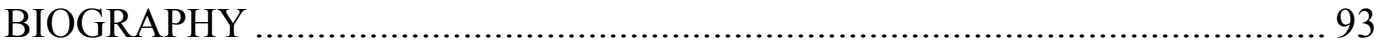

APPENDICES

A. Matlab State Variable Simulation ............................................................. 96

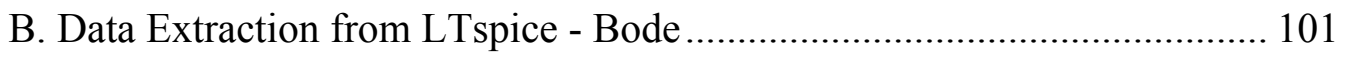

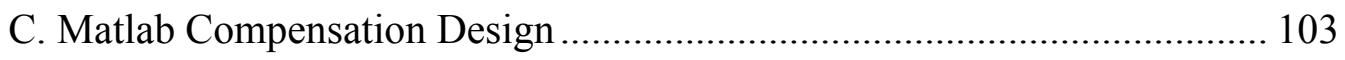

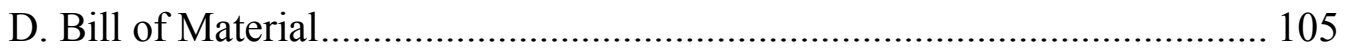

E. Altium PCB Layout .................................................................................. 107

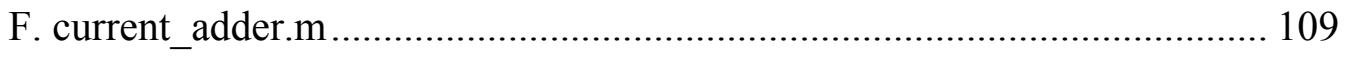

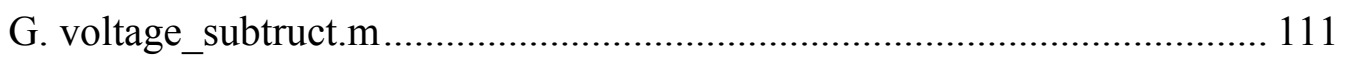

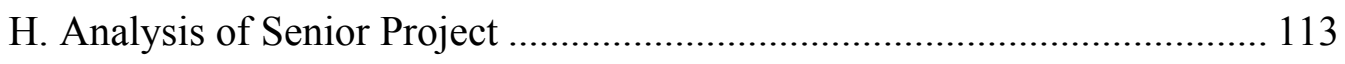




\section{LIST OF TABLES}

Table Page

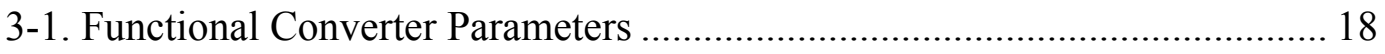

4-1. The 8 Different Types of Combinations for State Space............................ 28

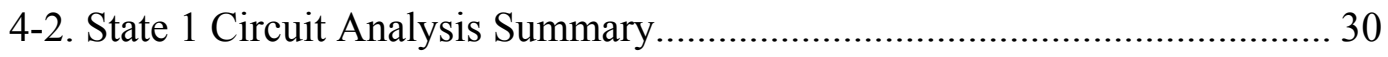

4-3. State 4 Circuit Analysis Summary ….................................................... 32

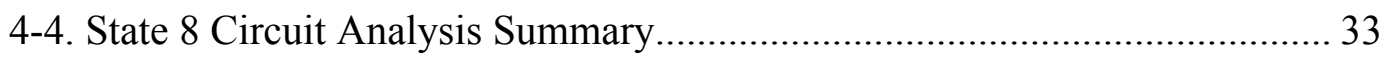

4-5. Modified Multiphase Boost Converter Component Averages ...................... 38

4-6. Converter Design Parameter Summary ....................................................... 41

4-7. Matlab and Theoretical Modified Multiphase Boost Design DC

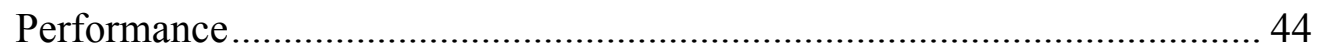

4-8. Standard Boost Simulation Measurement Comparison ............................... 52

4-9. Modified Multiphase Boost Simulation Measurement Comparison ............ 52

4-10. Simulated Boost Converter Input Current Ripple Reduction ...................... 53

5-1. WE-HCC High Current Inductor Series Fixed Inductor Properties .............. 56

5-2. Capacitors Configuration and Properties................................................ 58

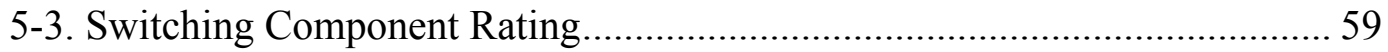

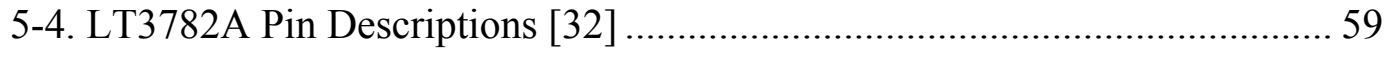

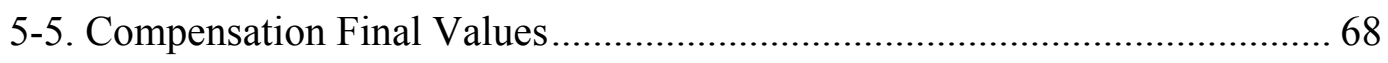

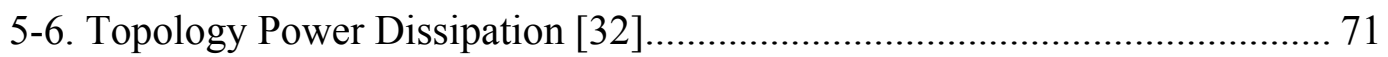

5-7. Standard Multiphase Boost Hardware Results ........................................... 80

5-8. Modified Multiphase Boost Hardware Results .......................................... 86

5-9. Hardware Performance Comparison ….................................................. 88

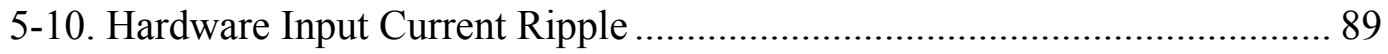




\section{LIST OF FIGURES}

Figure

1-1. Microprocessor Data Over Time .................................................................... 2

1-2. Annual U.S. Solar PV Installations, Q1 2012-Q1 2017 ............................... 3

2-1. The Basic Schematic of a Boost Converter. ................................................ 6

2-2. Modified Boost Converter Schematic .............................................................. 9

2-3. Ripple Cancellation for Multiphase Converter.............................................. 10

2-4. Normalized input RMS current vs. Operational Duty Cycle with One, Two,

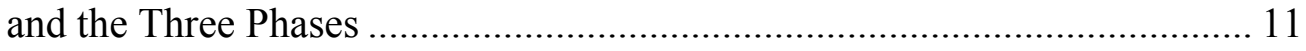

2-5. Design of a Two-Phase Hybrid Boost DC/DC Converter............................. 12

2-6. Two Phase Boost Converter with Directly Coupled Inductors ..................... 12

2-7. Input current Ripple Versus Duty Cycle for Directly Coupled and Uncoupled

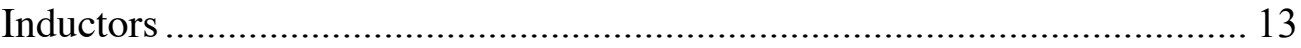

2-8. Two-Phase Interleaved Coupled-Boost Converter with an Additional Active Clamping Circuit for Each Channel [22] ................................................ 14

2-9. Multiphase Coost Converter with $\mathrm{P}=2$ and $\mathrm{N}=2$ [24] ........................... 14

4-1. Modified Multiphase Boost Converter ....................................................... 19

4-2. Two-phase Conventional Boost Converter............................................... 20

4-3. Multiphase Boost Converter Output Capacitor Charge Storage .................. 23

4-4. Multiphase Boost Converter Input Capacitor Charge Storage ...................... 24

4-5. Standard Versus Modified Output Capacitor Current Waveforms ............... 26

4-6. Modified Multiphase Boost Converter General Case................................... 28

4-7. All Options for State Space Schematics ................................................... 29

4-8. Timing Diagram of Gate Drivers for Switching Devices............................ 30

4-9. Matlab Modified Multiphase Boost Inductors Current Waveforms.............. 42

4-10. Matlab Modified Multiphase Boost Capacitors Voltage Waveforms ......... 43

4-11. Matlab Modified Multiphase Boost Capacitors Current Waveforms.......... 43

4-12. LTSpice Standard Multiphase Boost Behavioral Simulation...................... 45

4-13. LTSpice Ripple Waveforms for Standard Multiphase Boost ..................... 45

4-14. LTSpice Modified Multiphase Boost Behavioral Simulation ..................... 46 
4-15. LTSpice Modified Multiphase Boost Inductor Current Waveforms ........... 46

4-16. LTSpice Modified Multiphase Boost Capacitor Voltage Waveforms ........ 47

4-17. LTSpice Modified Multiphase Boost Capacitor Current Waveforms ......... 47

4-18. LTSpice Standard Multiphase Boost Transient Simulation Using

Controller

4-19. LTSpice Standard Multiphase Boost Ripple Waveforms Using

Controller

4-20. LTSpice Modified Multiphase Boost Transient Simulation Using

Controller.

4-21. LTSpice Modified Multiphase Boost Inductor Current Waveforms Using

Controller. 50

4-22. LTSpice Modified Multiphase Boost Capacitor Voltage Waveforms Using Controller. 50

4-23. LTSpice Modified Multiphase Boost Capacitor Current Waveforms Using Controller 51

5-1. LT3782A Output Voltage Programming................................................ 61

5-2. LT3782A Switching Frequency vs R $\mathrm{FREQ}_{\text {Fe }}$ [32] ....................................... 61

5-3. LT3782A Frequency Programming.... 61

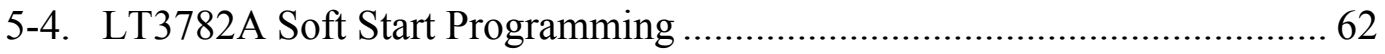

5-5. LT3782A Slope Compensation Programming ......................................... 63

5-6. LT3782A Current Sensing Setup 63

5-7. Comparing Voltage After the MOSFET (Vsense_noisy) to after the Low-

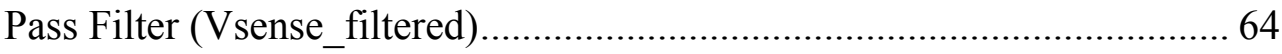

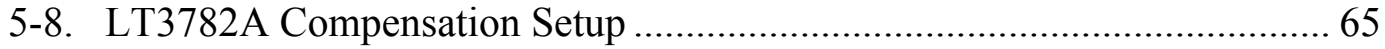

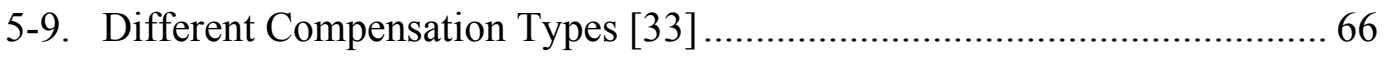

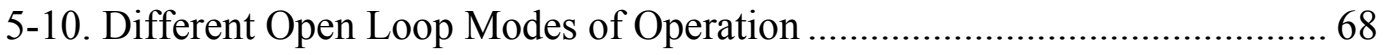

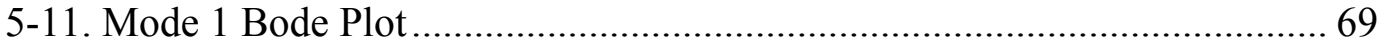

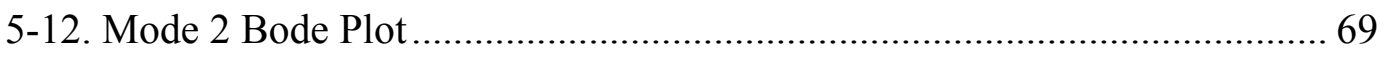

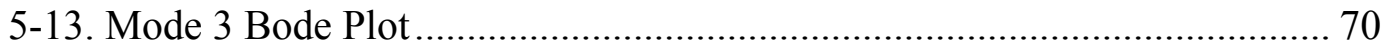

5-14. Top and Bottom Sides of the PCB with Highlighted Power Path and Control System 
5-15. Assembled Standard PCB (Top View) ..................................................... 74

5-16. Assembled Modified PCB (Top View) …………………………............ 75

5-17. Ground Pin Contraption for Voltage Scope Captures …………………..... 76

5-18. Hardware Test Connections...................................................................... 76

5-19. Laboratory Test Configuration .............................................................. 78

5-20. Standard Multiphase Boost Hardware Output Voltage and Gate Drives .... 79

5-21. Standard Multiphase Boost Hardware Inductors' Current (C4 = phase 1, M4

= Phase 2) and Gate Drives .................................................................... 79

5-22. Standard Multiphase Boost Hardware Input Current ................................. 80

5-23. Standard Multiphase Boost Hardware Efficiency Versus Load Percentage

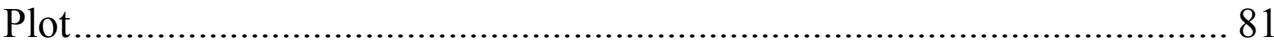

5-24. Modified Multiphase Boost Hardware Output Voltage and Gate Drives ... 82

5-25. Modified Multiphase Boost Hardware Vx Voltage (Positive Node of Feedback Capacitor) and Gate Drives ....................................................... 82

5-26. Modified Multiphase Boost Hardware Feedback Capacitor Voltage.......... 83

5-27. Modified Multiphase Boost Hardware Inner Inductors' $\left(\mathrm{L}_{2 \mathrm{~T}}\right.$ and $\mathrm{L}_{2 \mathrm{~B}}$ )

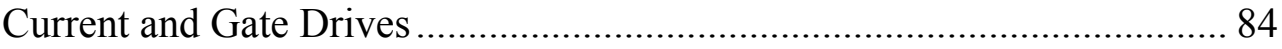

5-28. Modified Multiphase Boost Hardware Outer Inductors' $\left(\mathrm{L}_{1 \mathrm{~T}}\right.$ and $\left.\mathrm{L}_{1 \mathrm{~B}}\right)$

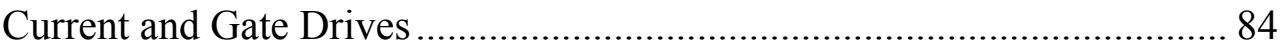

5-29. Modified Multiphase Boost Hardware Input Current................................... 85

5-30. Modified Multiphase Boost Hardware Efficiency Versus Load Percentage Plot

B-1. Window Showing Setting Access from Simulation Plot ........................... 101

B-2. Window Showing Data Exporting Option................................................ 102

B-3. Window Showing Choosing Data and Exporting ...................................... 102

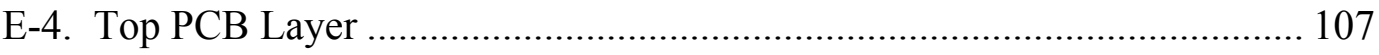

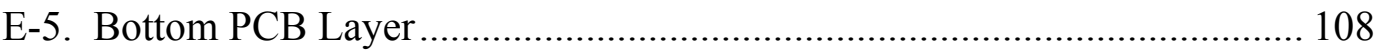




\section{INTRODUCTION}

The average annual electricity consumption for a U.S. residential utility customer is 10,812 kilowatt-hours (kWh) [1]. From the car's control panel to the washing machines, society lives on electricity. Without the necessary power systems with its transmission and distribution systems, and down to power circuitry to turn such devices on, lives will be inconvenient and complicated. The power delivered to American homes is now easily consumed by DC based technology as the use of consumer and portable electronics increases. With the predominantly AC system, this implies that a power conversion stage is always needed to interface between AC electricity from the wall outlets and embedded electronics inside these devices. This is where power electronics plays an important role in providing the bridges between different sources of power.

Power electronics handles all different exchanges of power from AC to DC, DC to $\mathrm{AC}, \mathrm{AC}$ to $\mathrm{AC}$, and $\mathrm{DC}$ to $\mathrm{DC}$. The ability of power electronic converters to stay efficient over a range of changing loads has made them the most fitting for power transformations. The high efficiency of power electronics owes to the solid-state switches and magnetics employed in the majority of power electronic circuits. The switches allow the magnetics to charge and discharge in order to produce the desirable output parameters. Such method should introduce marginal power loss since magnetics are not only storing devices.

One major reason power electronics expanded is due to advancements in semiconductor devices. In the early days of power electronics around 1960s, BJTs allowed for the first switch based power electronics circuitry to be developed. Back then, the BJTs based converter were running on 10-20kHz switching frequency [2]. This seems 
extremely low considering modern day switching frequency runs on Megahertz speeds. As time passes by, revolutionary transistors discoveries have resulted in significant overall performance of those devices. Transistor became more capable of operating at higher frequency and thus led to the integration of MOSFETs in switching converters. The main advantage of such operation is the smaller magnetics since their size is inversely proportional to frequency.

As the consumer electronics advances, so does the thirst for power to operate them. Many new applications have demanded even higher power requirements. Microprocessors, for instance, continue to raise their number of transistors which consequently increases their power requirement as shown in Figure 1-1 [3].

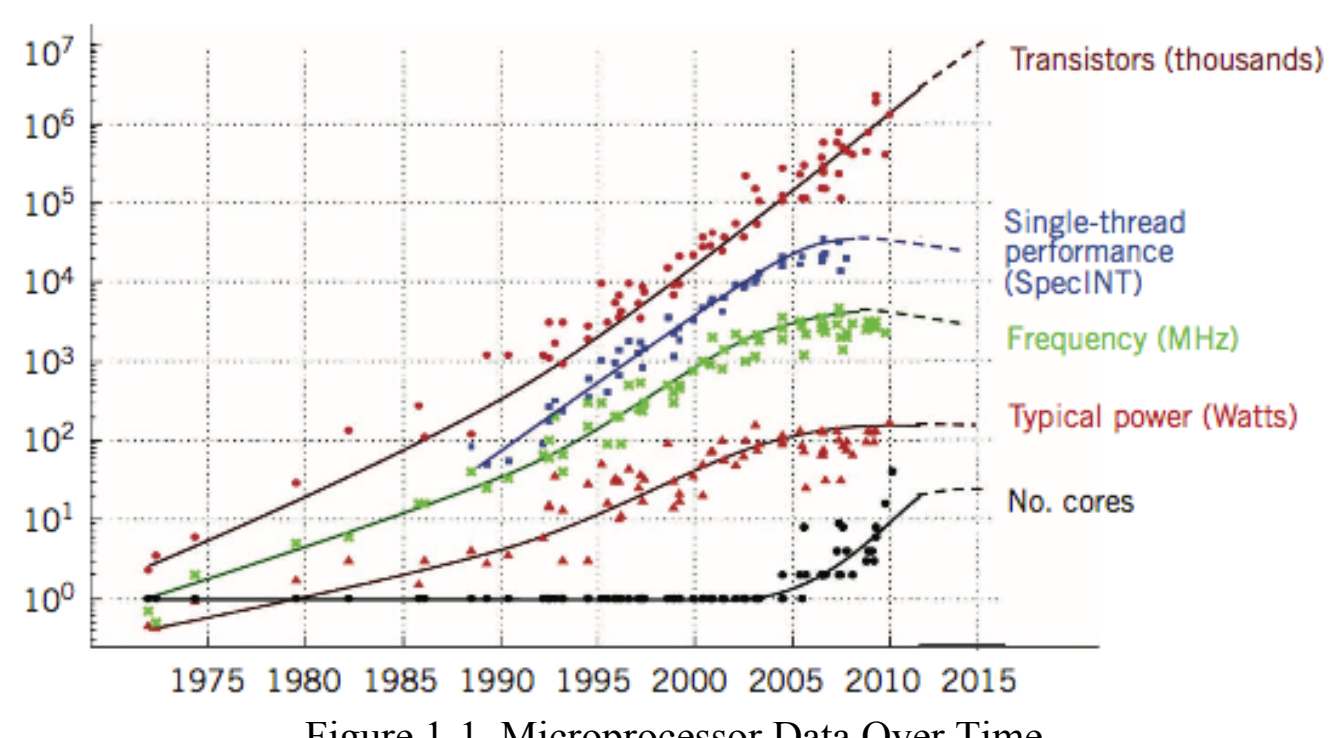

Figure 1-1. Microprocessor Data Over Time

The higher power puts a lot of stress on components, increasing their operating temperature and reducing their lifetime while taking a significant toll on the overall converter's efficiency. The issue of high power load requirement is further worsens when the load operates at very low voltage. As an answer, multiphase topologies have been 
introduced and developed. Multiphase allows higher power capabilities due to splitting of currents among multiple paralleled connected power converter units, thus sharing the energy delivery from the source to the load, and in turn improving overall efficiency of the power converter.

Another type of power electronic device that has become widely used in recent years is the inverter. This is due to the growing popularity of solar panels as indicated in Figure 1-2 [4].

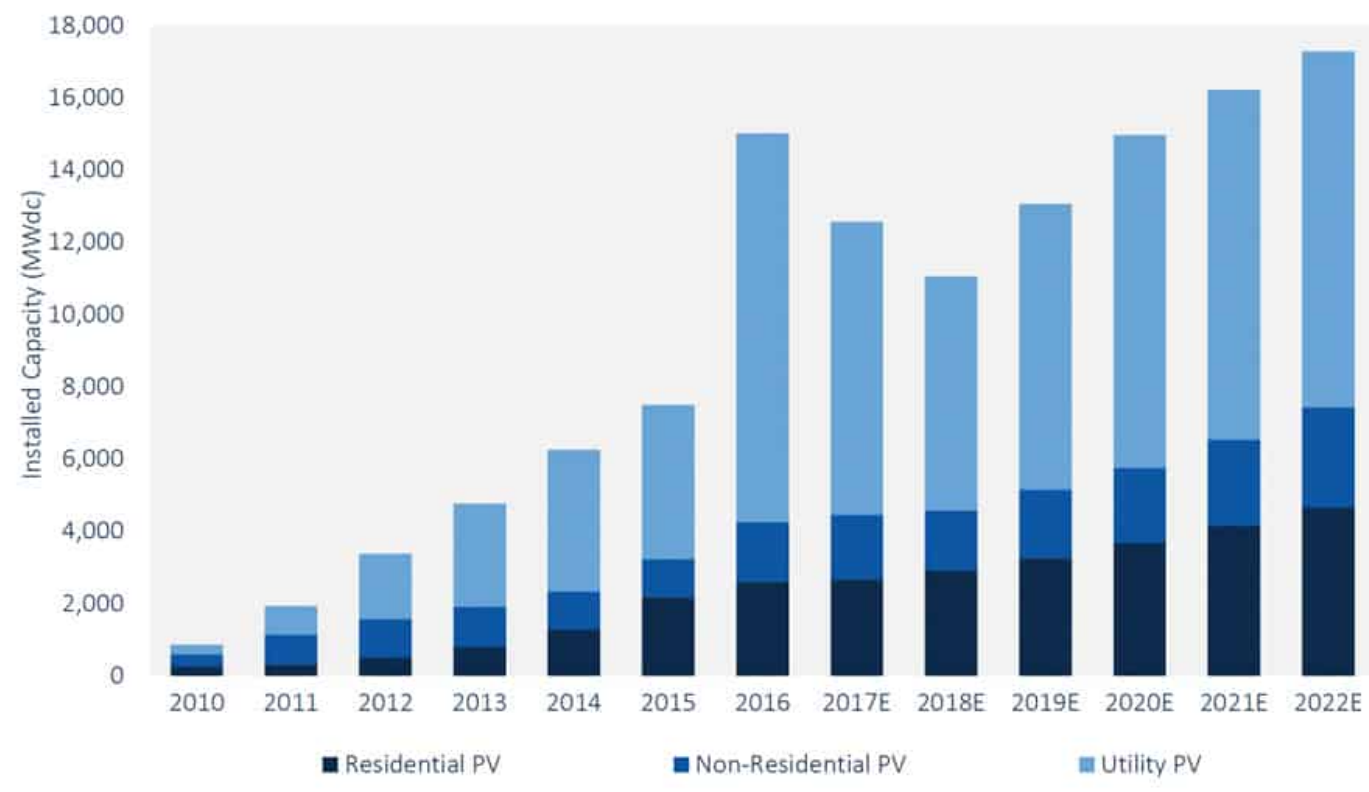

Figure 1-2. Annual U.S. Solar PV Installations, Q1 2012-Q1 2017

Since solar panel is typically connected to the AC grid, an inverter is necessary to convert the DC power to AC power. For residential level, solar panels usually come in at a low DC output voltage that needs to be amplified in order to interface with existing AC infrastructures. This process calls for another converter stage called a Boost converter. Just like the other converters, the Boost converter must be efficient in performing its function. As previously explained, one method to improve converter's efficiency 
especially with high power level is to employ multiphase technique. For residential solar panel applications, some type of multiphase boost topology may achieve this. 


\section{BACKGROUND}

\subsection{DC-to-DC Converter Characteristics}

A DC-to-DC converter performance can be determined based on the following characteristics: efficiency, transient response, line/load regulations, and input and output ripples. Efficiency across different loads of the converter is the most common priority for any designer. A converter's efficiency is determined by the observation of average output power versus average input power. In an ideal situation, the output power would equal the input power, thus resulting in $100 \%$ efficiency. Due to non-ideal components with their parasitic and inherent losses, the efficiency will never be $100 \%$. However, the efficiency may be improved and optimized by careful selection of components or by modifying the topology.

With increased power requirement, another worry for a DC-DC converter is temperature. Since power is proportional to temperature; therefore, high power operation will impact component's rated values and lead to cracking and fracture over a course of time [5]. In DC-DC converters, one method to reduce temperature rise in high power operation is to employ multiphasing and/or interleaving configuration.

Another technical challenge in DC-DC converters especially in large power applications is their ability to handle sudden peak transients on the load and stabilize quickly into the steady state operation. Such transients are major strains on converter's components. For the magnetic components in particular, these transients translate into undesirable saturation of components. To address this issue, careful design of converter's control system must be performed. 
Lastly, some loads are very sensitive to variations in their input power such as microprocessors. This will require DC-DC converters, which supply power to these loads, to have clean output voltage ripples. If the source to DC-DC converter comes from a single DC bus connected to other sensitive loads, then the DC-DC converter should also draw current with minimum ripple. In many cases, reducing ripples means employing filters. However, reducing ripples may also be achieved by modifying converter's topology. A good example of this is the Cuk converter where the main inductors are being placed strategically at its input and output; thus, resulting in clean input and output currents.

\subsection{Boost Converter}

One most commonly used switching converter topology for non-isolated step-up in voltage is the boost converter. In the simplest form, a boost converter is constructed using an inductor, a switch, and a diode as seen in Figure 2-1. The inductor provides the heart of the circuitry due to its nature under DC biasing. It enables the circuit to store energy when the switch is closed, and to release it when the switch is open. This is done while effectively imposing zero average voltage across the inductor according to Volt Second Balance.

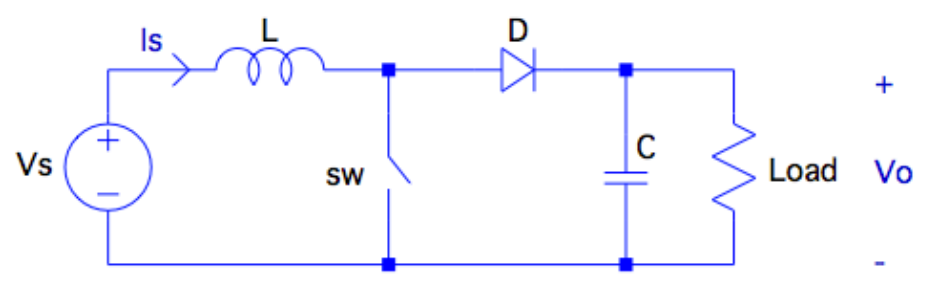

Figure 2-1. The Basic Schematic of a Boost Converter. 
The boost converter has continuous input signal when operated in continuous conduction mode. This is due to the inductor connecting directly to the input. This helps to maximize the output power drawn from a source such as solar, marine, wind energy, fuel cells, and batteries [6]. While boost converter has continuous input signal, the input current ripple is determined by the inductor current waveform, which in turn depends on the inductance value. Therefore, in order to minimize the input current ripple, the inductor value will need to be large. However, this comes at the cost of size of the converter as inductor is inherently bulky.

For photovoltaics (PV), small input ripple is essential. At low-insolation levels, a small ripple can cause a major difference in the output power of PV system. A ripple can have a major effect on efficiency as seen by the equation below [7].

$$
\eta_{\text {prip }}=\frac{P_{\text {avg }}}{V_{m p p}\left(I_{s c} R-I_{s}\left(e^{\frac{m V_{m p p}}{N_{c e l l} V_{t}}}-1\right)-\frac{V_{m p p}}{R_{p}}\right)}
$$

This equation is known as the "transfer efficiency" for the all PV panel. The transfer efficiency describes the average power result divided by the average power at the DC maximum power operation point. The term, $\mathrm{V}_{\mathrm{mpp}}$, is the peak power point voltage of the panel, which included the peak voltage. Thus the higher the ripple, the larger the efficiency drop.

\subsection{EMI Noise}

Due to the switch in power electronic converters, EMI noise is unavoidable. The dynamic excitation of the switches results in high frequency voltage and current contents. The EMI noise propagates to the power and ground rails, which may cause failures [8]. 
There are many methods to suppress EMI. The most important is to utilize capacitor banks at the input and output of a converter. There are usually two types of capacitors placed to serve this purpose: Electrolytic bulk capacitor and Ceramic SMT capacitor. The bulk capacitors are generally very high valued in capacitance and are used to decouple low-frequency switching noise (typically $100-300 \mathrm{KHz}$ switching rate and its harmonics). The ceramic SMT capacitors are placed closer to the switches to provide high frequency current corresponding to the rise and fall times of the switching waveform (>30 MHz) [9].

Real world capacitors are not perfect capacitances; thus, it is important to observe their non-ideal properties such ESR (Equivalent Series Resistance). For electrolytic capacitors, the ESR tends to be high, affecting the efficiency and transient response of converters. On the opposite end, ceramics capacitors have small ESR value; however, under high voltage biasing, they tend to loss their capacitive values [10].

Inserting capacitance works well, but usually not enough to meet the EMI suppression requirements. Therefore, an alternative method such as expanding a converter to multiphase topology is needed to minimize ripples and EMI while cutting down on input and/or output capacitances. This in turn frees up space and helps improve the overall efficiency.

\subsection{Modified Boost Converter Topology}

Through the modification of a boost converter, the ripples may be decreased further. One example of a modified Boost converter is shown in Figure 2-2, which has been demonstrated to improve input current ripple by $40 \%$ [11]. The additional inductor 
and capacitor pairs are bypass components between the input and output stages to increase energy storage capacity and lower input/output ripples.

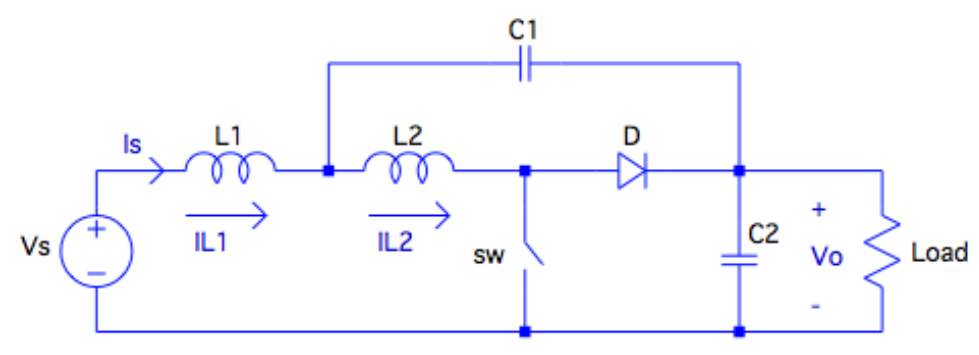

Figure 2-2. Modified Boost Converter Schematic

\subsection{Multiphase}

Even though ripples has improved significantly in the modified boost converter, the topology will still be troublesome in high power applications due to increased components' stress. Additionally, the high power requirement demands big components in a single stage converter configuration. As a result, the multiphase solution is necessary. Multiphase allows the division of power path between multiple converter's phases. Each phase is identical; thus, each performs uniformly. As a result, each phase is designed according to the output power requirement divided by the number of phases. This yields enhanced overall converter system efficiency, reliability, and flexibility.

Moreover, multiphase controllers intrinsically generate switching signals that are mismatched to create ripple cancellation on the output as seen in Figure 2-3 [12] [13]. This phenomenon is known as interleaving [14]. The ripple cancellation causes a new output frequency of the converter where it is described by the switching frequency times the number of phases [15]. As a result, filtering and transient response improve drastically [16]. This allows the controller to operate at lower frequency, while harmonics associated with the converter will be located at multiples of the higher output frequency. 


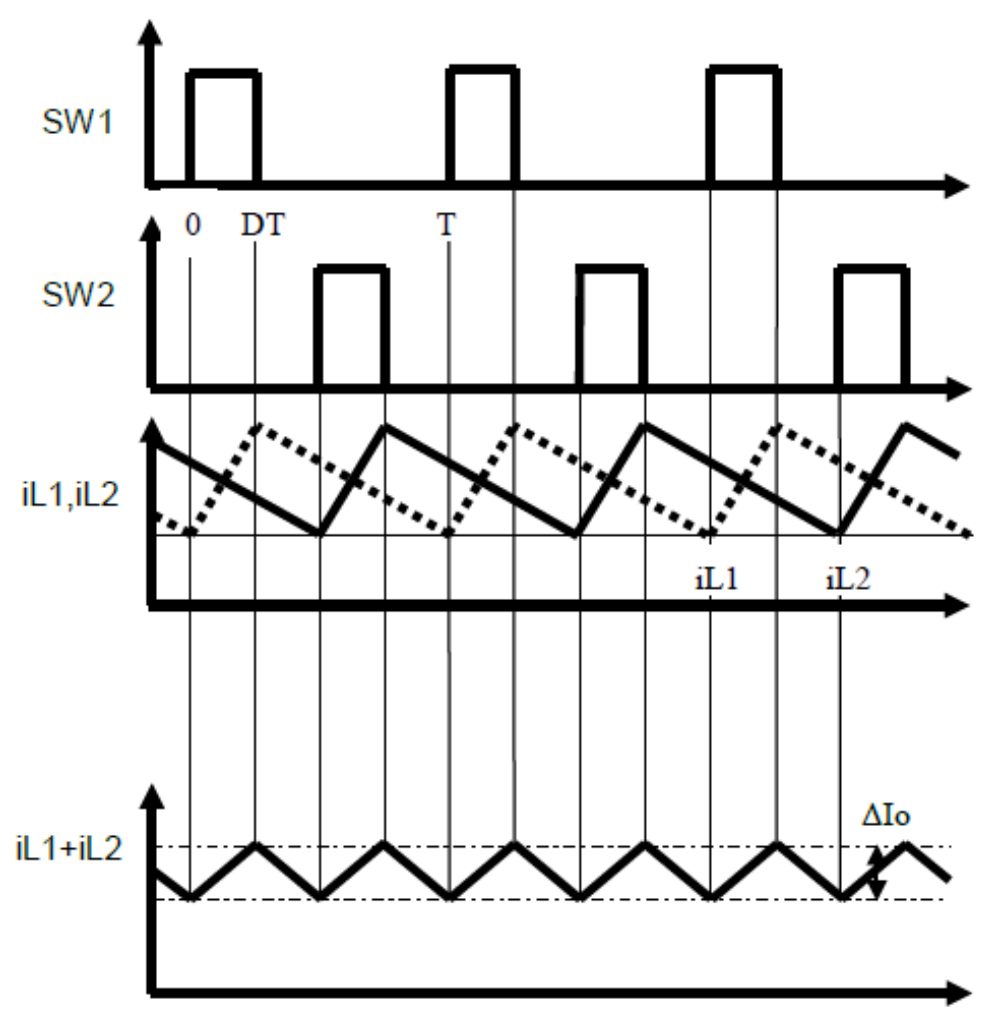

Figure 2-3. Ripple Cancellation for Multiphase Converter

The equation below describes the necessary phase shift to implement interleaving, where $\mathrm{n}$ is a specific phase and $\mathrm{N}$ is the total number of phases. For each phase, $\mathrm{n}$, the equation describes the necessary shifted phase angles at which the ripple is minimized [17] [18] [19].

$$
\phi_{n}=(n-1) \cdot \frac{360^{\circ}}{N}
$$

As the phase number increases, the more the maximum ripple value subsides. Since the overall ripple is smaller, input and output RMS currents are also minimized. Figure 2-4 demonstrates how phase number affects RMS value. However, the more phases added the smaller the maximum duty cycle of each phase becomes. This requires a sensitive and dynamic controller. The maximum duty cycle for each phase is described in Equation 2-3, where $\mathrm{N}$ is the total number of phases. 


$$
D_{\max }=\frac{1}{N} \quad(\text { Equation } 2-3)
$$

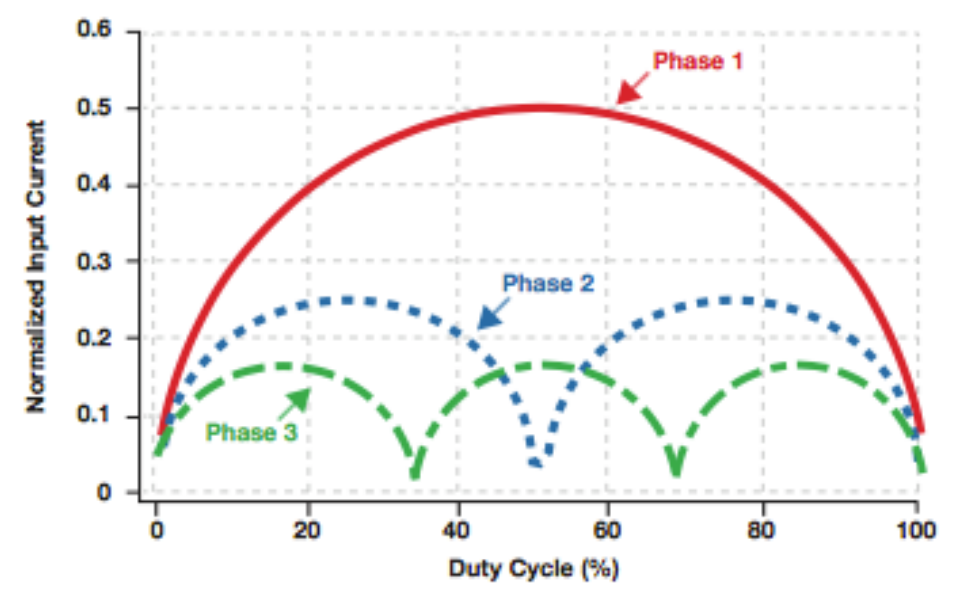

Figure 2-4. Normalized input RMS current vs. Operational Duty Cycle with One, Two, and the Three Phases

\subsection{Multiphase Modified Boost Topologies}

Multiphase configuration in DC-DC converters simplifies a lot of the complications encountered in high power and low ripple applications. However, an even better response may be achieved by combining the multiphase topology with modified converter topology that inherently minimized ripples. For boost converter, one example is the Novel Multiphase Hybrid Boost Converter seen in Figure 2-5. If the design was a single phase, it would require a large filtering due to the big voltage gain. The topology is designed to handle $40-60 \mathrm{~V}$ input to $120 \mathrm{~V}$ output, where output power can vary between $100-150 \mathrm{~W}$ with sub $90 \%$ efficiency. As previously stated, the more phases added, the better the input current ripple becomes. However such design is very hard to control and it becomes expensive quickly [20]. 


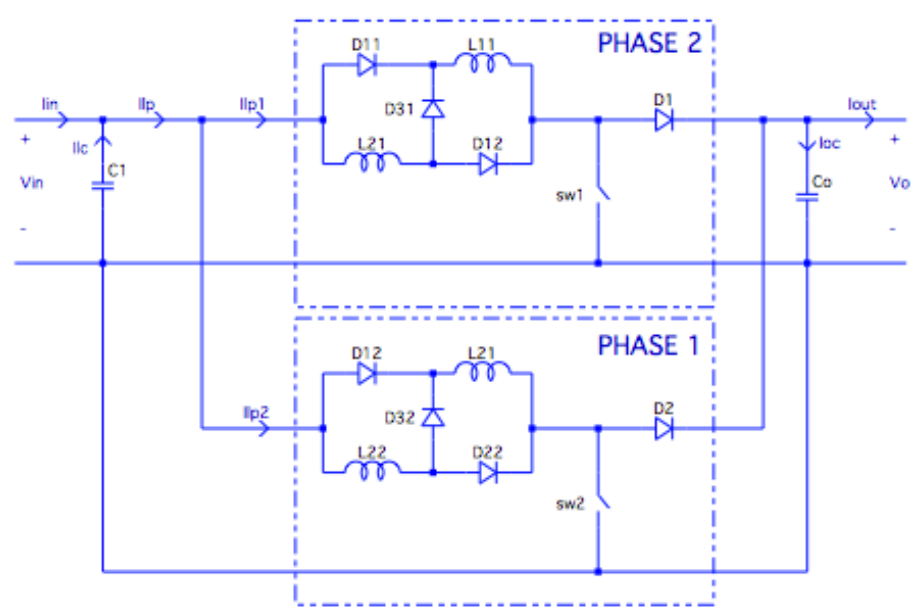

Figure 2-5. Design of a Two-Phase Hybrid Boost DC/DC Converter

Multiphase-coupled inductor topology is another approach as displayed in Figure 2-6. It aims to eliminate the number of components and magnetics. Due to the nature of coupled windings, a ripple can be exchanged between windings, which creates a ripple free input and output currents [21].

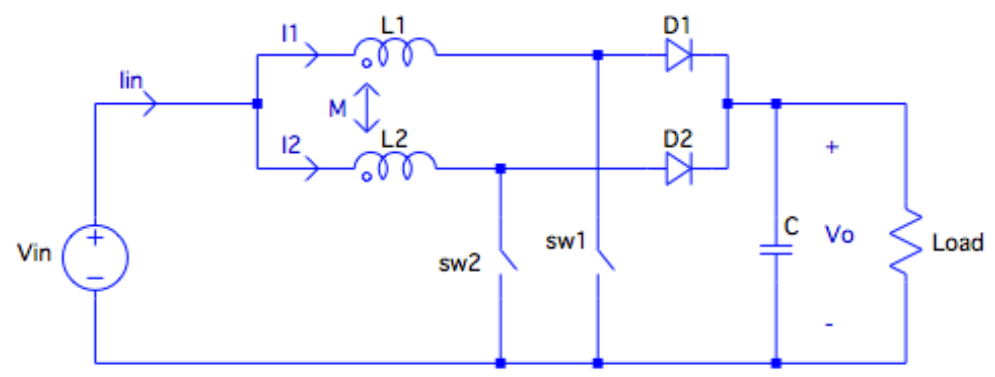

Figure 2-6. Two Phase Boost Converter with Directly Coupled Inductors

Coupled inductors have mutual inductance, which is taken into consideration when deriving the transfer function of the converter. The coupling coefficient, $\alpha$, differentiates between a regular boost converter and a coupled inductor topology. The parameter $\alpha$ may take the values between -1 and 1 . Figure $2-7$ shows the input current variation of uncoupled and the directly coupled inductors respectively. 


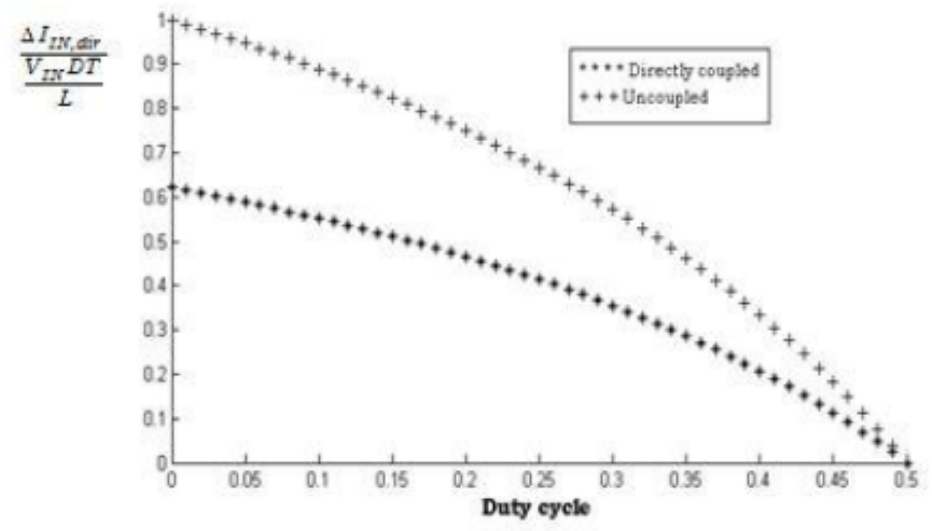

Figure 2-7. Input current Ripple Versus Duty Cycle for Directly Coupled and Uncoupled Inductors

A different configuration specifically helps with clamping the voltage spikes on the MOSFETS while using coupled inductors, which can extend the duty cycle [22]. This circuit looks like the one depicted in Figure 2-8. However, the leakage inductance from the inductors causes voltage spikes across the MOSFETs, and thus greater power losses. The inductances combines with output filtering cap during transition periods creates a resonating oscillations. These oscillations are known as ringing [9] [23]. This topology suggests including an active clamp method, which eliminates the addition of snubber circuitry. The capacitor is considered a voltage source because it is big; thus, it will be hard to change its current quickly. As a result, the spikes across the MOSFET dwindle. 


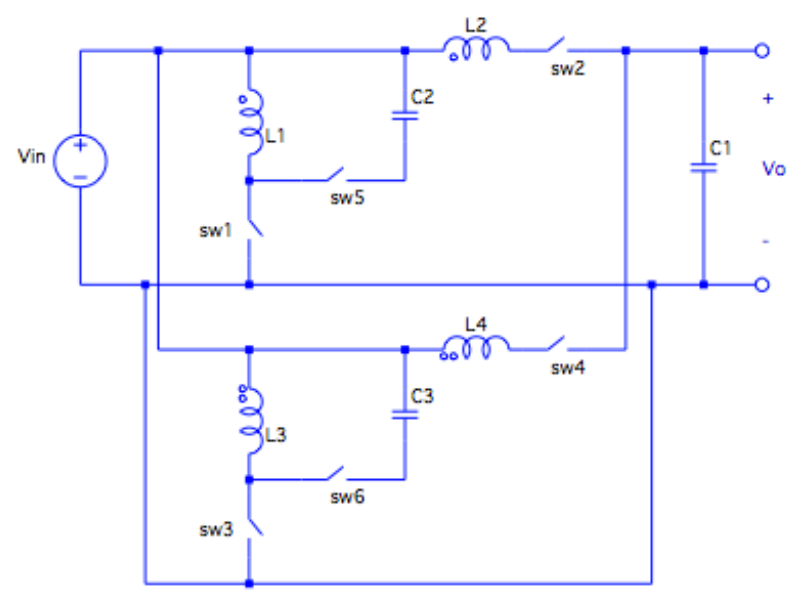

Figure 2-8. Two-Phase Interleaved Coupled-Boost Converter with an Additional Active Clamping Circuit for Each Channel [22]

While coupled inductors have great benefits, most power electronics engineers still feel unease using them due to difficulty of analysis. As a result, more topologies emerge with non-coupled inductors like the Schuck's design. This design permits a large voltage gain with individual magnetics. The design is based on adding an auxiliary circuitry before the filtering stage of a boost converter as seen in Figure 2-9. A voltage gain of 5 times a conventional boost can be achieved using this topology. Furthermore, this topology enables zero voltage soft switching and as result eliminates the diode reverse recovery issue and expands the voltage gain [24].

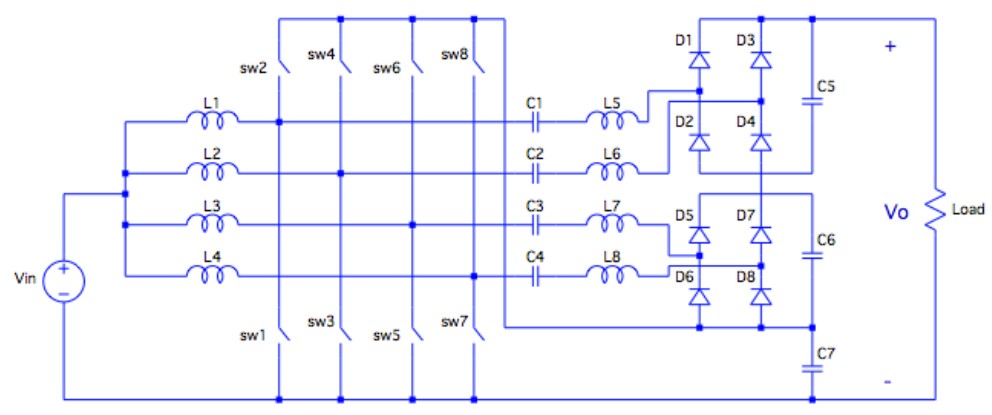

Figure 2-9. Multiphase Coost Converter with $\mathrm{P}=2$ and $\mathrm{N}=2$ [24] 


\subsection{Thesis Objective}

All those previously mentioned multiphase modified boost designs use complex control signals or coupled inductors. Coupled inductors are not always symmetric. Consequently, the output ripple fluctuates to a point where it causes unnecessary stress on the converter which is regulating the output voltage. Also, coupled inductors have 3 times longer winding path compared to non-coupled inductors. As a result, at high power application, there is higher IR loss across the winding of the coupled inductor.

As inductors are being integrated into converter's packages, a coupled inductors structure proposes a great challenge in optimizing size and power density. Lastly, in general, in order to optimize efficiency at light load, DC converters operate in DCM (Discontinuous Conduction Mode) rather than CCM (Continuous Conduction Mode). This method works very well for non-coupled inductors, however for coupled inductors this technology fails. After the integration of DCM mode for coupled inductors, the efficiency for 2-phase coupled inductor buck was 18\% lower than the 2-phase noncoupled inductor [25].

In this thesis, the use of non-coupled inductors to achieve the similar coupled inductors benefits such as low ripple, fast transient, and high efficiency in multiphase boost converter will be investigated. More specifically, this thesis aims to expand Lentz's modified boost topology to multiphase configuration, where the addition of active components achieves better performance. This thesis will further evaluate the benefits through design and testing of the new multiphase modified boost topology. 


\section{DESIGN REQUIREMENTS}

While physical size of converter circuit in general is important to help with cost reduction, the proposed multiphase boost design will focus on optimizing mainly the input ripple. This objective is especially important with the integration of the proposed modified multiphase boost converter in photovoltaics (PV) and inverter system. As mentioned in the previous section, the input voltage ripple of the boost converter directly affects the maximum power drawn from a source such as PV. Therefore, the input voltage ripple of the proposed converter is designed for minimum peak-to-peak modulation of $10 \%$.

Inherently, the implementation of multiphase configuration with interleaving control signals should provide superior output ripple minimization. Therefore, having a targeted output ripple of $2 \%$ is considered reasonable even with the minimum number of interleaving phases; i.e. two phases. In fact, the proposed multiphase modified boost converter will incorporate two phases to demonstrate its functionality and performance. The use of two phases further implies that the maximum duty cycle for each of the two phases is $50 \%$. With the chosen input voltage of $12 \mathrm{~V}$ and output voltage of $19 \mathrm{~V}$, as explained later, the nominal duty cycle is approximately $37 \%$. With the possible fluctuations in the soutput voltages, having the nominal duty cycle with margins away form $50 \%$ ensures that there will be no overlap between phases.

To demonstrate the operation of the proposed converter, the input voltage is chosen to be $12 \mathrm{~V}$ while the output is selected to be $19 \mathrm{~V}$. The $12 \mathrm{~V}$ input is a common voltage level from battery as well as $\mathrm{PV}$. The proposed converter will be designed to 
provide a regulated $19 \mathrm{~V}$ output voltage which represents the voltage level used by the larger DC powered loads such as laptop and future use of the new USB-C devices.

The use of multiphase configuration in the proposed converter allows for higher total power transfer than that provided by a single boost design. This is true since the multiphase converter splits the power among the phases; thus, enabling increased power capability of the converter while maintaining high converter's efficiency and improved thermal distribution. For the proposed multiphase converter, the components will be sized to handle maximum output power of $95 \mathrm{~W}$. This corresponds to a nominal full load current of $5 \mathrm{~A}$.

The proposed converter itself must offer high overall efficiency in order to maintain optimal transfer of power. High efficiency results in several benefits such as converter's physical size, longer lifetime, cooling requirement, and cost. At full load, the proposed converter should have at least $90 \%$ efficiency. At lower load conditions, the efficiency typically takes a dip due to the bigger fraction of loss in the converter compared to the power delivered to the output. As load increases, higher current flows through the converter causing bigger losses in the main components such as MOSFETs, inductors, diodes and capacitors. In the proposed multiphase modified boost converter, the converter's efficiency throughout its load range should be better than that obtained by a single boost configuration.

Line regulation in converters refers to the ability of a converter to maintain the output voltage while the input voltage is changing. In this design, the input voltage will be varied from its minimum value of $11.8 \mathrm{~V}$ to its maximum value of $13.2 \mathrm{~V}$. These values are chosen considering the fact that duty cycle is determined from input and output 
voltages. As previously mentioned, the proposed converter will utilize two phases and so it is important that the duty cycle be maintained below $50 \%$.

Lastly, the proposed converter will be designed to have load regulation of $5 \%$.

This means that as the load is varied from its lowest to highest points, the converter must maintain the output voltage tightly around the nominal $19 \mathrm{~V}$.

Table 3-1 summarizes the design parameters for the proposed multiphase modified boost converter.

Table 3-1. Functional Converter Parameters

\begin{tabular}{|c|c|}
\hline Parameter & Value \\
\hline Efficiency (at Full Load) & $>90 \%$ \\
\hline Output Power & $95 \mathrm{~W}$ \\
\hline Output Voltage & $19 \mathrm{~V}$ \\
\hline Input Voltage & $12 \mathrm{~V}$ \\
\hline Output Voltage Ripple & $2 \%$ \\
\hline Input Current Ripple & $10 \%$ \\
\hline Line Regulation & $10 \%$ \\
\hline Load Regulation & $5 \%$ \\
\hline
\end{tabular}




\section{ANALYSIS AND SIMULATION}

Where a single conventional boost converter topology fails to address the issue of high output power with the corresponding high input and output voltage ripples, the modified boost converter topology serves the need. The expansion of Lentz's modified boost topology into two phases has minimal implication on the derivation of key characteristics. However, the multiphase topology has more operating zones, which needs to be taken into consideration. The design and analysis in this section look at the following two-phase modified boost topology:

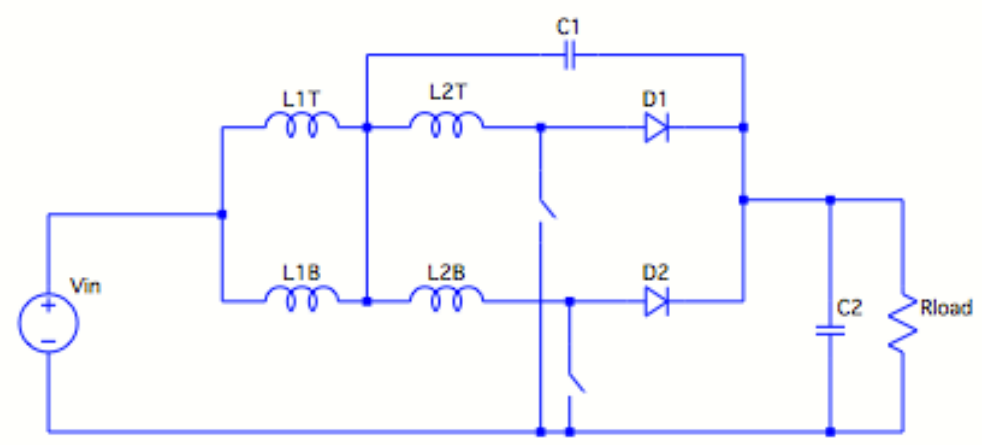

Figure 4-1. Modified Multiphase Boost Converter

This topology is identified by one feedback capacitor $(\mathrm{C} 1)$ and two input inductors (LIT and L1B). This circuit can be simplified by combining L1T and L1B or enlarged by having two feedback capacitors, one per stage. This design will explore whether having one capacitor per DC block and individual inductors per phase in single topology results in better output and input characteristics. The design will also be compared to a regular multiphase boost to establish the benefits when adding more components. 


\subsection{Multiphase Boost Calculations}

A typical two single phase conventional boost converter is shown in Figure 4-2.

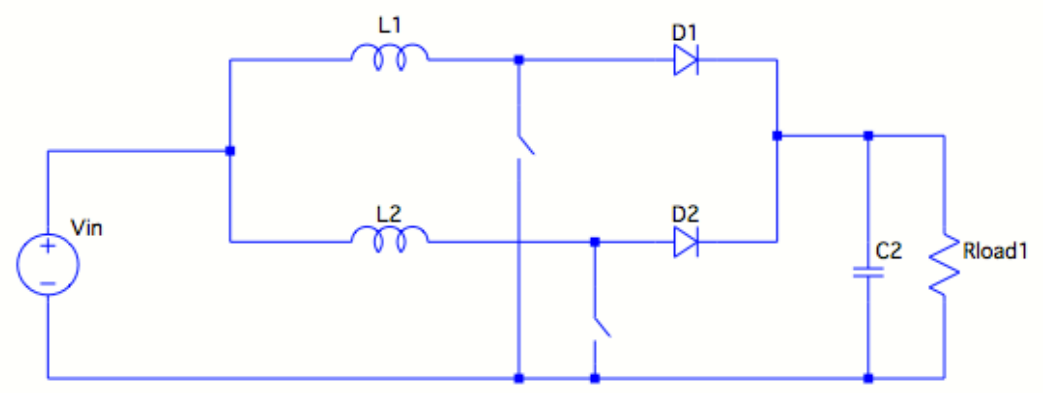

Figure 4-2. Two-phase Conventional Boost Converter

The multiphase topology has an interleaving control for each of the switches allowing for inductor current ripple cancellation, and thus lower output voltage ripple. Consequently, one of the switching devices from the first phase will always be on at the same time as a bottom-switching device. Each phase can act, as singular boost converter where the only difference from a single-phase boost, is the current through each phase. The input current is forced to split into two inductor currents $180^{\circ}$ out of phase implying new average level for current ripple calculations.

\subsubsection{Operating Conditions}

Any DC-to-DC converters rely on the duty cycle to determine the input and output relations. The transfer function of a converter is written in terms of the duty cycle. The duty cycle for a boost converter is defined as:

$$
D=-\frac{\left(V_{\text {in }}-V_{\text {out }}\right)}{V_{\text {out }}}
$$

The other key operational condition is the output resistance. The output resistance identifies the output power of the converter and it is calculated from: 


$$
R_{\text {out }}=\frac{\left(V_{\text {out }}\right)^{2}}{P_{\text {out }}}
$$

For this design, the duty cycle and output resistance are:

$$
\begin{gathered}
D=\frac{-(12 \mathrm{~V}-19 \mathrm{~V})}{19 \mathrm{~V}} \cong 0.368 \\
R_{\text {out }}=\frac{(19 \mathrm{~V})^{2}}{95 \mathrm{~W}}=3.8 \Omega
\end{gathered}
$$

\subsubsection{Inductor Calculations}

Choosing an inductor size is typically based on percentage peak to peak inductor current ripple at maximum load condition. A $30 \%$ to $40 \%$ is typically chose for inductor design. The best tradeoff between size and ripple occurs at this range. For example, bigger inductor sizes help reduce core magnetic losses; however, will slow down the current slew rate $\left(a d_{L} / d t=V_{L} / L\right)$.

By choosing a ripple bigger than the design requirement of $10 \%$, the modified boost's low input current ripple is showcased. The ripple for the inductor is described by the following equation:

$$
\Delta i_{L} \cong \Delta i_{L} 40 \% \cdot \frac{V_{\text {out }} \cdot I_{\text {out }}}{2 \cdot V_{\text {in }}}
$$

Determining critical inductance value is calculated using the ripple found earlier and shown in Equation 4-3:

$$
L=\frac{V_{\text {in }} \cdot D}{f \cdot \Delta i_{L}}
$$

For the design presented in this thesis, the $\Delta i_{L}$ and $L$ values can now be calculated: 


$$
\begin{gathered}
\Delta i_{L} \cong 40 \% \cdot \frac{19 \mathrm{~V} \cdot 5 \mathrm{~A}}{2 \cdot 12 \mathrm{~V}}=1.583 \mathrm{~A} \\
L=\frac{12 \mathrm{~V} \cdot 0.368}{200 \mathrm{kHz} \cdot 1.583 \mathrm{~A}}=14 \mu \mathrm{H}
\end{gathered}
$$

Due to the limited commercially available inductor values; the actual inductor value is chosen to be $4.7 \mu \mathrm{H}$. This will result in a higher ripple of $4.703 \mathrm{~A}$.

\subsubsection{Output Capacitor}

The combination of the currents through the diodes in each phase supplies the output capacitor current. Due to the interleave configuration for the control signal and a low duty cycle, there are specific periods of time where the two diode currents are overlapping, which further causes current ripple cancellation. Deciding the capacitor value depends on the capacitor waveform and evaluation of the charge per periodic intervals.

The capacitor waveform will look differently between the multiphase conventional and modified topologies. The waveform used to investigate the capacitor value is displayed in Figure 4-3. This waveform provides the best estimation for output capacitance. 


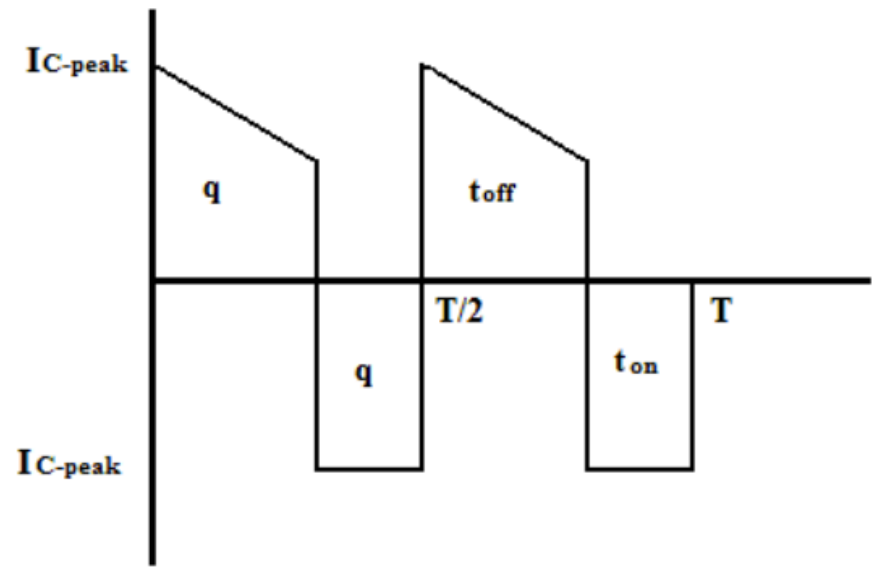

Figure 4-3. Multiphase Boost Converter Output Capacitor Charge Storage In order to calculate the capacitor value the definition of capacitance is used:

$$
\begin{gathered}
q=C \cdot \Delta V \\
\int I_{C} d t=C \cdot \Delta V \rightarrow \bar{I}_{\text {switch }} \cdot t_{\text {diode }- \text { on }}=C_{\text {out }} \cdot \Delta V \\
\left(\bar{I}_{\text {switch } \max }\right)\left(\frac{T}{2}-D T\right)=C_{\text {out }} \cdot \Delta V, \quad \bar{I}_{\text {switch }}=D \bar{I}_{o} \\
C_{\text {out }}=\frac{D \cdot \bar{I}_{o} \cdot\left(\frac{1}{2}-D\right) T}{\Delta V}=\frac{D \cdot \bar{I}_{o} \cdot\left(\frac{1}{2}-D\right)}{\Delta V \cdot f}=\frac{\bar{V}_{\text {out }} \cdot D \cdot(1-2 D)}{\Delta V \cdot f \cdot R_{\text {out }} \cdot 2} \\
C_{\text {out }}=\frac{\bar{V}_{\text {out }} \cdot D \cdot(1-2 D)}{\Delta V \cdot f \cdot R_{\text {out }} \cdot 2}
\end{gathered}
$$

Considering that the current waveform does not accurately describe a plot of nonideal multiphase boost output capacitor current, extra capacitance is added to ensure that the chosen capacitance is meeting the voltage ripple requirement. The resulting capacitance needed for a $2 \%$ ripple is:

$$
C_{\text {out }}=\frac{19 \mathrm{~V} \cdot 0.367 \cdot(1-2 \cdot 0.367)}{(19 \mathrm{~V} \cdot 2 \%) \cdot 200 \mathrm{kHz} \cdot 3.8 \Omega \cdot 2}=3.21 \mathrm{uF}
$$


For ease of component selection, two ceramic $10 \mu \mathrm{F}$ capacitors and a $22 \mu \mathrm{F}$ electrolytic capacitor will be used for the output. The use of two ceramics lowers the overall ESR of the capacitors to allow for limited power loss. The electrolyte capacitor allows for higher and more stable (over temperature and voltage range) capacitance in a desirable package.

\subsubsection{Input Capacitor}

The necessity of input capacitance is directly implied from the combination of the inductor currents. The addition of the inductor currents yields a linear charging and discharging characteristic with twice the original frequency. A plot of the input current waveform through the capacitor is shown in Figure 4-4. As can be seen, the original triangular form is maintained.

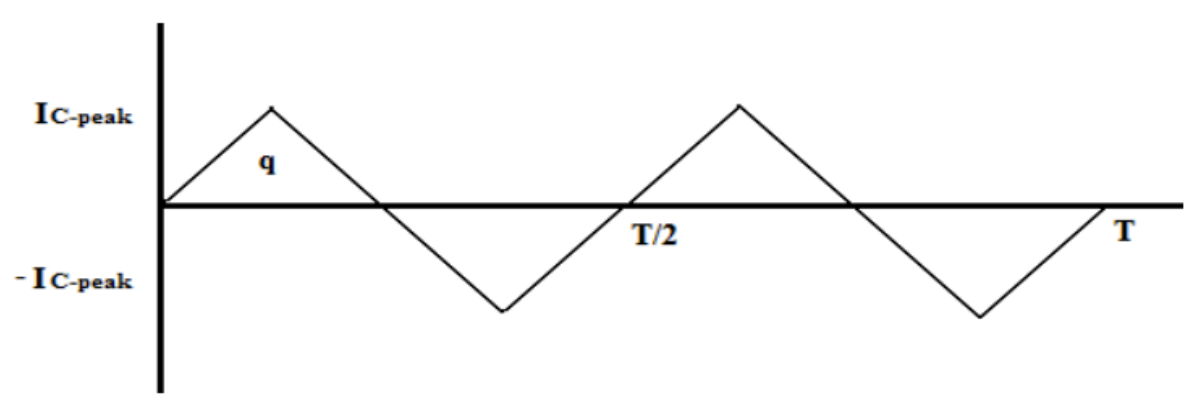

Figure 4-4. Multiphase Boost Converter Input Capacitor Charge Storage

$$
\begin{gathered}
q=C \cdot \Delta V \\
\int I_{C} d t=C \cdot \Delta V \rightarrow \frac{1}{2} \cdot \frac{\Delta i_{L}}{2} \cdot \frac{T}{4}=C_{i n} \cdot \Delta V \\
C_{i n}=\frac{\frac{1}{2} \cdot \frac{\Delta i_{L}}{2} \cdot \frac{T}{4}}{\Delta V}=\frac{\Delta i_{L}}{16 \cdot f \cdot \Delta V}=\frac{V_{i n} \cdot D}{f \cdot L} \cdot \frac{1}{16 \cdot f \cdot \Delta V}=\frac{D}{16 \cdot f^{2} \cdot \frac{\Delta V}{V_{i n}} \cdot L}
\end{gathered}
$$




$$
C_{i n}=\frac{D}{16 \cdot f^{2} \cdot \frac{\Delta V}{V_{i n}} \cdot L}
$$

Using a $10 \%$ input current ripple and $2 \%$ input voltage ripple, the output capacitance can be determined as:

$$
C_{\text {in }}=\frac{\left(0.1 \cdot \frac{95 \mathrm{~W}}{12 \mathrm{~V}}\right)}{16 \cdot 200 \mathrm{kHz} \cdot(12 \cdot 0.02)}=1.03 \mu \mathrm{F}
$$

In order to enforce the low ripple, two $10 \mu \mathrm{F}$ capacitor are used.

\subsection{Modified Multiphase Topology}

Where a standard multiphase boost uses one inductor per stage, the modified boost topology splits in half the calculated inductor value in order to provide further filtering while maintaining linear relationship for the current. As employed in Lentz single-phase topology, choosing an equal half value of the single inductor found for a normal multiphase boost minimizes the input ripple current [11].

The feedback capacitor is chosen to relocate the frequency of the resonance away from the switching frequency of $200 \mathrm{kHz}$. The capacitance of the feedback capacitor must be less than the output capacitance for the modified topology to operate correctly. The feedback capacitor is chosen to be $30 \mu \mathrm{H}$, similar to Lentz single phase topology [11].

Comparing the output capacitor current of a standard multiphase to that of a modified multiphase as shown in in Figure 4-5, we can see that the overall shape is different. This directly relates to the addition of current coming from the feedback capacitor in the modified multiphase boost. 


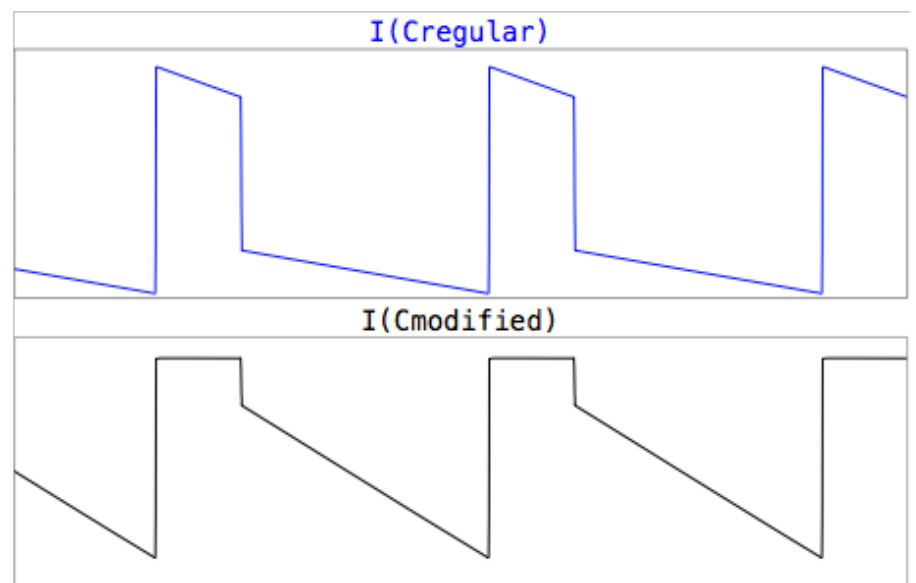

Figure 4-5. Standard Versus Modified Output Capacitor Current Waveforms

\subsubsection{State Space Representation And Analysis}

In order to compare the modified boost topology to the standard boost, a state space model is used. A state space utilizes first-order differential equations instead of one $\mathrm{n}^{\text {th }}$ order differential equation to describe a system, which allows for major simplification when solving. It especially comes in handy when there are multiple inputs and outputs. For this topology, there is a single input and output.

A state space model consists of a state equation and an output equation. The state variables associated with state model depend on the numbers of energy storing electrical components. The voltage across the capacitors counts as a variable due to the $\mathrm{dV}_{\mathrm{c}} / \mathrm{dt}=\mathrm{i}_{\mathrm{c}} / \mathrm{C}$. The current through an inductor constitutes another variable as $\mathrm{di}_{\mathrm{L}} / \mathrm{dt}=$ $\mathrm{V}_{\mathrm{L}} / \mathrm{dt}$. By this notion, the topology under observation has 6 states variables, where four are inductors currents and two are capacitor voltages. The equations for state and output equations are as follows:

$$
\begin{gathered}
\dot{x}=A x+B u \rightarrow \text { State Equation } \\
y=C x+D u \rightarrow \text { Output Equation }
\end{gathered}
$$

Where the following state vector, input, and output are defined as: 


$$
\dot{x}=\left[\begin{array}{c}
\frac{d i_{L 1 T}}{d t} \\
\frac{d i_{L 2 T}}{d t} \\
\frac{d i_{L 1 B}}{d t} \\
\frac{d i_{L 2 B}}{d t} \\
\frac{d v_{C 1}}{d t} \\
\frac{d v_{o}}{d t}
\end{array}\right], \quad x=\left[\begin{array}{c}
i_{L 1 T} \\
i_{L 2 T} \\
i_{L 1 B} \\
i_{L 2 B} \\
v_{C 1} \\
v_{o}
\end{array}\right], \quad u=v_{i n}, \quad y=v_{o}
$$

\subsection{State Space Equations Derivations}

Due to the nature of multiphase boost, the design has four switch-based elements that toggle according to the duty cycle. Complete cancelation of ripple occurs at $50 \%$ duty cycle due to the $180^{\circ}$ phase shift on the second boost phase. For this design, a $36.7 \%$ duty cycle per phase is determined from the transfer function. In order to simplify the plots for this section, it is rounded up to $40 \%$.

Even though there are four switches consisting of two MOSFETs and two diodes, they would never be all on at the same time. At any given time, two switching devices are conducting. Overall, there are $4^{2}(16)$ combinations that are possible for 4 switches. However, as stated previously, not all switches can be on or off at the same time due to the nature of interleaving operation. In addition, SW1 and D1 can never be on or off at the same time, and the same applies to SW2 and D2. This eliminates eight combinations, thus eight combinations remain.

The possible operations for the modified boost are as follows: 
Table 4-1. The 8 Different Types of Combinations for State Space

\begin{tabular}{|c|l|l|l|l|}
\hline State & \multicolumn{1}{|c|}{ S1 } & \multicolumn{1}{|c|}{ S2 } & \multicolumn{1}{|c|}{ D1 } & \multicolumn{1}{|c|}{ D2 } \\
\hline 1 & Closed & Opened & Opened & Closed \\
\hline 2 & Closed & Opened & Opened & Opened \\
\hline 3 & Opened & Opened & Closed & Opened \\
\hline 4 & Opened & Closed & Closed & Opened \\
\hline 5 & Opened & Closed & Opened & Opened \\
\hline 6 & Opened & Opened & Opened & Closed \\
\hline 7 & Closed & Closed & Opened & Opened \\
\hline 8 & Opened & Opened & Closed & Closed \\
\hline
\end{tabular}

All state schematics are based on the modified boost diagram shown in Figure 4-6.

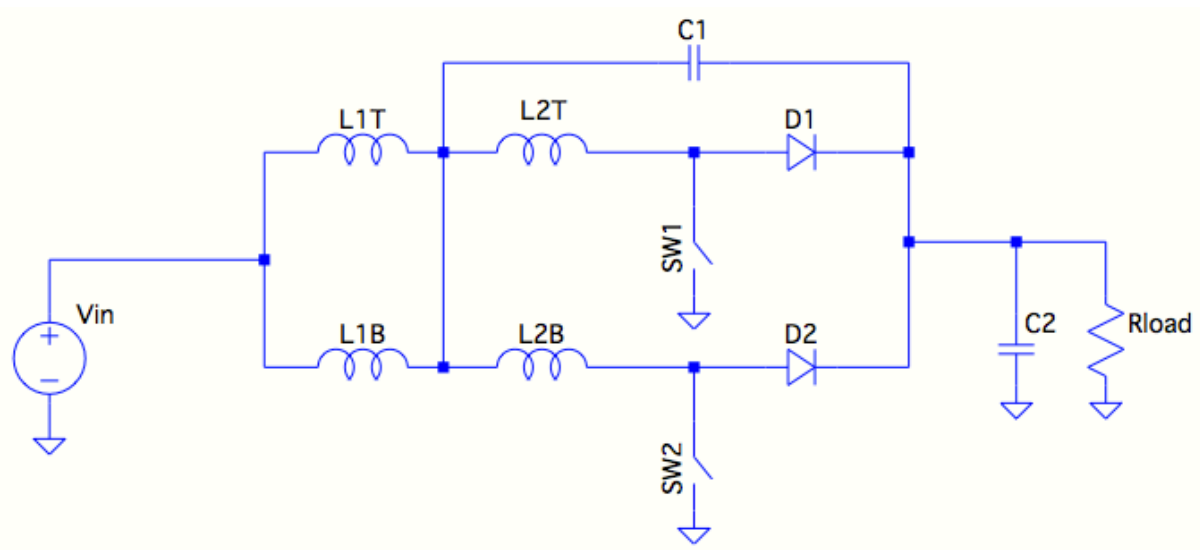

Figure 4-6. Modified Multiphase Boost Converter General Case 
The associated state schematics for each case are shown in Figure 4-7.
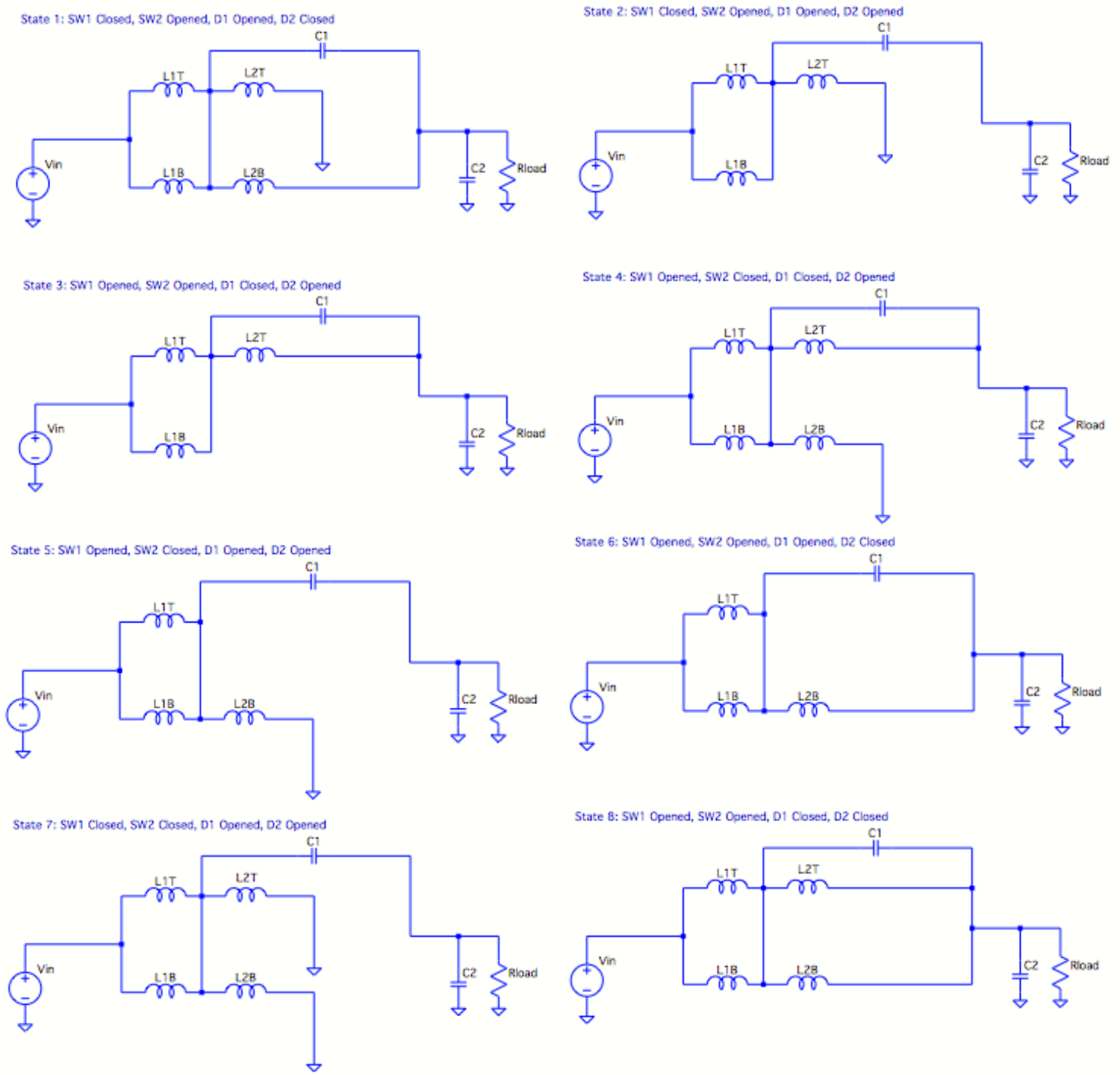

Figure 4-7. All Options for State Space Schematics

Due to the approximately $40 \%$ duty cycle, only specific cases become applicable for the modified boost design. As seen in Figure 4-8, only three cases have respective duty cycle overlap and thus the only three states that need to be evaluated are: State 1 , State 4 , and State 8. 


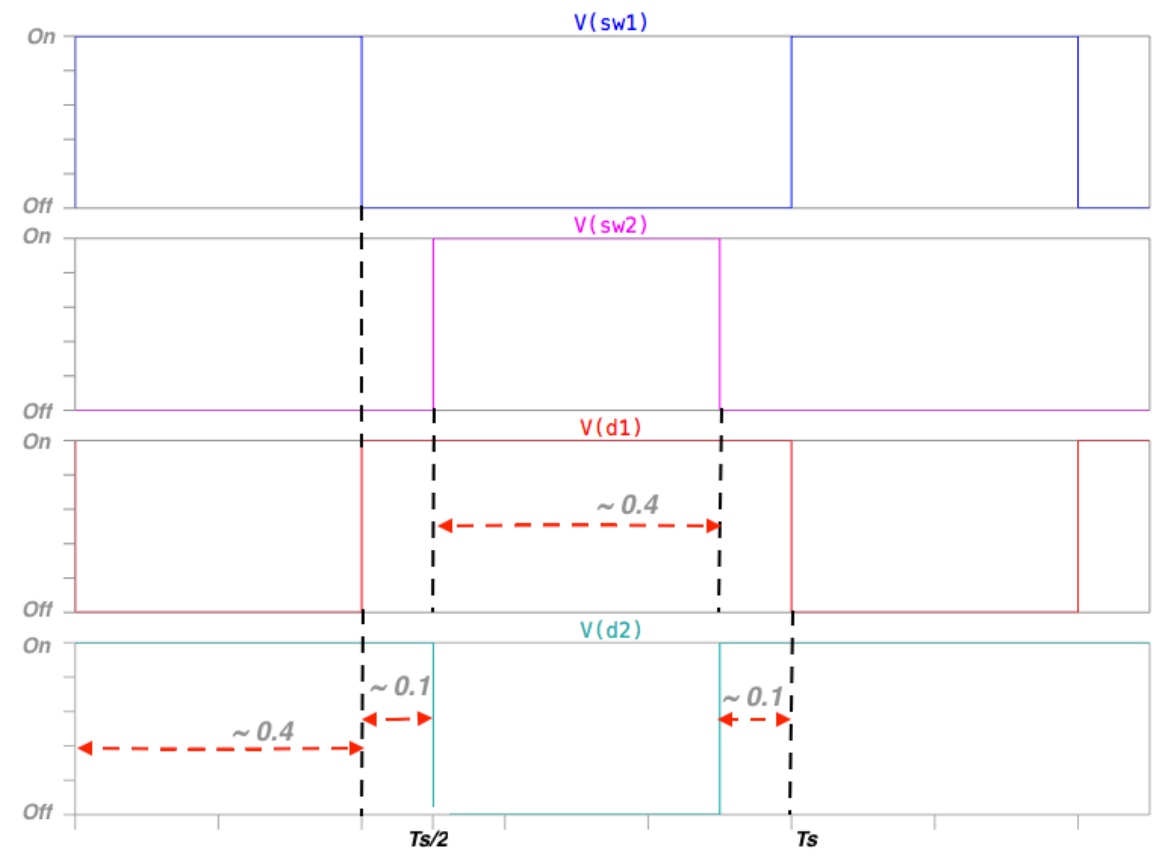

Figure 4-8. Timing Diagram of Gate Drivers for Switching Devices

Since for all states, the output remains the voltage across the output capacitor, the $\mathrm{C}$ and $\mathrm{D}$ matrices never change. The $\mathrm{D}$ and $\mathrm{C}$ matrices are as followed:

$$
C=\left[\begin{array}{llllll}
0 & 0 & 0 & 0 & 0 & 1
\end{array}\right], \quad D=0
$$

\subsubsection{State Space for State 1}

Performing circuit analysis for State 1, the following equations are extracted.

Table 4-2. State 1 Circuit Analysis Summary

\begin{tabular}{|c|c|}
\hline State Variable & Equation \\
\hline $\mathrm{i}_{\mathrm{L} 1 \mathrm{~T}}$ & $\begin{array}{c}\mathrm{V}_{\mathrm{in}}-\mathrm{V}_{\mathrm{L} 1 \mathrm{~T}}-\mathrm{V}_{\mathrm{L} 2 \mathrm{~T}}=0 \\
\end{array}$ \\
$\mathrm{~L}_{1 \mathrm{~T}} \frac{\mathrm{di}_{\mathrm{L} 1 \mathrm{~T}}}{\mathrm{dt}}=-\mathrm{V}_{\mathrm{c} 1}-\mathrm{V}_{0}+\mathrm{V}_{\mathrm{in}}$ \\
\hline $\mathrm{i}_{\mathrm{L} 2 \mathrm{~T}}$ & $\mathrm{~V}_{\mathrm{L} 2 \mathrm{~T}}-\mathrm{V}_{\mathrm{c} 1}-\mathrm{V}_{0}=0$ \\
& $\mathrm{~L}_{2 \mathrm{~T}} \frac{\mathrm{di} \mathrm{L}_{\mathrm{T}}}{\mathrm{dt}}=\mathrm{V}_{\mathrm{c} 1}+\mathrm{V}_{0}$ \\
\hline
\end{tabular}




\begin{tabular}{|c|c|}
\hline $\mathrm{i}_{\mathrm{L} 1 \mathrm{~B}}$ & $\begin{array}{c}\mathrm{V}_{\mathrm{in}}-\mathrm{V}_{\mathrm{L} 1 \mathrm{~B}}-\mathrm{V}_{\mathrm{L} 2 \mathrm{~B}}=0 \\
\mathrm{~L}_{1 \mathrm{~B}} \frac{\mathrm{di}_{\mathrm{L} 1 \mathrm{~B}}}{\mathrm{dt}}=-\mathrm{V}_{\mathrm{c} 1}-\mathrm{V}_{0}+\mathrm{V}_{\mathrm{in}}\end{array}$ \\
\hline $\mathrm{i}_{\mathrm{L} 2 \mathrm{~B}}$ & $\begin{array}{c}\mathrm{V}_{\mathrm{L} 2 \mathrm{~T}}-\mathrm{V}_{\mathrm{c} 1}=0 \\
\mathrm{~L}_{2 \mathrm{~B}} \frac{\mathrm{di}_{\mathrm{L} 2 \mathrm{~B}}}{\mathrm{dt}}=\mathrm{V}_{\mathrm{c} 1}\end{array}$ \\
\hline $\mathrm{V}_{\mathrm{c} 1}$ & $\begin{array}{l}-\mathrm{i}_{\mathrm{C} 1}+\mathrm{i}_{\mathrm{L} 1 \mathrm{~T}}-\mathrm{i}_{\mathrm{L} 2 \mathrm{~T}}+\mathrm{i}_{\mathrm{L} 1 \mathrm{~B}}-\mathrm{i}_{\mathrm{L} 2 \mathrm{~B}}=0 \\
\mathrm{C}_{1} \frac{\mathrm{dV_{ \textrm {C } 1 }}}{\mathrm{dt}}=\mathrm{i}_{\mathrm{L} 1 \mathrm{~T}}-\mathrm{i}_{\mathrm{L} 2 \mathrm{~T}}+\mathrm{i}_{\mathrm{L} 1 \mathrm{~B}}-\mathrm{i}_{\mathrm{L} 2 \mathrm{~B}}\end{array}$ \\
\hline $\mathrm{V}_{\mathrm{c} 2}$ & $\begin{array}{c}-\mathrm{i}_{\mathrm{c} 2}+\mathrm{i}_{\mathrm{c} 1}+\mathrm{i}_{\mathrm{L} 2 \mathrm{~B}}-\mathrm{V}_{0} / \mathrm{R}=0 \\
\mathrm{C}_{2} \frac{\mathrm{dV_{0 }}}{\mathrm{dt}}=\mathrm{i}_{\mathrm{L} 1 \mathrm{~T}}-\mathrm{i}_{\mathrm{L} 2 \mathrm{~T}}+\mathrm{i}_{\mathrm{L} 1 \mathrm{~B}}-\mathrm{V}_{0} / \mathrm{R}\end{array}$ \\
\hline
\end{tabular}

The resulting $\mathrm{A}$ and $\mathrm{B}$ matrices for State 1 are:

$$
A_{\text {State } 1}=\left[\begin{array}{cccccc}
0 & 0 & 0 & 0 & \frac{-1}{L_{1 T}} & \frac{-1}{L_{1 T}} \\
0 & 0 & 0 & 0 & \frac{1}{\mathrm{~L}_{2 \mathrm{~T}}} & \frac{1}{\mathrm{~L}_{2 \mathrm{~T}}} \\
0 & 0 & 0 & 0 & \frac{-1}{L_{1 B}} & \frac{-1}{L_{1 B}} \\
0 & 0 & 0 & 0 & \frac{1}{L_{2 B}} & 0 \\
\frac{1}{\mathrm{C}_{1}} & \frac{-1}{\mathrm{C}_{1}} & \frac{1}{\mathrm{C}_{1}} & \frac{-1}{\mathrm{C}_{1}} & 0 & 0 \\
\frac{1}{\mathrm{C}_{2}} & \frac{-1}{\mathrm{C}_{2}} & \frac{1}{\mathrm{C}_{2}} & 0 & 0 & \frac{-1}{R_{0} \cdot \mathrm{C}_{2}}
\end{array}\right] \quad \quad \quad B_{\text {State } 1}=\left[\begin{array}{c}
\frac{1}{L_{1 T}} \\
0 \\
1 \\
\frac{L_{1 B}}{0} \\
0 \\
0
\end{array}\right]
$$




\subsubsection{State Space for State 4}

Performing circuit analysis for State 4, the following equations are extracted.

Table 4-3. State 4 Circuit Analysis Summary

\begin{tabular}{|c|c|}
\hline State Variable & Equation \\
\hline $\mathrm{i}_{\mathrm{L} 1 \mathrm{~T}}$ & $\begin{array}{c}V_{i n}-V_{L 1 T}-V_{L 2 T}=0 \\
L_{1 T} \frac{d i_{L 1 T}}{d t}=-V_{c 1}-V_{0}+V_{i n}\end{array}$ \\
\hline $\mathrm{i}_{\mathrm{L} 2 \mathrm{~T}}$ & $\begin{array}{c}\mathrm{V}_{\mathrm{L} 2 \mathrm{~T}}-\mathrm{V}_{\mathrm{c} 1}-\mathrm{V}_{0}=0 \\
\mathrm{~L}_{2 \mathrm{~T}} \frac{\mathrm{di}_{\mathrm{L} 2 \mathrm{~T}}}{\mathrm{dt}}=\mathrm{V}_{\mathrm{c} 1}\end{array}$ \\
\hline$i_{L 1 B}$ & $\begin{array}{c}V_{\text {in }}-V_{L 1 B}-V_{L 2 B}=0 \\
\mathrm{di}_{1 \mathrm{~B} 1 \mathrm{~B}} \frac{\mathrm{d}}{\mathrm{dt}}=-\mathrm{V}_{\mathrm{c} 1}-\mathrm{V}_{0}+\mathrm{V}_{\mathrm{in}}\end{array}$ \\
\hline $\mathrm{i}_{\mathrm{L} 2 \mathrm{~B}}$ & $\begin{array}{c}\mathrm{V}_{\mathrm{L} 2 \mathrm{~T}}-\mathrm{V}_{\mathrm{c} 1}=0 \\
\mathrm{~L}_{2 \mathrm{~B}} \frac{\mathrm{di}}{\mathrm{L} 2 \mathrm{~B}}=\mathrm{V}_{\mathrm{c} 1}+\mathrm{V}_{0}\end{array}$ \\
\hline $\mathrm{V}_{\mathrm{c} 1}$ & $\begin{array}{l}-i_{\mathrm{c} 1}+i_{\mathrm{L} 1 \mathrm{~T}}-\mathrm{i}_{\mathrm{L} 2 \mathrm{~T}}+\mathrm{i}_{\mathrm{L} 1 \mathrm{~B}}-\mathrm{i}_{\mathrm{L} 2 \mathrm{~B}}=0 \\
\mathrm{C}_{1} \frac{\mathrm{dV_{ \textrm {C } 1 }}}{\mathrm{dt}}=\mathrm{i}_{\mathrm{L} 1 \mathrm{~T}}-\mathrm{i}_{\mathrm{L} 2 \mathrm{~T}}+\mathrm{i}_{\mathrm{L} 1 \mathrm{~B}}-\mathrm{i}_{\mathrm{L} 2 \mathrm{~B}}\end{array}$ \\
\hline $\mathrm{V}_{\mathrm{c} 2}$ & $\begin{array}{c}-i_{c 2}+i_{c 1}+i_{L 2 B}-V_{0} / R=0 \\
C_{2} \frac{d V_{0}}{d t}=i_{L 1 T}+i_{L 1 B}-i_{L 2 B}-V_{0} / R\end{array}$ \\
\hline
\end{tabular}

The resulting A and B matrices for State 4 are: 


$$
A_{\text {State } 4}=\left[\begin{array}{cccccc}
0 & 0 & 0 & 0 & \frac{-1}{L_{1 T}} & \frac{-1}{L_{1 T}} \\
0 & 0 & 0 & 0 & \frac{1}{\mathrm{~L}_{2 \mathrm{~T}}} & 0 \\
0 & 0 & 0 & 0 & \frac{-1}{L_{1 B}} & \frac{-1}{L_{1 B}} \\
0 & 0 & 0 & 0 & \frac{1}{L_{2 B}} & \frac{1}{L_{2 B}} \\
\frac{1}{\mathrm{C}_{1}} & \frac{-1}{\mathrm{C}_{1}} & \frac{1}{\mathrm{C}_{1}} & \frac{-1}{\mathrm{C}_{1}} & 0 & 0 \\
\frac{1}{\mathrm{C}_{2}} & 0 & \frac{1}{\mathrm{C}_{2}} & \frac{-1}{\mathrm{C}_{2}} & 0 & \frac{-1}{R_{0} \cdot \mathrm{C}_{2}}
\end{array}\right] \quad \quad B_{\text {State } 4}=\left[\begin{array}{c}
\frac{1}{L_{1 T}} \\
0 \\
1 \\
\frac{L_{1 B}}{1 B} \\
0 \\
0
\end{array}\right]
$$

\subsubsection{State Space for State Eight}

Performing circuit analysis for State 8 , the following equations are extracted.

Table 4-4. State 8 Circuit Analysis Summary

\begin{tabular}{|c|c|}
\hline State Variable & Equation \\
\hline $\mathrm{i}_{\mathrm{L} 1 \mathrm{~T}}$ & $\begin{array}{c}V_{\mathrm{in}}-\mathrm{V}_{\mathrm{L} 1 \mathrm{~T}}-\mathrm{V}_{\mathrm{L} 2 \mathrm{~T}}=0 \\
\mathrm{~L}_{1 \mathrm{~T}} \frac{\mathrm{di}_{\mathrm{L} 1 \mathrm{~T}}}{\mathrm{dt}}=-\mathrm{V}_{\mathrm{c} 1}-\mathrm{V}_{0}+\mathrm{V}_{\mathrm{in}}\end{array}$ \\
\hline $\mathrm{i}_{\mathrm{L} 2 \mathrm{~T}}$ & $\begin{array}{c}\mathrm{V}_{\mathrm{L} 2 \mathrm{~T}}-\mathrm{V}_{\mathrm{c} 1}-\mathrm{V}_{0}=0 \\
\mathrm{~L}_{2 \mathrm{~T}} \frac{\mathrm{di}_{\mathrm{L} 2 \mathrm{~T}}}{\mathrm{dt}}=\mathrm{V}_{\mathrm{c} 1}\end{array}$ \\
\hline $\mathrm{i}_{\mathrm{L} 1 \mathrm{~B}}$ & $\begin{array}{c}V_{\text {in }}-V_{L 1 B}-V_{L 2 B}=0 \\
L_{1 B} \frac{d_{L 1 B}}{d t}=-V_{c 1}-V_{0}+V_{i n}\end{array}$ \\
\hline $\mathrm{i}_{\mathrm{L} 2 \mathrm{~B}}$ & $\begin{array}{l}\mathrm{V}_{\mathrm{L} 2 \mathrm{~T}}-\mathrm{V}_{\mathrm{c} 1}=0 \\
\mathrm{~L}_{2 \mathrm{~B}} \frac{\mathrm{di}_{\mathrm{L} 2 \mathrm{~B}}}{\mathrm{dt}}=\mathrm{V}_{\mathrm{c} 1}\end{array}$ \\
\hline $\mathrm{V}_{\mathrm{c} 1}$ & $\begin{array}{c}-\mathrm{i}_{\mathrm{c} 1}+\mathrm{i}_{\mathrm{L} 1 \mathrm{~T}}-\mathrm{i}_{\mathrm{L} 2 \mathrm{~T}}+\mathrm{i}_{\mathrm{L} 1 \mathrm{~B}}-\mathrm{i}_{\mathrm{L} 2 \mathrm{~B}}=0 \\
\mathrm{C}_{1} \frac{\mathrm{dV_{ \textrm {C } 1 }}}{\mathrm{dt}}=\mathrm{i}_{\mathrm{L} 1 \mathrm{~T}}-\mathrm{i}_{\mathrm{L} 2 \mathrm{~T}}+\mathrm{i}_{\mathrm{L} 1 \mathrm{~B}}-\mathrm{i}_{\mathrm{L} 2 \mathrm{~B}}\end{array}$ \\
\hline
\end{tabular}




$$
\begin{aligned}
& -\mathrm{i}_{\mathrm{c} 2}+\mathrm{i}_{\mathrm{c} 1}+\mathrm{i}_{\mathrm{L} 2 \mathrm{~B}}-\mathrm{V}_{0} / \mathrm{R}=0 \\
& \mathrm{C}_{2} \frac{\mathrm{dV} \mathrm{V}_{0}}{\mathrm{dt}}=\mathrm{i}_{\mathrm{L} 1 \mathrm{~T}}+\mathrm{i}_{\mathrm{L} 1 \mathrm{~B}}-\mathrm{V}_{0} / \mathrm{R}
\end{aligned}
$$

The resulting A and B matrices for State 8 are:

$$
A_{\text {State } 8}=\left[\begin{array}{cccccc}
0 & 0 & 0 & 0 & \frac{-1}{L_{1 T}} & \frac{-1}{L_{1 T}} \\
0 & 0 & 0 & 0 & \frac{1}{\mathrm{~L}_{2 \mathrm{~T}}} & 0 \\
0 & 0 & 0 & 0 & \frac{-1}{L_{1 B}} & \frac{-1}{L_{1 B}} \\
0 & 0 & 0 & 0 & \frac{1}{L_{2 B}} & 0 \\
\frac{1}{\mathrm{C}_{1}} & \frac{-1}{\mathrm{C}_{1}} & \frac{1}{\mathrm{C}_{1}} & \frac{-1}{\mathrm{C}_{1}} & 0 & 0 \\
\frac{1}{\mathrm{C}_{2}} & 0 & \frac{1}{\mathrm{C}_{2}} & 0 & 0 & \frac{-1}{R_{0} \cdot \mathrm{C}_{2}}
\end{array}\right] \quad, \quad B_{\text {State } 8}=\left[\begin{array}{c}
\frac{1}{L_{1 T}} \\
0 \\
\frac{1}{L_{1 B}} \\
0 \\
0 \\
0
\end{array}\right]
$$

\subsubsection{Overall System State Space}

Since there are multiple A and B matrices, the total A and B matrices are defined as each matrix scaled by the associated duty cycle [26].

$$
\begin{aligned}
& A_{\text {total }}=\sum_{n=1}^{M} A_{n} \cdot D_{n}, \text { where } D_{n} \text { is duty cycle per state and } M \text { is the number of states } \\
& B_{\text {total }}=\sum_{n=1}^{M} B_{n} \cdot D_{n}, \text { where } D_{n} \text { is duty cycle per state and } M \text { is the number of states }
\end{aligned}
$$

The new state space equations are:

$$
\begin{gathered}
\dot{x}=A_{\text {total }} x+B_{\text {total }} u \\
y=C x+D u
\end{gathered}
$$

The total state equation is seen below: 


$$
\left[\begin{array}{l}
\frac{d i_{L 1 T}}{d t} \\
\frac{d i_{L 2 T}}{d t} \\
\frac{d i_{L 1 B}}{d t} \\
\frac{d i_{L 2 B}}{d t} \\
\frac{d v_{C 1}}{d t} \\
\frac{d v_{o}}{d t}
\end{array}\right]=D \cdot A_{\text {State } 1}\left[\begin{array}{c}
i_{L 1 T} \\
i_{L 2 T} \\
i_{L 1 B} \\
i_{L 2 B} \\
v_{C 1} \\
v_{o}
\end{array}\right]+(1-2 \cdot D) \cdot A_{\text {State } 8}\left[\begin{array}{c}
i_{L 1 T} \\
i_{L 2 T} \\
i_{L 1 B} \\
i_{L 2 B} \\
v_{C 1} \\
v_{o}
\end{array}\right]+D \cdot A_{\text {State } 4}\left[\begin{array}{c}
i_{L 1 T} \\
i_{L 2 T} \\
i_{L 1 B} \\
i_{L 2 B} \\
v_{C 1} \\
v_{o}
\end{array}\right]+\left[\begin{array}{c}
\frac{1}{L_{1 T}} \\
0 \\
1 \\
L_{1 B} \\
0 \\
0 \\
0
\end{array}\right] V_{I N}
$$

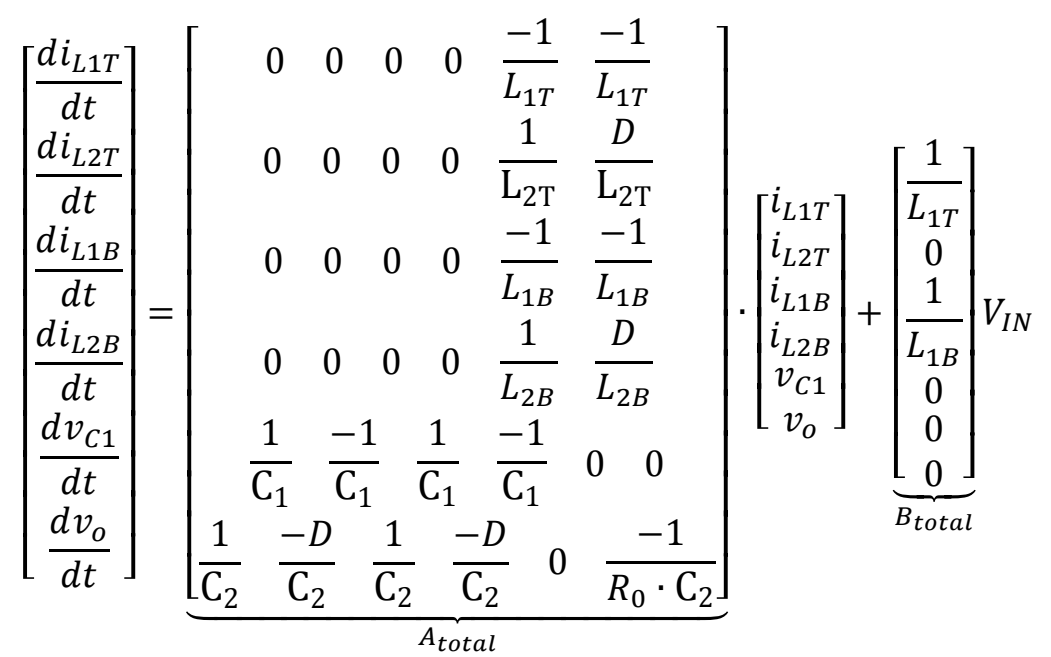

\subsubsection{Averaging and DC Transfer Functions}

In order to determine the steady state values for the state variables, all derivative terms are set to zero. Therefore to evaluate DC state, the state equation is set to zero. 


$$
\left[\begin{array}{l}
\frac{d i_{L 1 T}}{d t} \\
\frac{d i_{L 2 T}}{d t} \\
\frac{d i_{L 1 B}}{d t} \\
\frac{d i_{L 2 B}}{d t} \\
\frac{d v_{C 1}}{d t} \\
\frac{d v_{o}}{d t}
\end{array}\right]=\left[\begin{array}{l}
0 \\
0 \\
0 \\
0 \\
0 \\
0
\end{array}\right]
$$

Solving for the first state variable, a relationship between the input voltage, output voltage, and feedback capacitor voltage is identified.

$$
\begin{gathered}
-\frac{D}{L_{1 T}}\left(V_{C 1}+V_{\text {OUT }}\right)-\frac{(1-2 D)}{L_{1 T}}\left(V_{C 1}+V_{\text {OUT }}\right)-\frac{D}{L_{1 T}}\left(V_{C 1}+V_{\text {OUT }}\right)+\frac{1}{L_{1}} V_{I N}=0 \\
-D\left(V_{C 1}+V_{\text {OUT }}\right)-(1-2 D)\left(V_{C 1}+V_{\text {OUT }}\right)-D\left(V_{C 1}+V_{\text {OUT }}\right)+V_{I N}=0 \\
V_{I N}=V_{C 1}+V_{\text {OUT }}
\end{gathered}
$$

By exploring the second state variable, the feedback capacitor voltage is redefined in terms of duty cycle and output voltage

$$
\begin{gathered}
\frac{D}{L_{2 T}}\left(V_{C 1}+V_{\text {OUT }}\right)+\frac{(1-2 D)}{L_{2 T}}\left(V_{C 1}\right)+\frac{D}{L_{2 T}}\left(V_{C 1}\right)=0 \\
V_{C 1}=-D \cdot V_{\text {OUT }}=\text { Vin }- \text { Vout }
\end{gathered}
$$

Combining the two identities uncovers the transfer function for a modified multiphase boost, which is the same as the standard multiphase:

$$
\frac{V_{O U T}}{V_{I N}}=\frac{1}{1-D}
$$


Extrapolating the relationships in terms of currents, the connection between the inductors is reiterated in terms of output current.

$$
\begin{gathered}
\frac{D}{C 1}\left(i_{L 1 T}-i_{L 2 T}+i_{L 1 B}-i_{L 2 B}\right)+\frac{(1-2 D)}{C 1}\left(i_{L 1 T}-i_{L 2 T}+i_{L 1 B}-i_{L 2 B}\right)+\frac{D}{C 1}\left(i_{L 1 T}-i_{L 2 T}+i_{L 1 B}-i_{L 2 B}\right)=0 \\
i_{L 1 T}+i_{L 1 B}=i_{L 2 T}+i_{L 2 B}=I_{\text {in }} \\
\frac{D}{C 2}\left(i_{L 1 T}-i_{L 2 T}+i_{L 1 B}-\frac{V_{\text {OUT }}}{R_{0}}\right)+\frac{(1-2 D)}{C 2}\left(i_{L 1 T}+i_{L 1 B}-\frac{V_{\text {OUT }}}{R_{0}}\right)+\frac{D}{C 2}\left(i_{L 1 T}+i_{L 1 B}-i_{L 2 B}-\frac{V_{\text {OUT }}}{R_{0}}\right)=0 \\
-D \cdot i_{L 2 T}-D \cdot i_{L 2 B}+i_{L 1 T}+i_{L 1 B}-\frac{V_{\text {OUT }}}{R_{0}}=0 \\
-D \cdot i_{L 2 T}-D \cdot i_{L 2 B}+i_{L 2 T}+i_{L 2 B}-\frac{V_{\text {OUT }}}{R_{0}}=0 \\
i_{L 2 T}(1-D)+i_{L 2 B}(1-D)=I_{\text {out }}=-\frac{V_{C 1}}{D \cdot R_{0}} \\
I_{\text {out }}=-\frac{V_{C 1}}{D \cdot R_{0}}
\end{gathered}
$$

Throughout the simulation sections, the derived equation resurfaces to provide clear understanding of the waveforms.

\subsection{Matlab Simulation Using State Space}

Matlab provides the best environment to simulate state space equations as it effortlessly calculates matrices. The Matlab script will be used to only evaluate results of the modified multiphase boost topology. Using the Matlab built in function, ode45, a first ordered differential equations are solved represented as $\mathrm{y}^{\prime}=\mathrm{f}(\mathrm{t}, \mathrm{y})$. The ode 45 function takes in an input matrix, a switching period, and initial conditions. Since each involves different duty cycles, the differential solver will have to depend on the switching devices

operations. As mentioned above there is only 3 possible states, alternating between State 
1 , to State 8 , to State 4 , and then back to State 8 . This cycle will repeat every $n^{\text {th }}$ times until error is minimized between final values of State 4 and initial conditions is less than $0.0001 \%$. The Matlab script is included in APPENDIX I and it is based on Lentz's script for the single-phase topology.

\subsubsection{Initial Conditions}

The first initial conditions that start the iteration are presented in Table 4-5. A loop runs through a cycle that includes all the states to refine the initial values. The solution for the state equations is defined if the final state, which is the output of State 8 , has an error of less than $0.0001 \%$ from the initial state. As long as final state solutions do not suffice this requirement, the last final value will be assigned as the initial conditions and the loop will run again.

Table 4-5. Modified Multiphase Boost Converter Component Averages

\begin{tabular}{|c|c|c|}
\hline Component & Voltage & Current \\
\hline $\mathrm{L}_{1 \mathrm{~T}}$ & $0 \mathrm{~V}$ & $\mathrm{I}_{\mathrm{IN}} / 2$ \\
\hline $\mathrm{L}_{2 \mathrm{~T}}$ & $0 \mathrm{~V}$ & $\mathrm{I}_{\mathrm{IN}} / 2$ \\
\hline $\mathrm{L}_{1 \mathrm{~B}}$ & $0 \mathrm{~V}$ & $\mathrm{I}_{\mathrm{IN}} / 2$ \\
\hline $\mathrm{L}_{2 \mathrm{~B}}$ & $0 \mathrm{~V}$ & $\mathrm{I}_{\mathrm{IN}}-(1-2 \mathrm{D})$ \\
\hline $\mathrm{C}_{1}$ & -D V $\mathrm{V}_{\text {OUT }}$ & $0 \mathrm{~A}$ \\
\hline $\mathrm{C}_{2}$ & $\mathrm{~V}_{\text {OUT }}$ & $0 \mathrm{~A}$ \\
\hline
\end{tabular}

The initial value for the current of $\mathrm{L}_{2 \mathrm{~B}}$ has been chosen using iterative process to ensure that $\mathrm{I}_{\mathrm{L} 2 \mathrm{~T}}$ and $\mathrm{I}_{\mathrm{L} 2 \mathrm{~B}}$ are $180^{\circ}$ out of phase. 


\subsubsection{M-Domain State Space Transformation}

As discussed in Lentz single-phase design, in order to implement a state space, it necessary to convert the time-domain matrices into $\mathrm{m}$-domain. The m-domain represents periodically repeating PWM switching cycles, where n range from zero to infinity. By cycling through n cycles, a solution for the state space can be refined.

Since multiphase has two various switching signals they are represented as top and bottom $\mathrm{f}_{\mathrm{n}}$. The main differentiator between the two is the starting point.

$$
\begin{gathered}
f_{n_{-} \text {top }}(m)= \begin{cases}0, & 0 \leq m \leq D \\
1, & D \leq m \leq 1\end{cases} \\
f_{n_{-} \text {bottom }}(m)= \begin{cases}0, & D \leq m \leq 0.5+D \\
1, & 0.5+D \leq m \leq 1\end{cases}
\end{gathered}
$$

Naturally, the conversion between the time-domain to m-domain is using a recurring relation of:

$$
t=(n+m) T, \text { where } n \text { is the number of cyles }
$$

Since state space system is based on the first order derivatives, the differential equations are expressed in m-domain. The parallel lies by taking the derivative of the definition of the m-domain, thus resulting in the following equation:

$$
d t=d m \cdot T
$$

The only matrices affected by the domain shift are the matrices per each switch combinations, the A matrices. For Matlab purposes, a period is observed through cycling through the different states in the right orders. Therefore, each A matrix needs to be adjusted to m-domain separately. 


$$
A_{\text {State } 1}=\left[\begin{array}{cccccc}
0 & 0 & 0 & 0 & \frac{-T}{L_{1 T}} & \frac{-T}{L_{1 T}} \\
0 & 0 & 0 & 0 & \frac{T}{L_{2 T}} & \frac{T}{L_{2 T}} \\
0 & 0 & 0 & 0 & \frac{-T}{L_{1 B}} & \frac{-T}{L_{1 B}} \\
0 & 0 & 0 & 0 & \frac{T}{L_{2 B}} & 0 \\
\frac{T}{C_{1}} & \frac{-T}{C_{1}} & \frac{T}{C_{1}} & \frac{-T}{C_{1}} & 0 & 0 \\
\frac{T}{C_{2}} & \frac{-T}{C_{2}} & \frac{T}{C_{2}} & 0 & 0 & \frac{-T}{R_{0} \cdot C_{2}}
\end{array}\right]
$$

\subsection{Design Simulations}

The design is being simulated using three methodologies to provide the most comprehensive performance of modified topology versus a standard multiphase boost. 
The Matlab simulation utilizes the derived state equations, while the LTspice simulations use a behavioral model and IC intergraded simulation. Similar component values are used for both modified and standard multiphase topology to provide the most accurate comparison. Table 4-6 highlights the key characteristics for each converter. In each subsection, the DC characteristics will be compared to the measured simulated results.

Table 4-6. Converter Design Parameter Summary

\begin{tabular}{|c|c|c|c|}
\hline \multicolumn{2}{|c|}{ Standard Multiphase Boost Design } & \multicolumn{2}{|c|}{ Modified Multiphase Boost Design } \\
\hline $\mathbf{V}_{\text {IN }}$ & $12 \mathrm{~V}$ & $\mathbf{V}_{\text {IN }}$ & $12 \mathrm{~V}$ \\
\hline Vout & $19 \mathrm{~V}$ & $\mathbf{V}_{\text {OUT }}$ & $19 \mathrm{~V}$ \\
\hline$P_{\text {OUT }}$ & $95 \mathrm{~W}$ & $\mathbf{P}_{\text {out }}$ & $95 \mathrm{~W}$ \\
\hline $\mathbf{f}_{\mathrm{S}}$ & $200 \mathrm{kHz}$ & $\mathbf{f}_{\mathrm{S}}$ & $200 \mathrm{kHz}$ \\
\hline $\mathbf{R}$ & $3.8 \Omega$ & $\mathbf{R}$ & $3.8 \Omega$ \\
\hline \multirow{2}{*}{$\mathbf{L}_{1 \mathrm{~T}}$} & \multirow{2}{*}{$10 \mu \mathrm{H}$} & $\mathbf{L}_{1 \mathrm{~T}}$ & $4.7 \mu \mathrm{H}$ \\
\hline & & $\mathbf{L}_{2 \mathbf{T}}$ & $4.7 \mu \mathrm{H}$ \\
\hline \multirow{2}{*}{$\mathbf{L}_{1 B}$} & \multirow{2}{*}{$10 \mu \mathrm{H}$} & $\mathbf{L}_{1 \mathrm{~B}}$ & $4.7 \mu \mathrm{H}$ \\
\hline & & $\mathbf{L}_{2 B}$ & $4.7 \mu \mathrm{H}$ \\
\hline \multirow{2}{*}{$\mathrm{C} 2$} & \multirow{2}{*}{$42 \mu \mathrm{H}$} & $\mathbf{C}_{1}$ & $22 \mu \mathrm{F}$ \\
\hline & & $\mathrm{C}_{2}$ & $42 \mu \mathrm{F}$ \\
\hline
\end{tabular}

\subsubsection{Matlab Simulation}

The modified multiphase boost converter is simulated in Matlab using multiphase_boost_mod_cycle.m and multiphase_boost_mod_sim.m script provided in APPENDIX - A. The code was based on Lentz's single phase modified boost simulation, but expanded into two phases using the new state equations derived in section 4.3. All plots using a multiphase topology include two cycles per one m-domain cycle. By multiphasing, the frequency doubles and thus the period shrinks accordingly. If the plots were based on $\mathrm{m}$ equals to $1 / 2$, the response will be incomplete since the state variables for from $1 / 2$ to 1 are different than 0 to $1 / 2$. 
The total inductance per stage is halved since each modified phase includes two inductors per stage. The ripple across the inner inductors, $\mathrm{L}_{2 \mathrm{~T}}$ and $\mathrm{L}_{2 \mathrm{~B}}$, is twice as large due to the inverse relation of ripple and inductance. This is seen in inductor waveforms in Figure 4-9.

The input currents passing through the first inductors, $\mathrm{L}_{1 \mathrm{~T}}$ and $\mathrm{L}_{1 \mathrm{~B}}$, are the same due to current equally splitting between the two inductors with no relations to switching frequency.
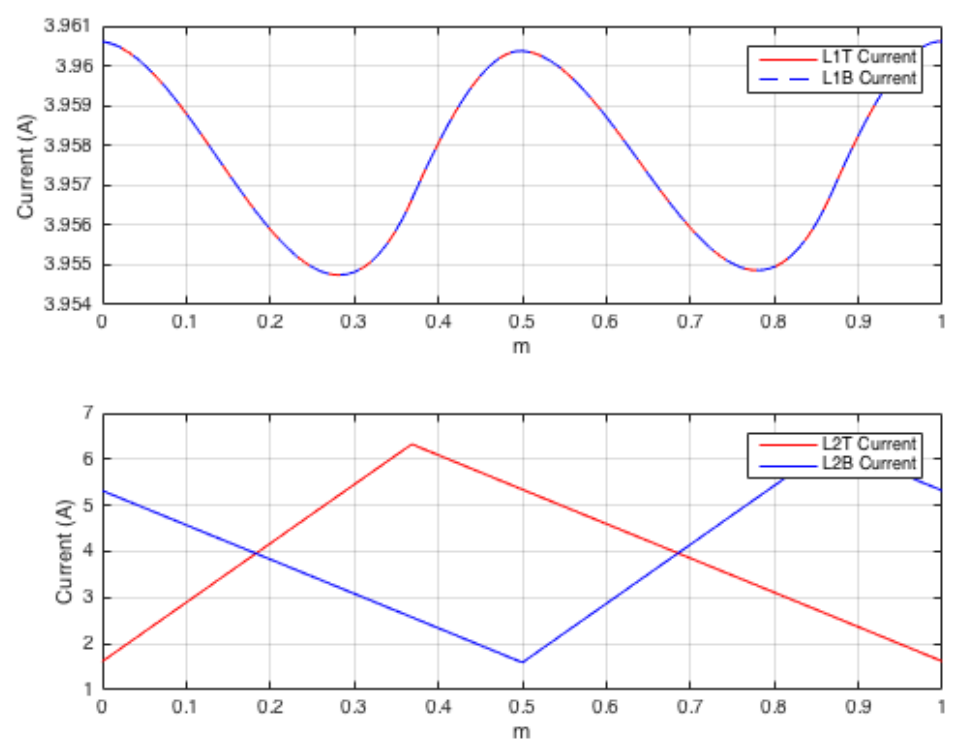

Figure 4-9. Matlab Modified Multiphase Boost Inductors Current Waveforms

Figure 4-10 highlights voltages induced on each capacitor. While the output capacitor voltage ripple is small, it is important to notice that it has to key characteristics: first is the Linear section, associated with both diodes being on and both switches turn off, and second is the Quadratic section, resulting from charging and discharging patterns of capacitors and inductors. 

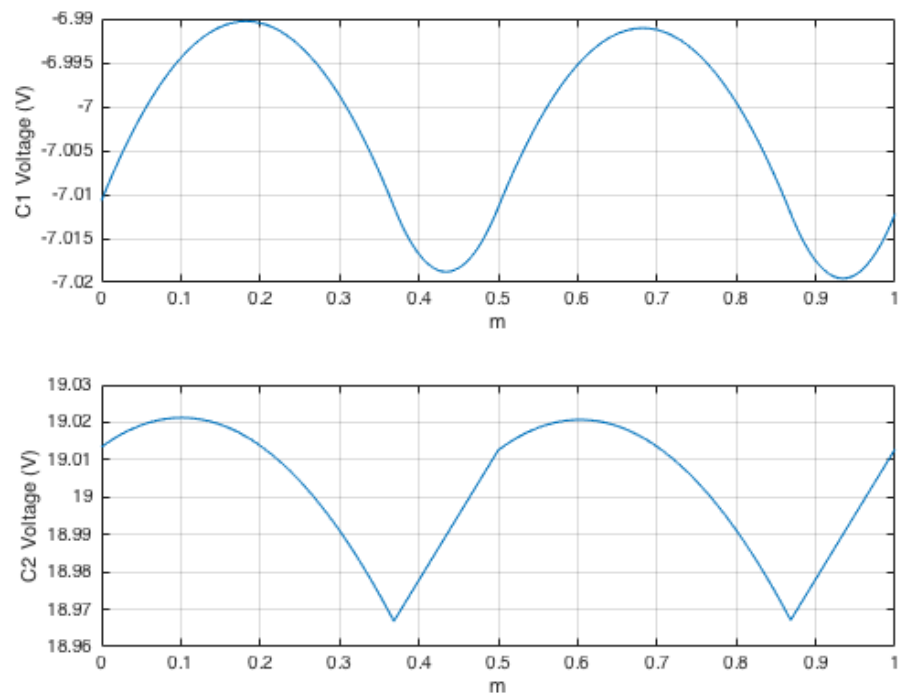

Figure 4-10. Matlab Modified Multiphase Boost Capacitors Voltage Waveforms

The current waveforms for the capacitors determine the RMS current rating for each capacitor. The waveforms are centered at zero due to capacitors average current always equal zero. Interestingly, the current through $\mathrm{C}_{1}$ is linear, which shapes the output current waveform. The currents waveforms provide future reference to calculating power loss across capacitors.
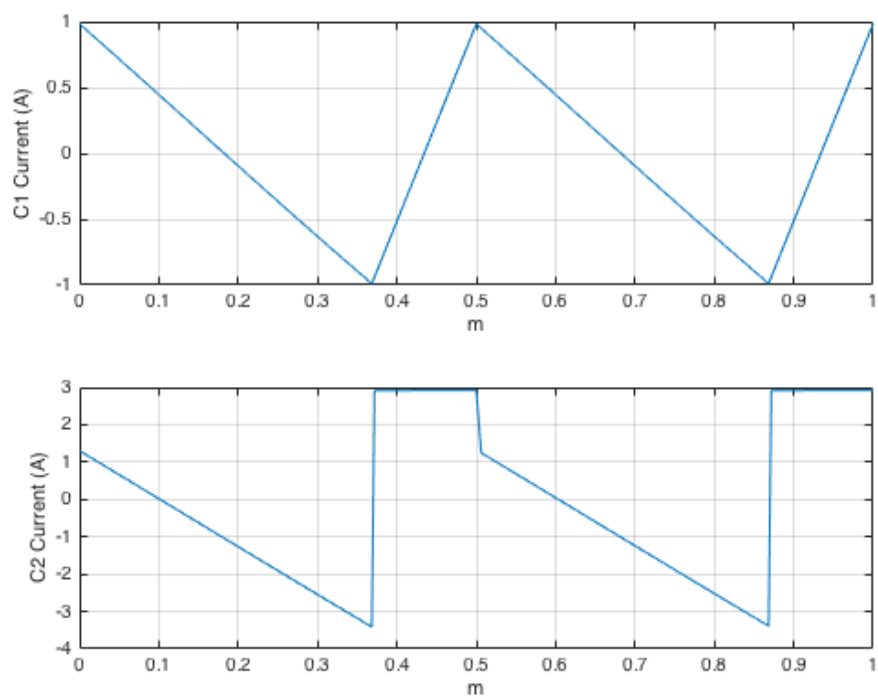

Figure 4-11. Matlab Modified Multiphase Boost Capacitors Current Waveforms 
Table 4-7 demonstrates the differences between theoretical calculations and Matlab results.

Table 4-7. Matlab and Theoretical Modified Multiphase Boost Design DC Performance

\begin{tabular}{|c|c|c|c|c|c|c|}
\hline & $\begin{array}{c}\mathbf{L}_{1 \mathbf{T}} \\
\text { Current } \\
(\mathbf{A})\end{array}$ & $\begin{array}{c}\mathbf{L}_{2 \mathbf{T}} \\
\text { Current } \\
(\mathbf{A})\end{array}$ & $\begin{array}{c}\mathbf{L}_{1 \mathbf{B}} \\
\text { Current } \\
(\mathbf{A})\end{array}$ & $\begin{array}{c}\mathbf{L}_{2 \mathbf{B}} \\
\text { Current } \\
(\mathbf{A})\end{array}$ & $\begin{array}{c}\mathbf{C}_{\mathbf{1}} \text { Voltage } \\
(\mathbf{V})\end{array}$ & $\begin{array}{c}\mathbf{C}_{2} \text { Voltage } \\
(\mathbf{V})\end{array}$ \\
\hline Matlab & 3.9581 & 3.9691 & 3.9581 & 3.9639 & -7.0073 & 18.998 \\
\hline Theory & 3.9583 & 3.9583 & 3.9583 & 3.9583 & -7 & 19 \\
\hline \%Diff & $0.00505 \%$ & $-0.273 \%$ & $0.00505 \%$ & $-0.141 \%$ & $0.104 \%$ & $0.0105 \%$ \\
\hline
\end{tabular}

\subsubsection{LTSpice Simulation Behavioral}

Simulations using a behavioral model only use the essential components to generate and compare the standard and modified multiphase topology. The circuits are energized with a DC input while the switches are driven with artificial PWM signal. The simulation runs for $30 \mathrm{~ms}$; however, only the last 5 cycles of each phase will be shown. Due to the nature of multiphase the output, the input and output parameters will have twice as many cycles and thus 10 cycles will be seen.

Figure 4-12 demonstrates the circuit diagram for standard multiphase boost. Analysis of the standard multiphase is compared to results of the modified solution. 


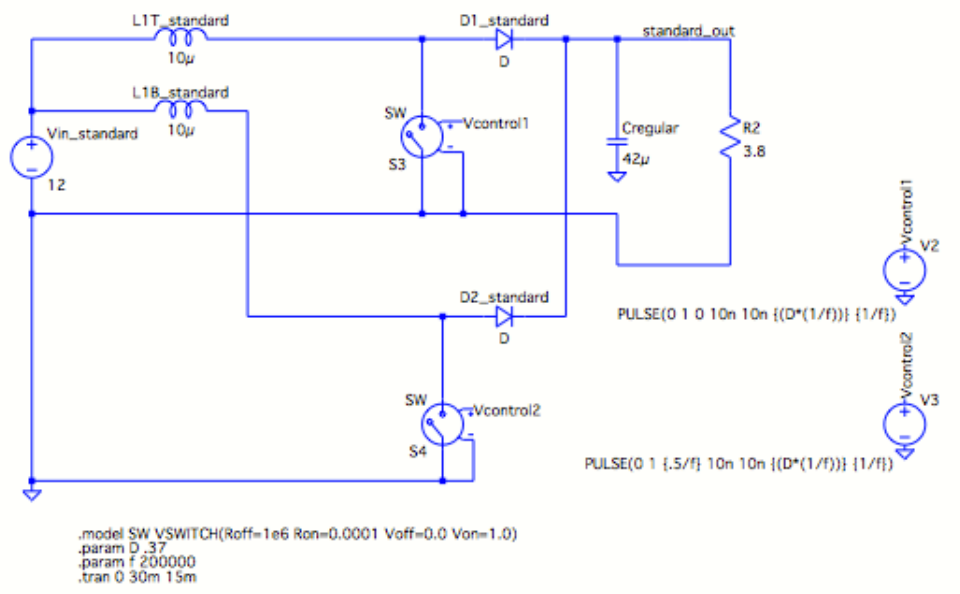

Figure 4-12. LTSpice Standard Multiphase Boost Behavioral Simulation

The inductor current ripple and output voltage ripple are demonstrated in Figure

4-13.
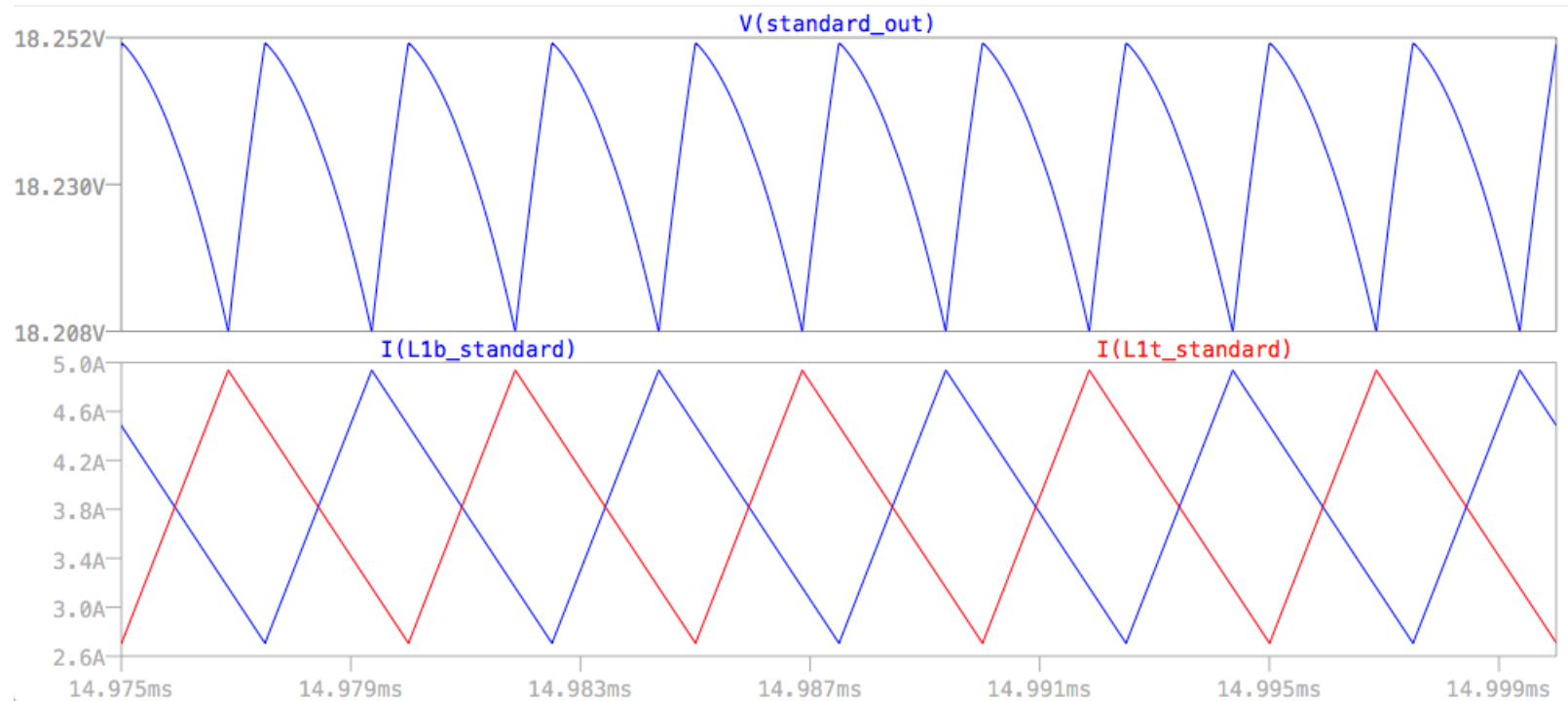

Figure 4-13. LTSpice Ripple Waveforms for Standard Multiphase Boost

For the modified multiphase boost topology the following LTSpice circuit has been used. 


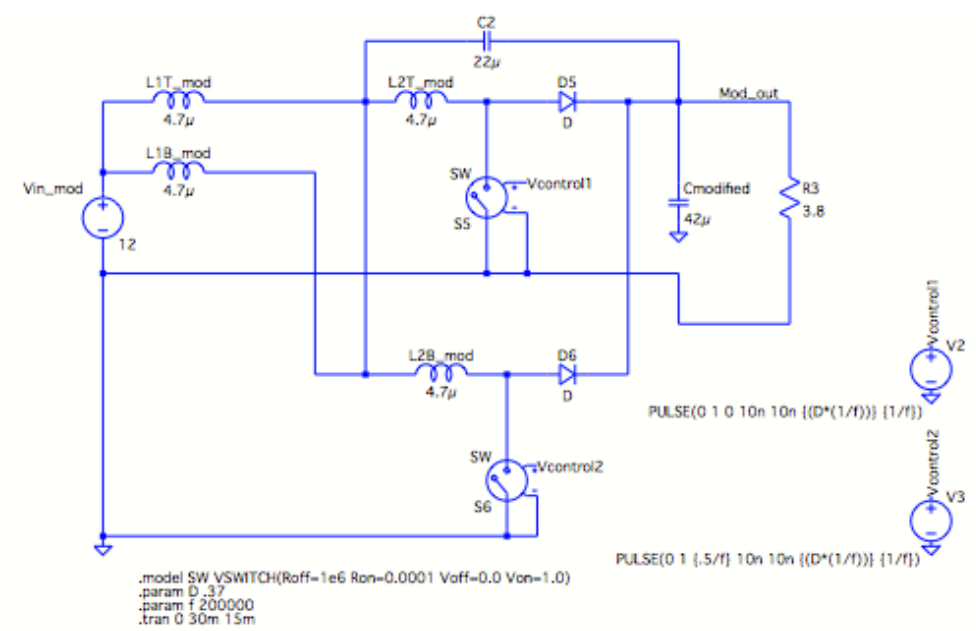

Figure 4-14. LTSpice Modified Multiphase Boost Behavioral Simulation

As a result of the modification, the current waveform of the input inductors are no longer linear as can be seen in Figure 4-15. Those waveforms are also overlapping as seen in the Matlab simulations.

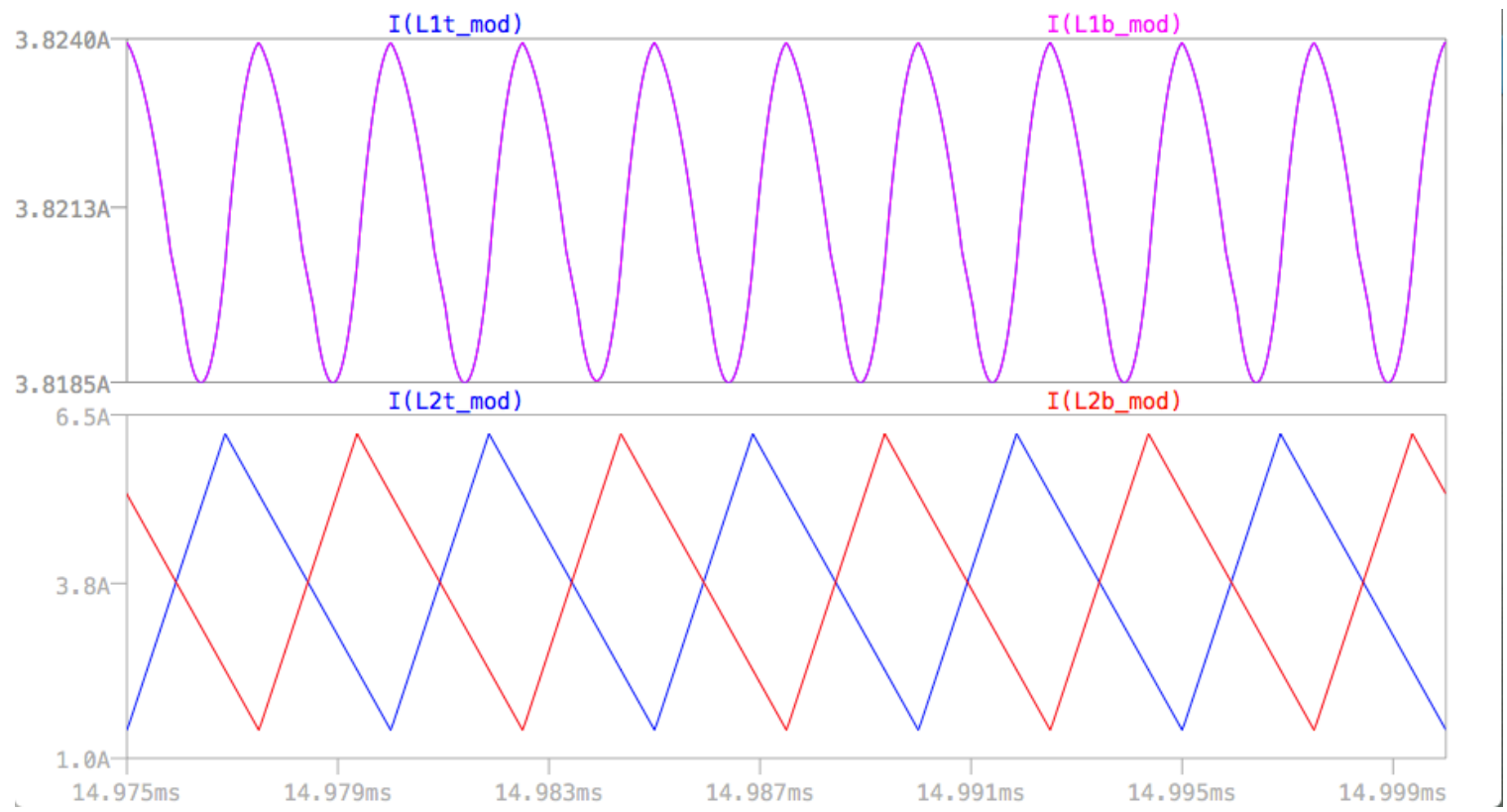

Figure 4-15. LTSpice Modified Multiphase Boost Inductor Current Waveforms

Figure 4-16 displays the voltage waveforms through the capacitors and shows the ripple associated with each capacitor. 


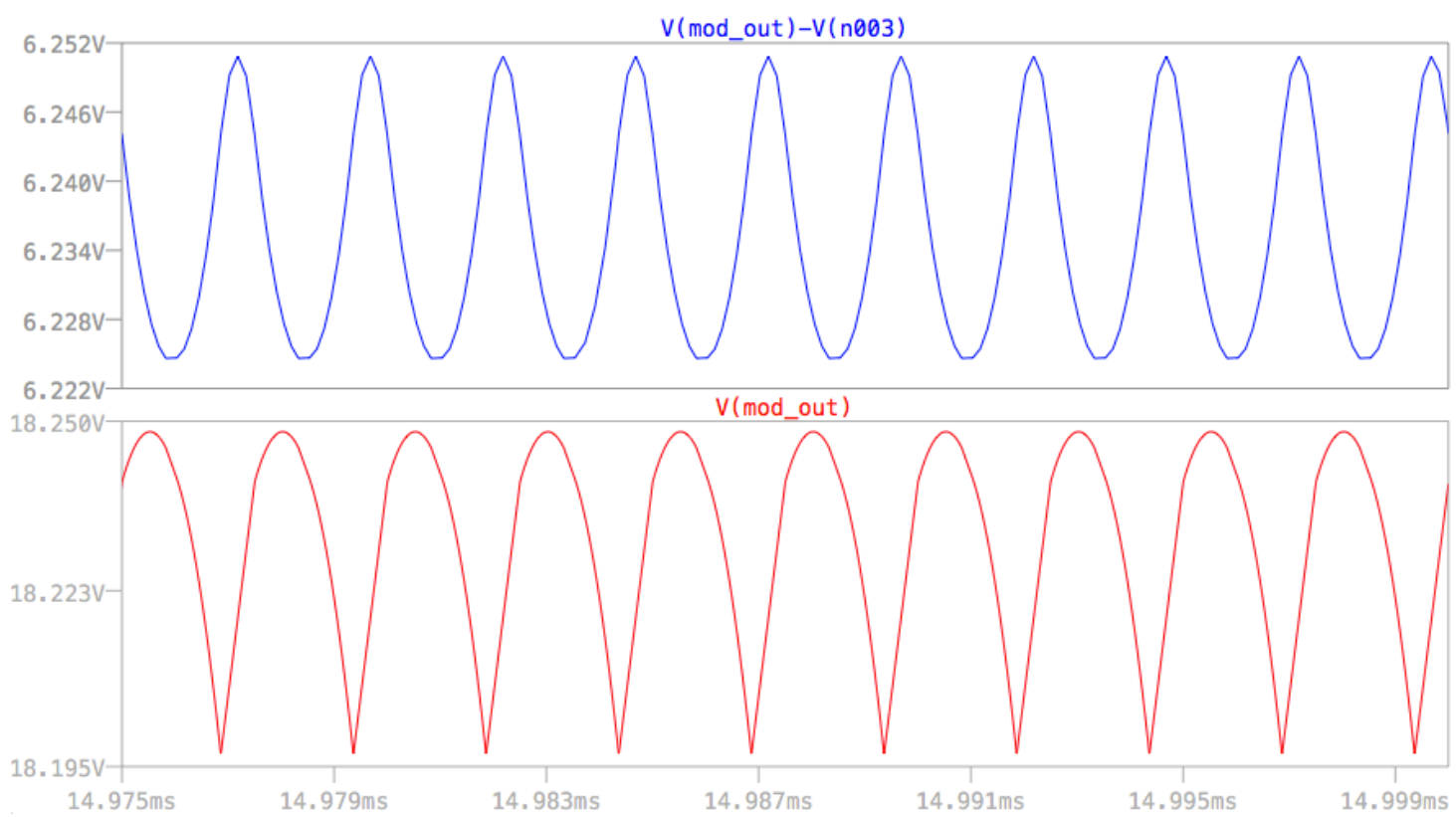

Figure 4-16. LTSpice Modified Multiphase Boost Capacitor Voltage Waveforms

The capacitor current waveforms are shown in Figure 4-17. They resemble the Matlab waveforms shown in the earlier section.

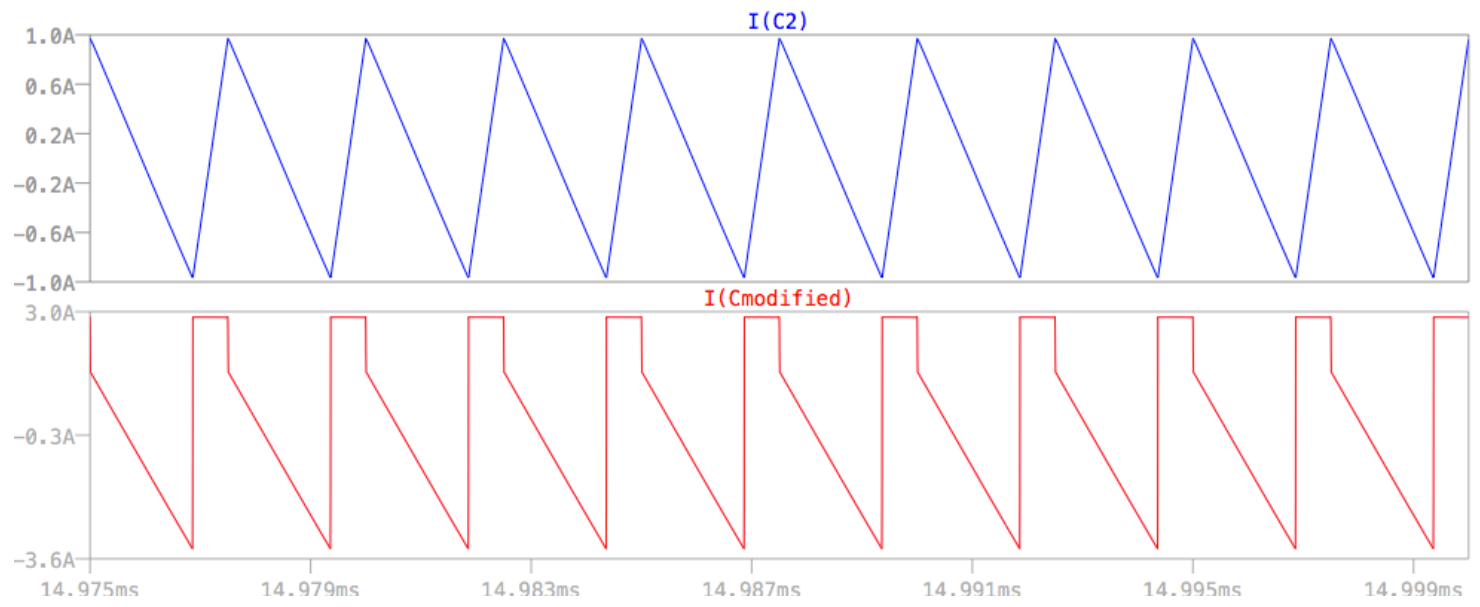

Figure 4-17. LTSpice Modified Multiphase Boost Capacitor Current Waveforms

\subsubsection{LTSpice Full Simulation - Using IC}

The main reason for simulating the design in LTSpice is for full integration of the controller IC with modified multiphase design. Component sizing for chip stability and proper operation will be discussed in the next chapter. For now, the waveforms of the 
currents and voltages are explored and compared to the Matlab and Behavioral LTspice simulations. In Figure 4-18 shows the complete design for a standard multiphase boost with the integral components to ensure appropriate performance.

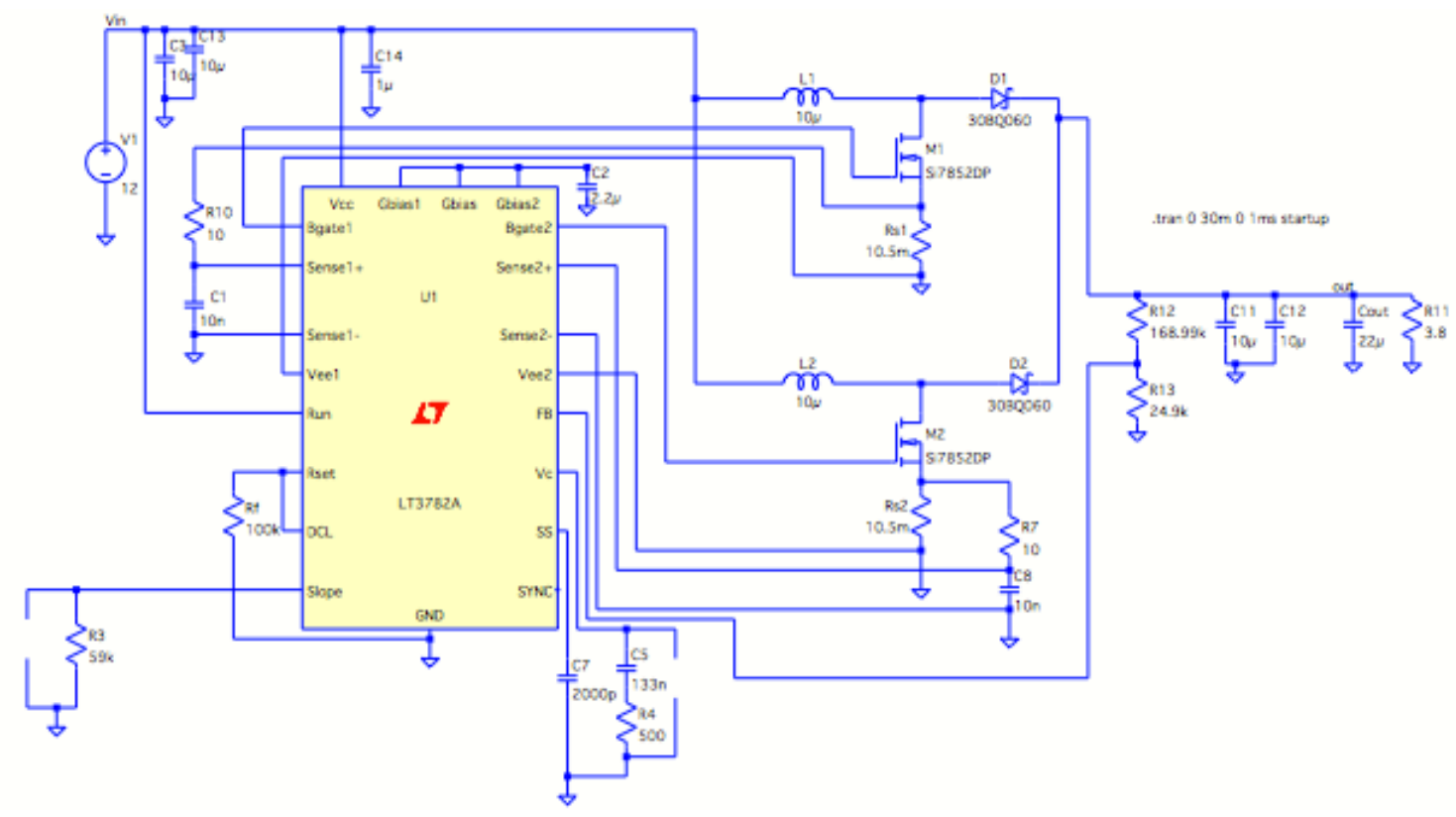

Figure 4-18. LTSpice Standard Multiphase Boost Transient Simulation Using Controller

Similar to the behavioral model, the currents through the inductors are linear and the output voltage has similar ripple characteristics. 


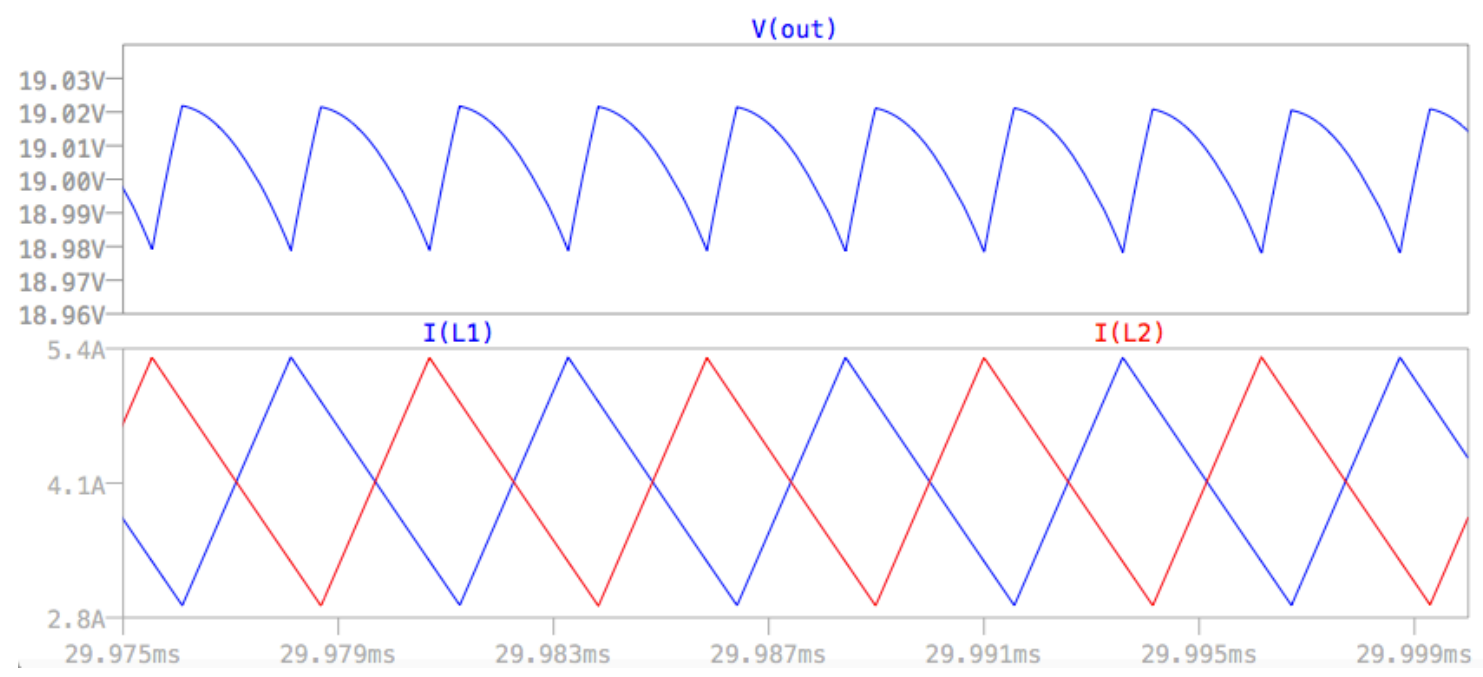

Figure 4-19. LTSpice Standard Multiphase Boost Ripple Waveforms Using Controller

Figure 4-20 shows the modified multiphase topology using the controller with all the same component values.

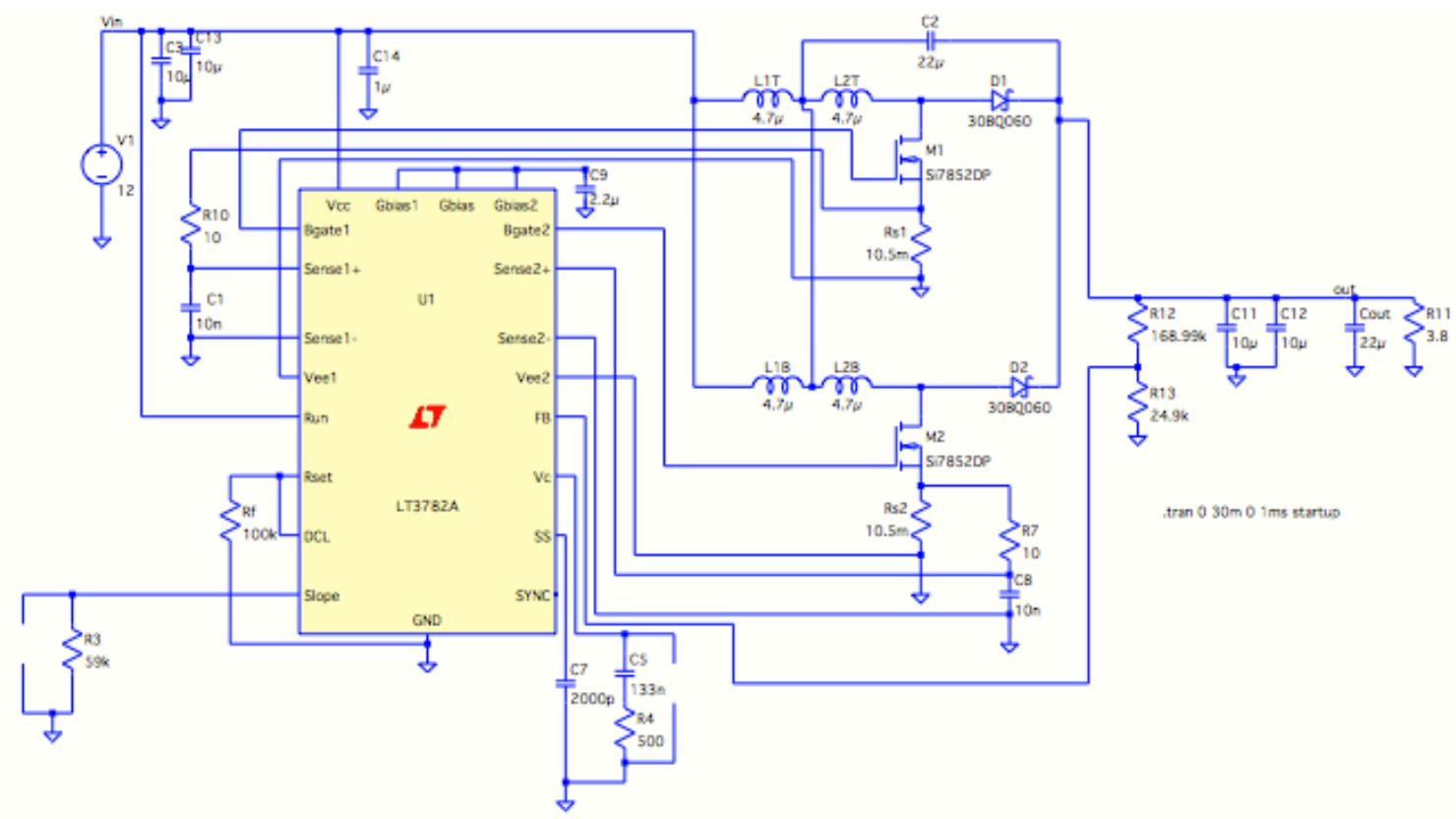

Figure 4-20. LTSpice Modified Multiphase Boost Transient Simulation Using Controller 
Figures 4-21 to 4-23 show the different waveforms for different state variables for comparison purposes in the next section. Since the controller involves extra components, currents and voltages may not match exactly to the Matlab simulations or the behavioral model. The controller model is also able to show resonance in the waveforms, and in order to see it in the plots the number of cycles has been increased to 20 .

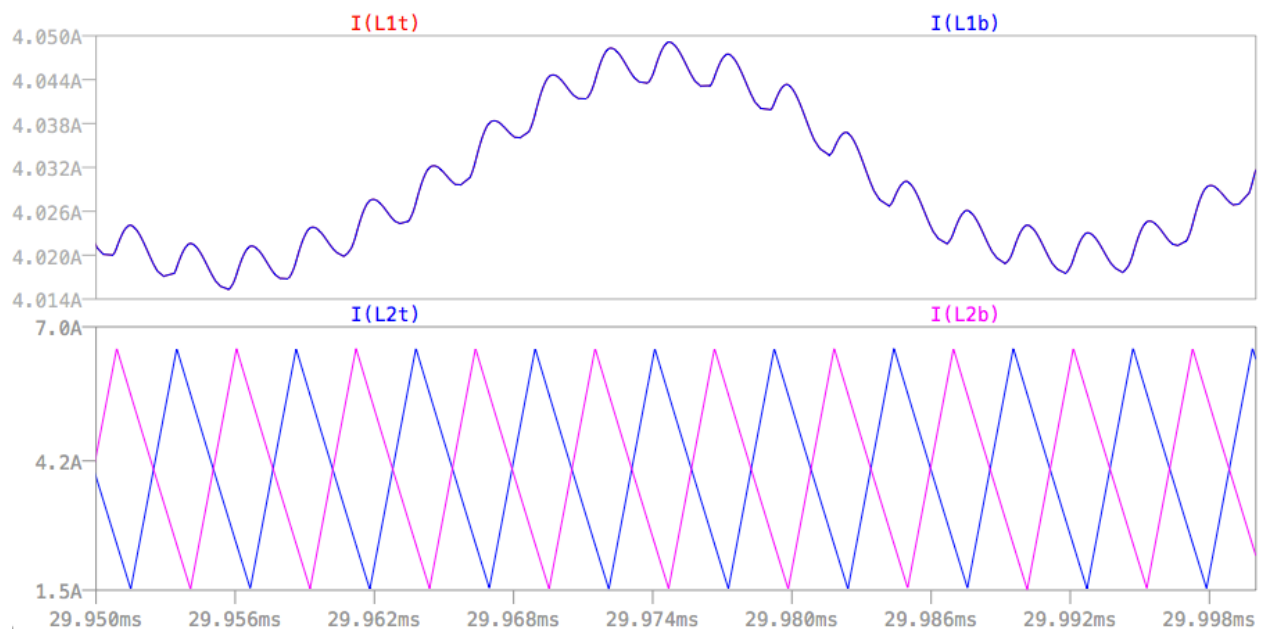

Figure 4-21. LTSpice Modified Multiphase Boost Inductor Current Waveforms Using Controller

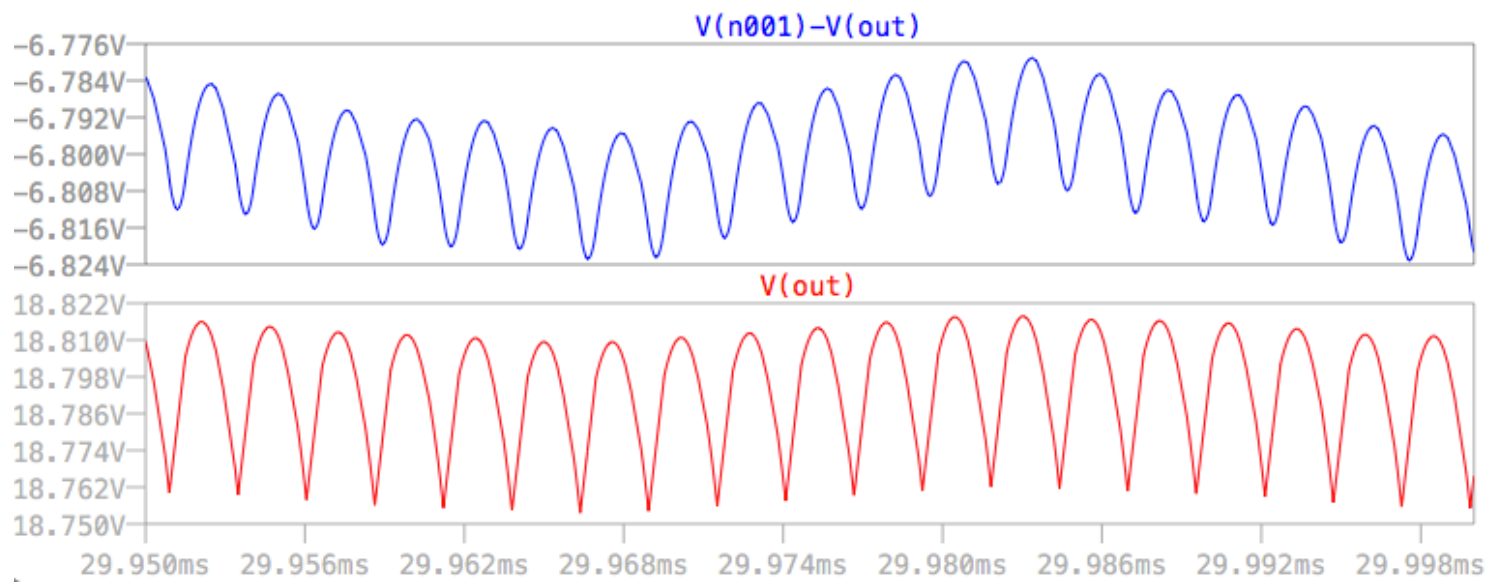

Figure 4-22. LTSpice Modified Multiphase Boost Capacitor Voltage Waveforms Using Controller 


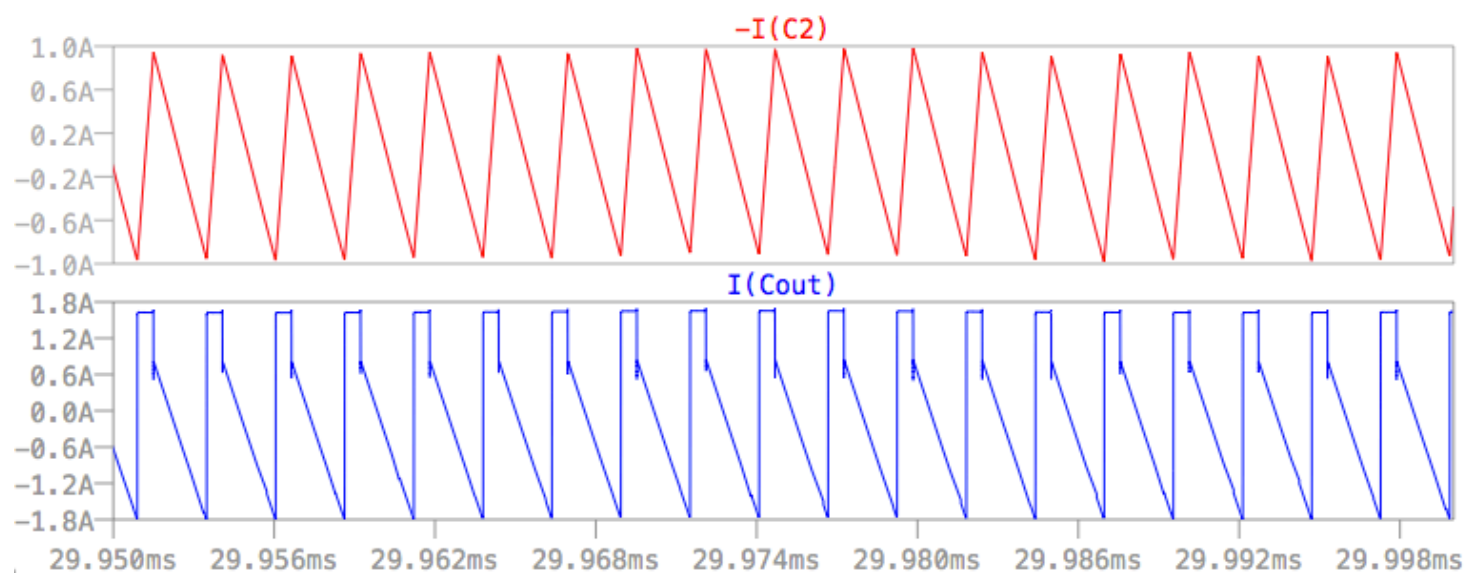

Figure 4-23. LTSpice Modified Multiphase Boost Capacitor Current Waveforms Using Controller

\subsection{Simulation Comparison}

A comprehensive comparison between the standard and modified multiphase topologies can be observed by comparing the average and peak-to-peak values of each state variable. Note that three simulation methodologies are used for comparison. Matlab only applies for the modified converter, while two LTSpice simulations apply for both modified and standard topologies. The LTSpice simulations provide two different transient analyses as one uses ideal switches and the other implements the controller model. By theory, using the controller model should yield a more accurate simulation since it incorporates surrounding components necessary for proper hardware assembly and testing.

Table 4-8 summarizes the key performance of the inductors and output capacitor of a standard multiphase topology. Those components define the input current ripple and output voltage ripple. The modified topology reduces the ripples and thus having initial values of a standard converter provide a point of comparison. 
Table 4-8. Standard Boost Simulation Measurement Comparison

\begin{tabular}{|c|c|c|c|c|c|c|}
\hline \multirow{2}{*}{} & \multicolumn{2}{|c|}{$\begin{array}{c}\text { Inductor Current } \mathbf{L}_{\mathbf{1 T}} \\
(\mathbf{A})\end{array}$} & \multicolumn{2}{|c|}{$\begin{array}{c}\text { Inductor Current } \mathbf{L}_{\mathbf{1 B}} \\
(\mathbf{A})\end{array}$} & \multicolumn{2}{c|}{$\begin{array}{c}\text { Capacitor Voltage } \mathbf{C}_{\mathbf{2}} \\
\text { (V) }\end{array}$} \\
\cline { 2 - 7 } & $\begin{array}{c}\text { LTSpice } \\
\text { Behavioral }\end{array}$ & $\begin{array}{c}\text { LTSpice } \\
\text { Chip }\end{array}$ & $\begin{array}{c}\text { LTSpice } \\
\text { Behavioral }\end{array}$ & $\begin{array}{c}\text { LTSpice } \\
\text { Chip }\end{array}$ & $\begin{array}{c}\text { LTSpice } \\
\text { Behavioral }\end{array}$ & $\begin{array}{c}\text { LTSpice } \\
\text { Chip }\end{array}$ \\
\hline Average & 3.786 & 4.119 & 3.865 & 4.111 & 18.233 & 19.005 \\
\hline Peak-Peak & 2.198 & 2.370 & 2.219 & 2.334 & 0.0427 & 0.0421 \\
\hline \%Ripple & $58.058 \%$ & $57.544 \%$ & $57.423 \%$ & $56.776 \%$ & $0.234 \%$ & $0.222 \%$ \\
\hline
\end{tabular}

The modified topology includes two extra inductors and feedback capacitor. The combination of the ripple across the initial inductors, $\mathrm{L}_{1 \mathrm{~T}}$ and $\mathrm{L}_{1 \mathrm{~B}}$, represents the input current. Notice that the input ripple is substantially smaller than a standard topology, however inner inductors, $\mathrm{L}_{2 \mathrm{~T}}$ and $\mathrm{L}_{2 \mathrm{~B}}$, undergo a major ripple swing of over $100 \%$. This may cause power loss and overheating that could lead to efficiency drop. The RMS current values assist in choosing capacitors ratings for the next section.

Table 4-9. Modified Multiphase Boost Simulation Measurement Comparison

\begin{tabular}{|c|c|c|c|c|c|c|}
\hline & \multicolumn{3}{|c|}{$\mathrm{L}_{1 \mathrm{~T}}$ Current (A) } & \multicolumn{3}{|c|}{$\mathrm{L}_{1 \mathrm{~B}}$ Current (A) } \\
\hline & Matlab & $\begin{array}{c}\text { LTSpice } \\
\text { Behavioral }\end{array}$ & $\begin{array}{l}\text { LTSpice } \\
\text { Chip }\end{array}$ & Matlab & $\begin{array}{c}\text { LTSpice } \\
\text { Behavioral }\end{array}$ & $\begin{array}{l}\text { LTSpice } \\
\text { Chip }\end{array}$ \\
\hline Average & 3.9581 & 3.8212 & 4.0294 & 3.9581 & 3.8212 & 4.0294 \\
\hline $\begin{array}{l}\text { Peak- } \\
\text { Peak }\end{array}$ & 0.005869 & 0.005445 & 0.03374 & 0.005869 & 0.005439 & 0.03358 \\
\hline \multirow[t]{3}{*}{ \%Ripple } & $0.14827 \%$ & $0.1425 \%$ & $0.8373 \%$ & $0.14827 \%$ & $0.1423 \%$ & $0.8334 \%$ \\
\hline & \multicolumn{3}{|c|}{$\mathrm{L}_{2 \mathrm{~T}}$ Current (A) } & \multicolumn{3}{|c|}{$\mathrm{L}_{2 \mathrm{~B}}$ Current (A) } \\
\hline & Matlab & $\begin{array}{c}\text { LTSpice } \\
\text { Behavioral }\end{array}$ & $\begin{array}{l}\text { LTSpice } \\
\text { Chip }\end{array}$ & Matlab & $\begin{array}{c}\text { LTSpice } \\
\text { Behavioral }\end{array}$ & $\begin{array}{c}\text { LTSpice } \\
\text { Chip }\end{array}$ \\
\hline Average & 3.9691 & 3.8213 & 4.0002 & 3.9639 & 3.8212 & 4.0754 \\
\hline Peak- & 4.7072 & 4.7214766 & 4.981036 & 4.7068 & 4.7214766 & 4.9614671 \\
\hline
\end{tabular}




\begin{tabular}{|c|c|c|c|c|c|c|}
\hline Peak & & & & & & \\
\hline \multirow{2}{*}{$\%$ Ripple } & $118.6 \%$ & $123.5568 \%$ & $124.5197 \%$ & $118.74 \%$ & $123.5600 \%$ & $121.7418 \%$ \\
\cline { 2 - 7 } & \multicolumn{3}{|c|}{$\mathbf{C}_{1}$ Voltage (V) } & \multicolumn{3}{c|}{$\mathbf{C}_{\mathbf{2}}$ Voltage (V) } \\
\hline Matlab & $\begin{array}{c}\text { LTSpice } \\
\text { Behavioral }\end{array}$ & $\begin{array}{c}\text { LTSpice } \\
\text { Chip }\end{array}$ & Matlab & $\begin{array}{c}\text { LTSpice } \\
\text { Behavioral }\end{array}$ & $\begin{array}{c}\text { LTSpice } \\
\text { Chip }\end{array}$ \\
\hline $\begin{array}{c}\text { Average } \\
\text { Peak- } \\
\text { Peak }\end{array}$ & -7.0073 & -6.2353 & -6.7998 & 18.998 & 18.231 & 18.794 \\
\hline \%Ripple & 0.02927 & 0.02619 & 0.04330 & 0.05441 & 0.050743 & 0.06354 \\
\hline & $0.4177 \%$ & $0.4200 \%$ & $0.6368 \%$ & $0.2864 \%$ & $0.2783 \%$ & $0.3381 \%$ \\
\cline { 2 - 7 } & Matlab & $\begin{array}{c}|c| \\
\text { L CTSpice } \\
\text { Behavioral }\end{array}$ & $\begin{array}{c}\text { LTSpice } \\
\text { Chip }\end{array}$ & Matlab & $\begin{array}{c}\text { LTSpice } \\
\text { Behavioral }\end{array}$ & $\begin{array}{c}\text { LTSpice } \\
\text { Chip }\end{array}$ \\
\hline RMS & 0.5972 & 0.563 & 0.551 & 2.4249 & 2.0455 & 1.1176 \\
\hline
\end{tabular}

The overall topology shows merits in the input current ripple reduction. Even though a standard multiphase experiences input ripple cancelation, it is incomparable to the modified topology. The results for input current ripple are summarized in Table 4-10.

Table 4-10. Simulated Boost Converter Input Current Ripple Reduction

\begin{tabular}{|c|c|c|c|c|c|c|}
\hline \multirow{2}{*}{} & \multicolumn{3}{|c|}{ Standard Multiphase Boost } & \multicolumn{3}{c|}{ Modified Multiphase Boost } \\
\cline { 2 - 7 } & Average & $\begin{array}{c}\text { Peak-Peak } \\
\text { (A) }\end{array}$ & \%Ripple & Average & $\begin{array}{c}\text { Peak-Peak } \\
\text { (A) }\end{array}$ & \%Ripple \\
\hline Matlab & $\mathrm{n} / \mathrm{a}$ & $\mathrm{n} / \mathrm{a}$ & $\mathrm{n} / \mathrm{a}$ & 7.9162 & 0.0117 & $0.1483 \%$ \\
\hline $\begin{array}{c}\text { LTSpice } \\
\text { Behavioral }\end{array}$ & 7.6371 & 0.9004 & $11.2878 \%$ & 7.6425 & 0.01087 & $0.1422 \%$ \\
\hline $\begin{array}{c}\text { LTSpice } \\
\text { Chip }\end{array}$ & 8.2307 & 0.8518 & $10.3491 \%$ & 8.0641 & 0.07937 & $0.984 \%$ \\
\hline
\end{tabular}

The major benefit of the modified topology is seen in the ripple calculations.

Where in the standard multiphase boost converter, the current is determined by the boost magnetics waveforms, the modified topology adds filtering components and eliminates the high ripple on the input inductors. As previously mentioned, this leads to larger ripple 
across inner inductors, $\mathrm{L}_{2 \mathrm{~T}}$ and $\mathrm{L}_{2 \mathrm{~B}}$, due to their lower inductance. This topology provides a very stable input ripple and output ripple of less than $1 \%$. 


\section{HARDWARE}

The hardware section describes the process for choosing: properly rated components based on design criteria, peripheral components to ensure proper workings of the controller, PCB layout design for EMI and heat dissipation reduction. The controller is used to test both the standard and modified topologies. The peripheral components are necessary to ensure stability and continuous conduction mode (CCM) at steady state. The section will also cover the tangible results for both topologies.

\subsection{Components Sizing}

The multiphase topology elevates voltage and current stress when selecting components. The ratings are derived from the peak values of the waveforms found in the simulation sections. While the modified topology demonstrate lower input current ripple, it inflicts much greater current ripple on the inner inductors, $\mathrm{L}_{2 \mathrm{~T}}$ and $\mathrm{L}_{2 \mathrm{~B}}$, and hence needs close considerations in rating the feedback capacitor, $\mathrm{C}_{1}$.

\subsubsection{Inductors Selection}

Inductor choice depends on the necessary nominal value as well DC current, saturation current, and DC resistance (DCR) of the inductor. The inductors in a multiphase topology specifically experience less DC current stress compared to the single-phase topology due to the splitting the current proportionally per phase. The standard topology has larger inductors, $10 \mu \mathrm{H}$, whereas the modified topology splits the inductors value equally, $4.7 \mu \mathrm{H}$. The average current running through all of the inductors is $3.96 \mathrm{~A}$. Due to the modified topology, the input current is filtered and the maximum 
current seen is $3.96 \mathrm{~A}$. However the inner inductors, $\mathrm{L}_{2 \mathrm{~T}}$ and $\mathrm{L}_{2 \mathrm{~B}}$, see much bigger ripple. The ripple can be calculated like the following:

$$
\Delta I_{L}=\frac{D \cdot V_{\text {in }}}{L \cdot f}=\frac{\frac{V_{o}-V_{i n}}{V_{o}} \cdot V_{\text {in }}}{L \cdot f}=\frac{\left(\frac{19 \mathrm{~V}-12 \mathrm{~V}}{19 \mathrm{~V}}\right) \cdot 12 \mathrm{~V}}{4.7 u \mathrm{H} \cdot 200 \mathrm{kHz}}=4.70 \mathrm{~A}
$$

When choosing the inductor, the saturation current must be above the maximum current seen by the inner inductors. The calculation for such is seen below.

$$
I_{S A T} \geq I_{L, \text { max }}=\bar{I}_{L}+\frac{\Delta I_{L}}{2}=3.96 \mathrm{~A}+\frac{4.70 \mathrm{~A}}{2}=6.31 \mathrm{~A}
$$

The inductors chosen are Wurth Electronics Inc. WE-HCC High Current Inductor Series fixed Ferrite inductors with surface mount technology [27] [28]. Table 5-1 summarizes the important properties of the inductors that suffice the necessary requirements for design.

Table 5-1. WE-HCC High Current Inductor Series Fixed Inductor Properties

\begin{tabular}{|c|c|c|c|c|c|}
\hline Components & Inductance & $\mathbf{I}_{\mathbf{D C}}$ & $\mathbf{I}_{\text {sat }}$ & Max DCR & Tolerance \\
\hline $\begin{array}{c}\text { Standard } \\
\text { Boost } \\
\text { Inductors }\end{array}$ & $10 \mathrm{uH}$ & $9 \mathrm{~A}$ & $10 \mathrm{~A}$ & $16.7 \mathrm{~m} \Omega$ & $\pm 20 \%$ \\
\hline $\begin{array}{c}\text { Modified } \\
\text { Boost } \\
\text { Inductor }\end{array}$ & $4.7 \mathrm{uH}$ & $15.5 \mathrm{~A}$ & $17 \mathrm{~A}$ & $7.9 \mathrm{~m} \Omega$ & $\pm 20 \%$ \\
\hline
\end{tabular}

\subsubsection{Capacitors Selection}

The input and output capacitors themselves see combined interleaved waveforms that result in cancelation and lower peaks. This allows for lower capacitance to filter the input and output stages. Due to Amp-Second balance theorem, the capacitors should not 
see any DC current. Thus, the reactive power, associated with the RMS currents, will be dissipated through the capacitors. Capacitors naturally have parasitic resistance associated with their model, known as Equivalent Series Resistance (ESR). The ESR value of a capacitor is how power is dissipated. Paralleling the capacitors together can reduce total ESR and hence reducing the power loss.

The capacitor choices are determined based on the ripple in input and output voltage waveforms. However the ripple of such waveforms is positively deformed due to the multiphase switching, which results in minimal required capacitance per given ripple. Thus, it is crucial to look at the low pass behavior created by the combination of the inductor and capacitor. Through multiple experiments, low-pass cut-off frequency should be less than two decades below the switching frequency. The calculations for new capacitance are shown below:

$$
\begin{gathered}
f_{c}<\frac{2 f_{s}}{100}=\frac{2 \cdot 200 \mathrm{kHz}}{100}=4 \mathrm{kHz} \\
f_{c}=\frac{1}{2 \pi \sqrt{L \cdot C}} \rightarrow C>\left(\frac{100}{2 \pi \cdot 2 f_{s}}\right)^{2}\left(\frac{1}{L}\right)=\left(\frac{100}{2 \pi \cdot 400 \mathrm{kHz}}\right)^{2}\left(\frac{1}{10 \mathrm{uH}}\right)=168 \mathrm{uF}
\end{gathered}
$$

The implementation of compensation lowers the capacitance to $20 \mu \mathrm{F}$ and $32 \mu \mathrm{F}$ for the input and output respectively.

The input capacitance consists of all ceramic capacitors while the output has one ceramic and one electrolytic. The ceramic helps lower the ESR while the electrolytic holds charge better while maintaining the original capacitance. Having both capacitors will provide improved transient due to lower ESR [10].

The capacitor chosen are displayed in Table 5-2 [29]. 
Table 5-2. Capacitors Configuration and Properties

\begin{tabular}{|c|c|c|c|c|c|c|}
\hline Components & Capacitance & Quantity & $\begin{array}{c}\mathbf{V}_{\text {DC }} \\
\text { Rating }\end{array}$ & ESR & Dielectric & Tolerance \\
\hline $\begin{array}{c}\text { Input } \\
\text { Capacitor }\end{array}$ & $10 \mathrm{uF}$ & 2 & $50 \mathrm{~V}$ & $14 \mathrm{~m} \Omega$ & X7R & $\pm 10 \%$ \\
\hline $\begin{array}{c}\text { Modified } \\
\text { Boost } C_{1}\end{array}$ & $10 \mathrm{uF}$ & 3 & $50 \mathrm{~V}$ & $14 \mathrm{~m} \Omega$ & X7R & $\pm 10 \%$ \\
\hline $\begin{array}{c}\text { Output } \\
\text { Capacitor }\end{array}$ & $10 \mathrm{uF}$ & 1 & $50 \mathrm{~V}$ & $14 \mathrm{~m} \Omega$ & X7R & $\pm 10 \%$ \\
\cline { 2 - 7 } & $22 \mathrm{uF}$ & 1 & $50 \mathrm{~V}$ & Bigger & $\begin{array}{c}\text { Aluminum } \\
\text { Electrolytic }\end{array}$ & $\pm 20 \%$ \\
\hline
\end{tabular}

\subsubsection{Switching Devices Selection}

The multiphase design provides lower average currents through the switching devices (MOSFETs) and Schottky diodes. The calculation for maximum DC current seen by each device is:

$$
\begin{gathered}
\bar{I}_{S W}=\bar{I}_{L} \cdot D=\frac{\bar{I}_{\text {in }}}{2} \cdot D=\frac{95 \mathrm{~W}}{2 \cdot 12 \mathrm{~V}} \cdot \frac{19 \mathrm{~V}-12 \mathrm{~V}}{19 \mathrm{~V}}=1.468 \mathrm{~A} \\
\bar{I}_{D}=\bar{I}_{L} \cdot(1-D)=\frac{\bar{I}_{\text {in }}}{2} \cdot(1-D)=\frac{95 \mathrm{~W}}{2 \cdot 12 \mathrm{~V}} \cdot\left(1-\frac{19 \mathrm{~V}-12 \mathrm{~V}}{19 \mathrm{~V}}\right)=2.5 \mathrm{~A}
\end{gathered}
$$

The maximum voltage that both the switch and diode see is the peak output voltage. Since the ripple on the output voltage is so minimal, the maximum voltage will be practically the average output voltage of $19 \mathrm{~V}$.

The standard and modified topologies have similar current and voltage characteristics on the switch and diode, thus the same components can be used for both topologies. Due to multiphase, there will be one set of switching components per phase. The switch used is IRF60B217 TO-220 package and the diode used is MBR10100G TO220 package [30] [31]. Their respective characteristics are shown in Table 5-3. 
Table 5-3. Switching Component Rating

\begin{tabular}{|c|c|c|c|}
\hline Components & Max Voltage & Max Current & $\mathbf{R}_{\text {DS(on) }}$ \\
\hline IRF60B217 & $60 \mathrm{~V}$ & $60 \mathrm{~A}$ & $7.3 \mathrm{~m} \Omega$ \\
\hline MBR10100G & $100 \mathrm{~V}$ & $10 \mathrm{~A}$ & $\mathrm{n} / \mathrm{a}$ \\
\hline
\end{tabular}

\subsection{Controller Selection}

The controller chosen for both topologies is the LT3782A [32]. The LT3782A is a 2-phase current mode with protection circuitry (under voltage lockout, current limit and duty cycle clamp). The IC also allows for programmable switching frequency for optimal switching losses. It has current sensors on the bottom of the MOSFETs, which does not affect the inductors' series path of the modified topology. Table 5-4 shows the pin configuration of the LT3782A.

Table 5-4. LT3782A Pin Descriptions [32]

\begin{tabular}{|c|c|c|}
\hline Pin Name & Pin No. & Description \\
\hline SGATE2 & 1 & Synchronous option for phase 2 . No connect for this thesis. \\
\hline SGATE1 & 2 & Synchronous option for phase 1 . No connect for this thesis. \\
\hline GND & $\begin{array}{c}4 / 29 \\
\text { (Exposed } \\
\text { Pad) }\end{array}$ & $\begin{array}{l}\text { Ground. Exposed pad } 29 \text { must be solder down to PCB to help } \\
\text { with thermal relief. }\end{array}$ \\
\hline SYNC & 5 & Synchronize the inputs due to multiphase topology. \\
\hline DELAY & 6 & $\begin{array}{l}\text { For synchronous topology to cut overlap between switching } \\
\text { devices to cut switching losses. No connect for this thesis. }\end{array}$ \\
\hline DCL & 7 & Duty cycle limiter. $\mathrm{R}_{\text {set }}$ limits duty cycle to $90 \%$. \\
\hline $\mathrm{SENSE}^{+}$ & 8 & $\begin{array}{l}\text { Current sense positive input for Phase 1. Measure across RC } \\
\text { filter. }\end{array}$ \\
\hline SENSE1 $^{-}$ & 9 & Current sense negative input for Phase 1. \\
\hline SLOPE & 10 & Increases slope compensation of PWM. \\
\hline $\mathrm{R}_{\mathrm{SET}}$ & 11 & Determines oscillation frequency. \\
\hline SENSE2 $^{-}$ & 12 & Current sense negative input for Phase 2. \\
\hline SENSE$^{+}$ & 13 & $\begin{array}{l}\text { Current sense positive input for Phase 2. Measure across RC } \\
\text { filter. }\end{array}$ \\
\hline SS & 14 & Programmable soft start, which is the ramp up rate for the output. \\
\hline
\end{tabular}




\begin{tabular}{|c|c|l|}
\hline VC & 15 & $\begin{array}{l}\text { The output of the error amplifier, where compensation is } \\
\text { connected. }\end{array}$ \\
\hline FB & 16 & The resistor divider that sets the output voltage. \\
\hline RUN & 17 & Dictates Shutdown mode when output goes below 2.3V. \\
\hline VEE2 & 19 & Ground of gate driver BGATE2. \\
\hline BGATE2 & 20 & Second phase gate driver. \\
\hline GBIAS2 & 21 & Bias for BGATE2. Connected to ground. \\
\hline GBIAS1 & 22 & Bias for BGATE1. Connected to ground. \\
\hline BGATE1 & 23 & First phase gate driver. \\
\hline VEE1 & 24 & Ground of gate driver BGATE1. \\
\hline VCC & 27 & Chip supply. Connected to input. \\
\hline GBIAS & 28 & $\begin{array}{l}\text { 11V regulator for internal circuitry biasing. Connected to } \\
\text { GBIAS1 and GBIAS2. }\end{array}$ \\
\hline NC & $3 / 18 /$ & No Connects. \\
\hline
\end{tabular}

\subsubsection{Output Voltage Programming}

The resistor divider monitors the output voltage and allows for PWM adjustments based on comparison of a threshold value of $2.44 \mathrm{~V}$ to the divider voltage. The equation necessary to determine the resistor divider values is:

$$
V_{\text {out }}=2.44\left(1+\frac{R_{F 1}}{R_{F 2}}\right)
$$

$\mathrm{R}_{\mathrm{F} 1}$ and $\mathrm{R}_{\mathrm{F} 2}$ must have a low tolerance of at least $1 \%$. The resistors cannot change otherwise output voltage fluctuates. $\mathrm{R}_{\mathrm{F} 1}$ has standard value of $169 \mathrm{k} \Omega$, thus producing $\mathrm{R}_{\mathrm{F} 2}$ with standard value of $24.9 \mathrm{k} \Omega$ as seen below.

$$
R_{F 2}=\frac{R_{F 1}}{\frac{V_{\text {out }}}{2.44}-1}=\frac{169 \mathrm{k} \Omega}{\frac{19 \mathrm{~V}}{2.44}-1}=24.9 \mathrm{k}
$$

Figure 5-1 below demonstrates the implementation of the resistor divider values. 


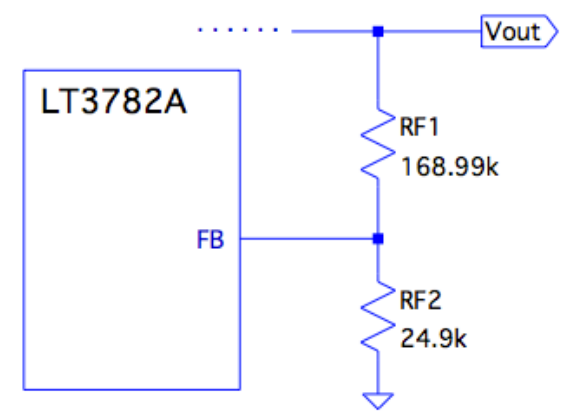

Figure 5-1. LT3782A Output Voltage Programming

\subsubsection{Frequency Setting}

The LT3782A allows for programmable frequency ranging from $150 \mathrm{kHz}$ to $500 \mathrm{kHz}$. For both topologies, frequency of $200 \mathrm{kHz}$ is chosen. The resistor is determined from the Switching Frequency versus $\mathrm{R}_{\mathrm{FREQ}}$ plot as shown in Figure 5-2.

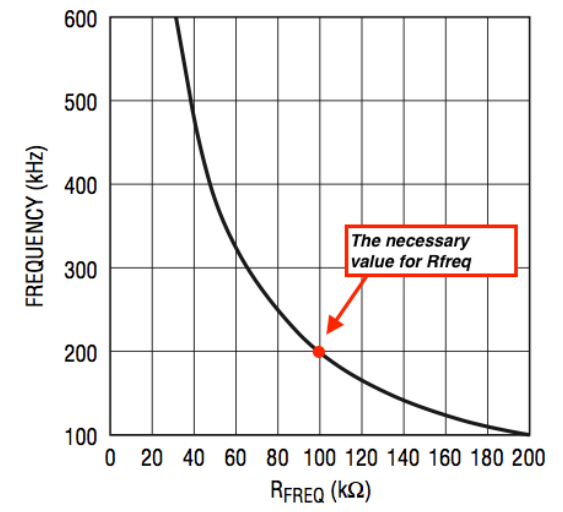

Figure 5-2. LT3782A Switching Frequency vs R

The implementation of the $\mathrm{R}_{\text {freq }}$ is seen in Figure 5-3.

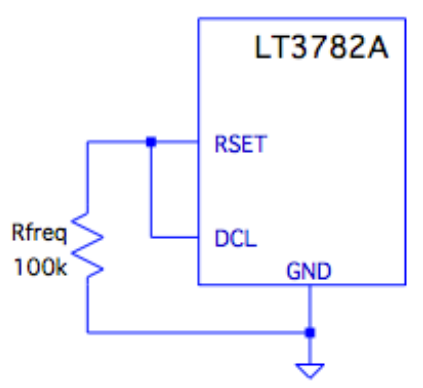

Figure 5-3. LT3782A Frequency Programming 


\subsubsection{Soft Start}

The soft start feature allows for pre-determined output turn-on time, thus

elevating the transient that occurs at start up. The time it takes for the output to reach the designed voltage is calculated by the equation below:

$$
t=\frac{C \cdot 2.44 V}{10 \mu A}
$$

The $2.44 \mathrm{~V}$ reference voltage is the compare voltage for the error amplifier and thus dictates the soft start time. Choosing a 2000pF capacitor the turn on time is:

$$
t=\frac{2000 p F \cdot 2.44 V}{10 u A}=0.488 s
$$

The diagram below demonstrates how to connect the soft start capacitor.

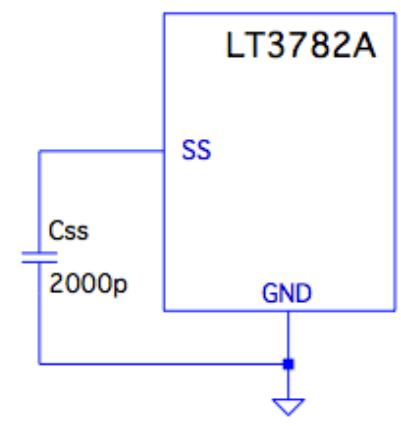

Figure 5-4. LT3782A Soft Start Programming

\subsubsection{Slope Compensation}

The slope compensation pin allows decreasing jitter created during switching. This is especially necessary if the converter is either high voltage and/or high current. Since the current sensing is on the source of the MOSFET the voltage waveform is not continuous. There is a built-in compensation for the current sensing amplifier, and this pin provides additional compensation to the loop. The compensation resistor must be 
more than $\mathrm{R}_{\mathrm{FREQ}} / 2$. The lower the value of $\mathrm{R}_{\mathrm{FREQ}}$, the higher the compensation affect, thus a value chosen is $59 \mathrm{k} \Omega$. Figure $5-5$ shows how to connect the external slope compensation resistor.

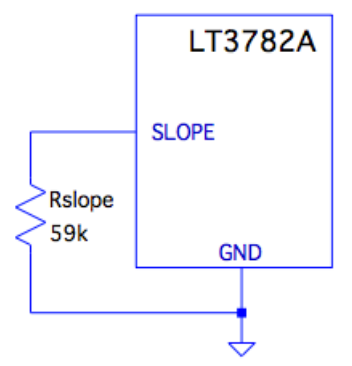

Figure 5-5. LT3782A Slope Compensation Programming

\subsubsection{Current Mode Sense Pins}

Since the LT3782A is a current mode controller, it has both error amplifier and current sensing amplifier. The current sense resistors are located between the source pins of the MOSFETs and ground. This permits current sensing using only one voltage measurement per phase as can be seen in Figure 5-6. The current sensing resistors are very small value in order to trim down power dissipation.

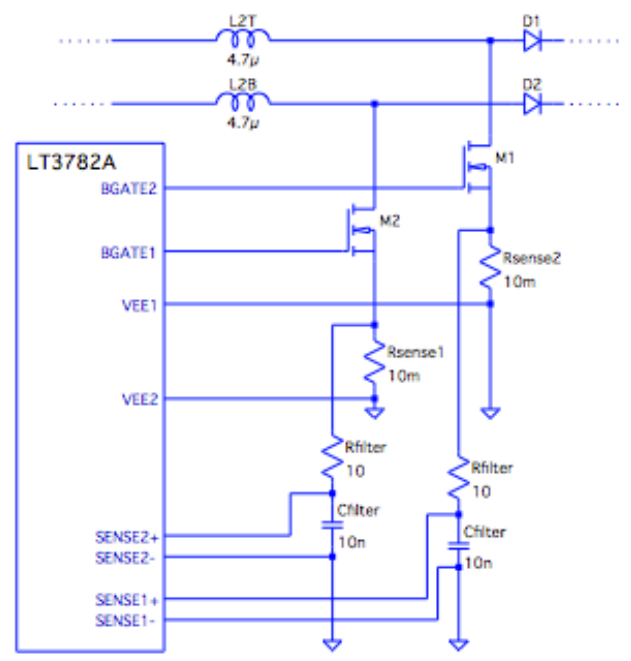

Figure 5-6. LT3782A Current Sensing Setup 
The sensing resistor is determined based on the worst conditions for the converter.

The equation and calculations defining the sense resistor are listed below:

$$
\begin{gathered}
R_{\text {SENSE }} \leq V_{\text {SENSE }(M A X)} \cdot \frac{1-D_{\text {MAX }}}{1.2 \cdot \frac{I_{O(M A X)}}{2}} \\
V_{\text {SENSE }(M A X)}=63 \mathrm{mV} \\
I_{o(M A X)}=\hat{I}_{S W}=\frac{\bar{I}_{\text {in }}}{2}+\frac{\Delta I_{\text {in }}}{2}=\frac{\bar{I}_{\text {in }}}{2}+\frac{V_{\text {in }} \cdot D}{2 f_{S} \cdot L}=\frac{7.9167 \mathrm{~A}}{2}+\frac{12 \mathrm{~V} \cdot 0.368}{2 \cdot 200 \mathrm{kHz} \cdot 4.7 u \mathrm{H}}=6.31 \mathrm{~A} \\
R_{\text {SENSE }} \leq 63 \mathrm{mV} \cdot \frac{1-0.369}{1.2 \cdot \frac{6.31 \mathrm{~A}}{2}}=10.5 \mathrm{~m} \Omega
\end{gathered}
$$

Originally, the resistor value used is $10 \mathrm{~m} \Omega$. Moreover, a low pass filter is applied before taking the sense measurement between SENSE1 ${ }^{+}$and SENSE1 ${ }^{-}$and SENSE2 ${ }^{+}$and SENSE2- This eliminates the noise due to switching as can be seen in Figure 5-7.

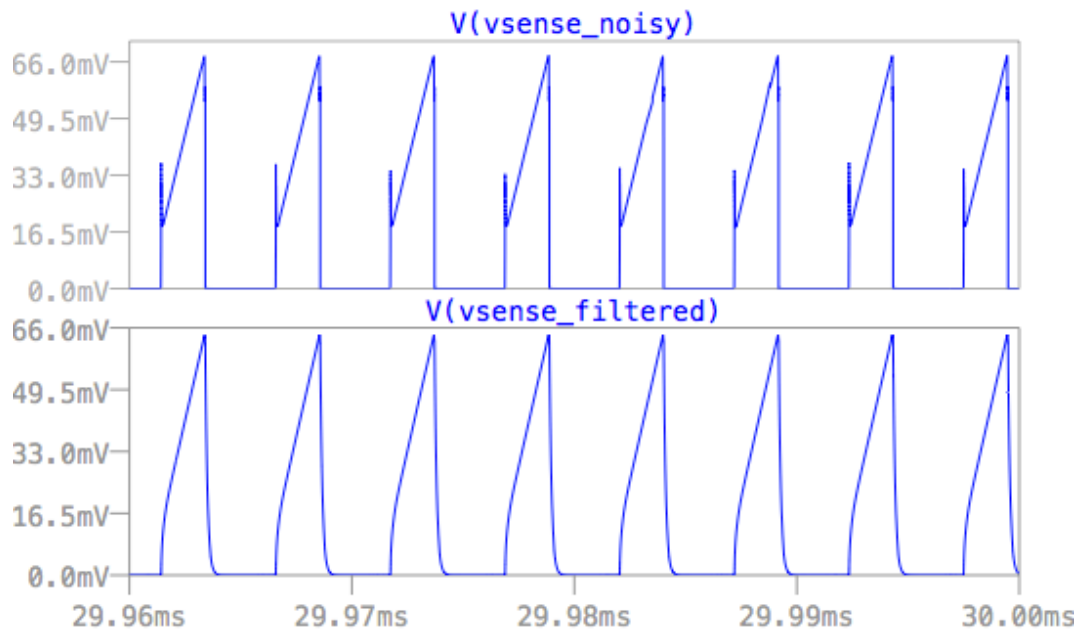

Figure 5-7. Comparing Voltage After the MOSFET (Vsense_noisy) to after the Low-Pass Filter (Vsense_filtered)

The low pass filter has a cutoff frequency of $1.59 \mathrm{MHz}$ as calculated below.

$$
f_{c}=\frac{1}{2 \pi \cdot R C}=\frac{1}{2 \pi \cdot 10 \Omega \cdot 10 \mathrm{nF}} \approx 1.59 \mathrm{MHz}
$$


This cutoff frequency is far away from the switching frequency, thus it does not filter the switching waveforms but does eliminates the switching spikes and other EMI noise.

\subsubsection{Compensation}

The topologies can be stabilized either using parallel combinations of high valued capacitors on the output or using compensation. The limited capacitance on the output does not provide enough loop gain at $\mathrm{DC}$, and thus compensation is necessary. The compensation should create a very high gain at DC and start decreasing the gain accordingly. This provides attenuation of high frequency content, which lowers the effect of such harmonic on the output. Compensation is always connected to the output of the error amplifier as shown in Figure 5-8.

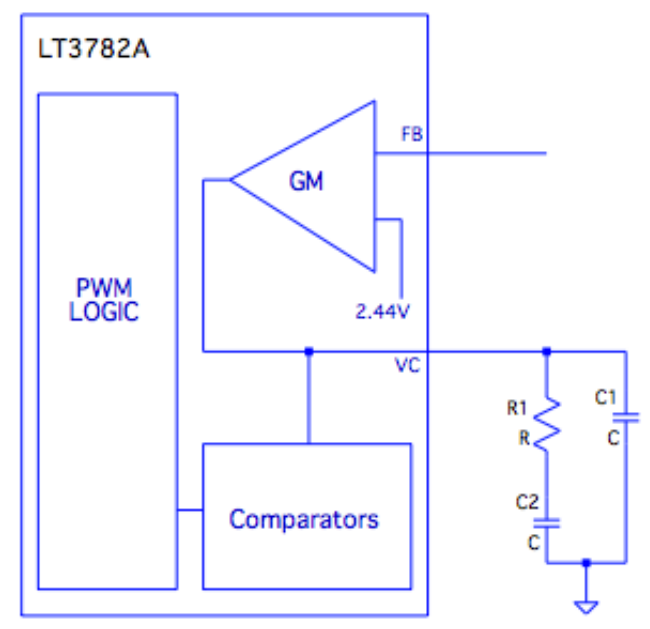

Figure 5-8. LT3782A Compensation Setup

Compensation options range from Type I to Type III. Depending on the original control loop behavior, a certain compensation option is chosen. The higher type represents more poles and zeros. The number of poles and zeros create different bode plots and allows for more flexible compensation. However, by creating higher order 
compensation, the control loop design becomes more complicated and would require more components.

Figure 5-9 shows the different passive components combinations to create different filter types. While calculating compensation using the following equations provides a starting point to achieve loop stability, implementation and adjustments might be necessary in hardware to maximize the benefits of compensation.
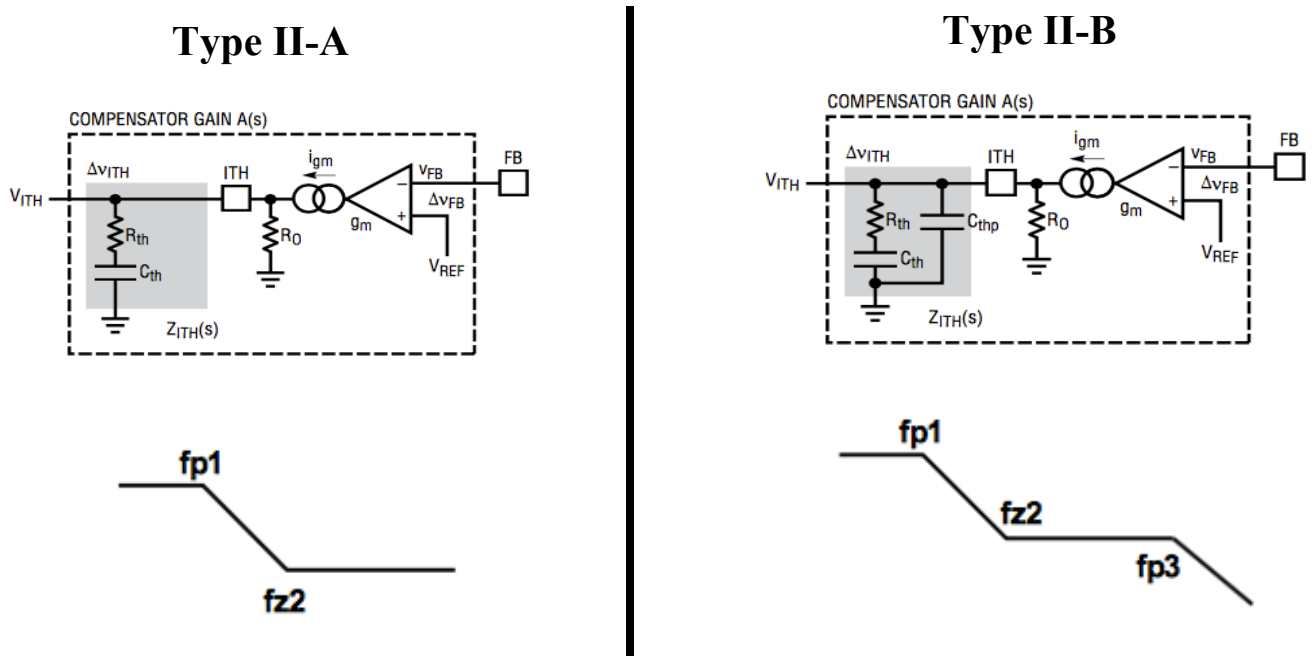

Figure 5-9. Different Compensation Types [33]

According to an application note by the controller manufacturer, the output resistance varies between $500 \mathrm{k} \Omega$ to $1 \mathrm{M} \Omega$ [34]. However, those values resulted in an unstable compensation network as demonstrated by computer simulations. As a result the output resistance was chosen to be $50 \mathrm{k} \Omega$, which is similar to the value used in Lentz's thesis [11].

The compensation is designed based on a crossover frequency that provides proper phase margin. The cutoff frequency is recommended to be at least a decade below the right-half plane zero [35]. The zero is determined based on the converter's properties. The calculation for the right-half plane zero and crossover frequency is demonstrated 
below. A higher inductance for a boost topology produces the critical minimum frequency for the zero, therefore the inductor value used for calculation is $10 \mu \mathrm{H}$.

$$
\begin{gathered}
f_{z-R H P}=\frac{R\left(\frac{V_{I N}}{V_{\text {OUT }}}\right)^{2}}{2 \pi \cdot L} \\
f_{z-R H P}=\frac{(3.8 \Omega)\left(\frac{12 \mathrm{~V}}{19 \mathrm{~V}}\right)^{2}}{2 \pi \cdot(10 \mu \mathrm{H})} \approx 24.1 \mathrm{kHz} \\
f_{c} \approx \frac{24.1 \mathrm{kHz}}{10} \approx 2.4 \mathrm{kHz}
\end{gathered}
$$

A Type II-B compensator was implemented for the LT3782A. The equations for determining the components for each capacitor and resistors are demonstrated below. The last pole, $\mathrm{p}_{2}$, is determined based on the fact that it is necessary to almost cancel the zero, and thus a pole is placed right before it.

$$
\begin{gathered}
f_{p 1-\mathrm{comp}}=\frac{1}{2 \pi \cdot C_{t h} R_{\text {out }}} \approx \frac{f_{c}}{100} \\
f_{z-\mathrm{comp}}=\frac{1}{2 \pi \cdot C_{t h} R_{t h}} \approx f_{c} \\
f_{p 2-\mathrm{comp}}=\frac{1}{2 \pi \cdot C_{t h p} R_{t h}} \approx 0.95 * f_{z-R H P} \\
C_{t h}=\frac{1}{2 \pi \cdot \frac{f_{c}}{100} R_{\text {out }}}=\frac{1}{2 \pi \cdot \frac{2.4 \mathrm{kHz}}{100} \cdot 50 \mathrm{k \Omega}} \approx 132.6 \mathrm{nF} \\
R_{t h}=\frac{1}{2 \pi \cdot f_{c} \cdot C_{t h}}=\frac{1}{2 \pi \cdot 2.4 \mathrm{kHz} \cdot 132.6 \mathrm{nF}}=500 \Omega \\
\frac{1}{2 \pi \cdot 0.9 * f_{z-R H P} \cdot R_{t h}}=\frac{1}{2 \pi \cdot 0.95 \cdot 24.1 \mathrm{kHz} \cdot 50 \mathrm{k} \Omega}=13.9 \mathrm{nF}
\end{gathered}
$$

Choosing values according to standard values, the resulting resistors and capacitors and their associated poles or zeros are listed in Table 5- 5. 
Table 5-5. Compensation Final Values

\begin{tabular}{|c|c|c|}
\hline \multicolumn{3}{|c|}{ Components Selection } \\
\hline Cth & Rth & Cthp \\
\hline $120 \mathrm{nF}$ & $500 \Omega$ & $12 \mathrm{nF}$ \\
\hline \multicolumn{3}{|c|}{ Poles and Zeros } \\
\hline$f_{p 1-c o m p}$ & $f_{z-\text { comp }}$ & $f_{p 2-c o m p}$ \\
\hline $26.53 \mathrm{~Hz}$ & $2.652 \mathrm{kHz}$ & $26.53 \mathrm{kHz}$ \\
\hline
\end{tabular}

In order to test calculated values, a simplified open loop bode plot was generated using the LTspice circuits seen in Figure 5-10. The three modes of operations as discussed in Chapter 3 derived those models. Because each mode has a different overall circuit, the closed loop behavior is slightly different.
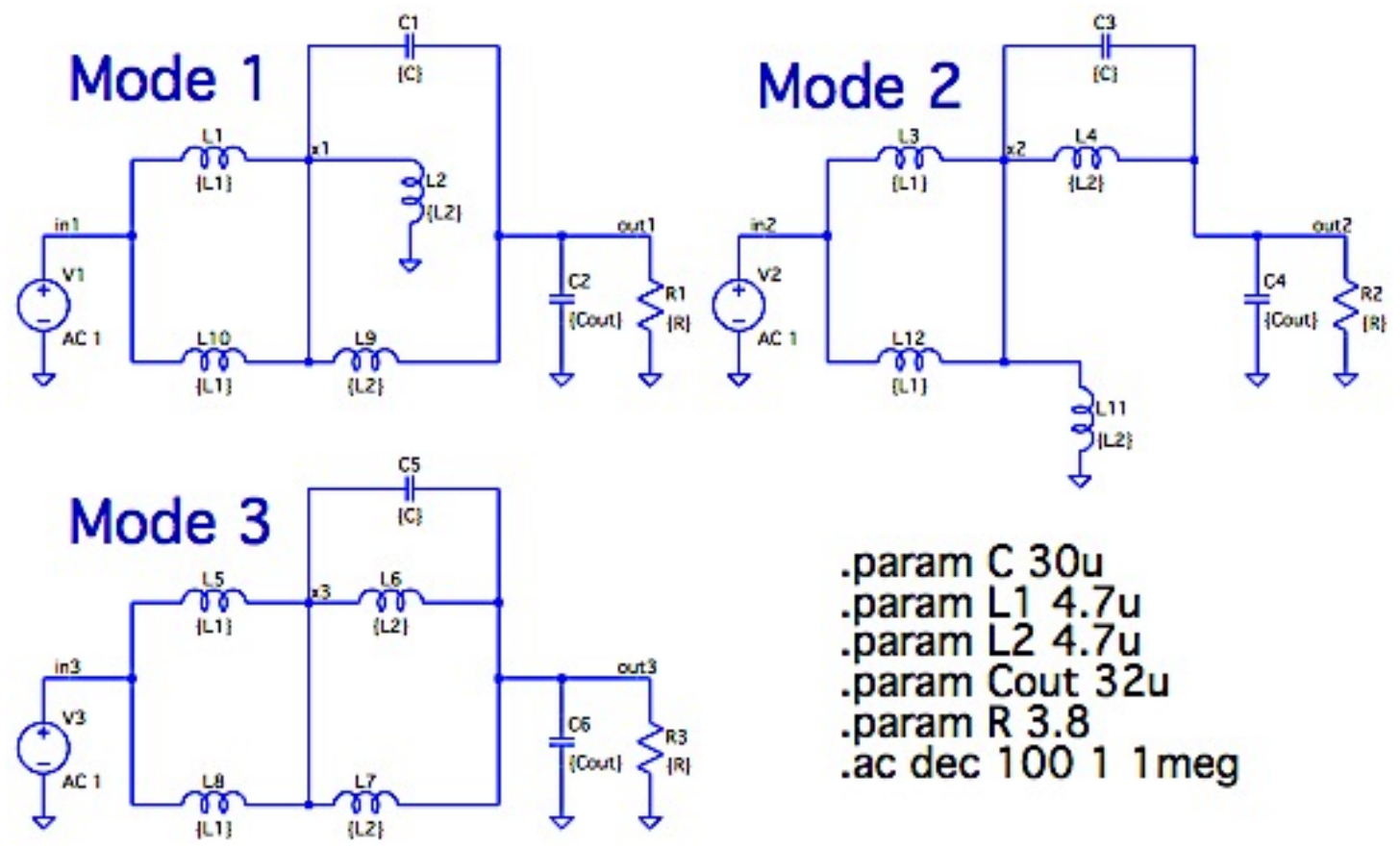

.param C 30u .param L1 $4.7 \mathrm{u}$ .param L2 4.7u .param Cout 32u .param R 3.8 .ac dec $10011 \mathrm{meg}$

Figure 5-10. Different Open Loop Modes of Operation

The bode plot data is extracted and combined with the designed compensation to create a closed loop response. The data extraction from LTspice is described in APPENDIX - II and the Matlab code used to generate the compensation and produce the 
bode plot is located in APPENDIX - III. Three plots are generated as shown in Figures 511 to 5-13, where each shows the expected closed loop response for each mode.
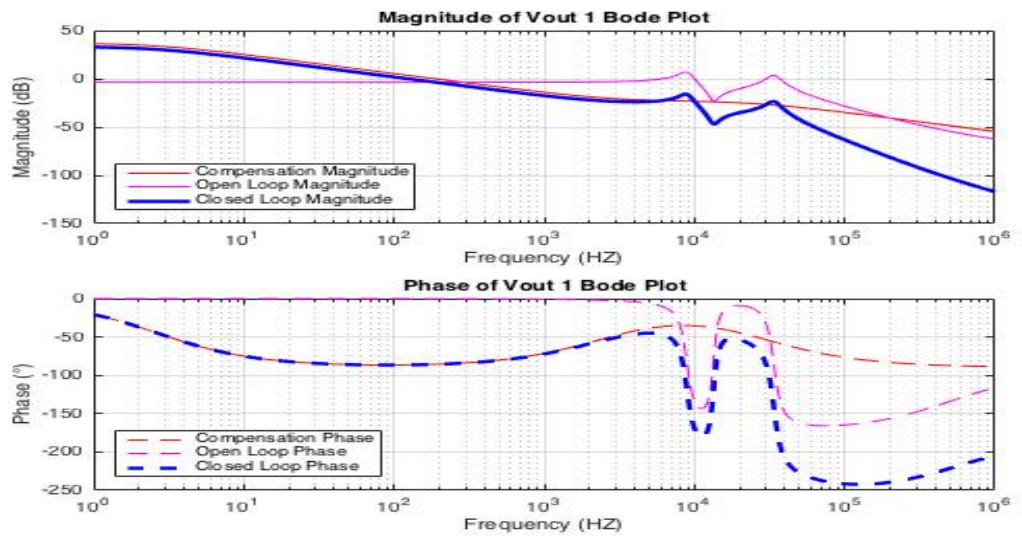

Figure 5-11. Mode 1 Bode Plot
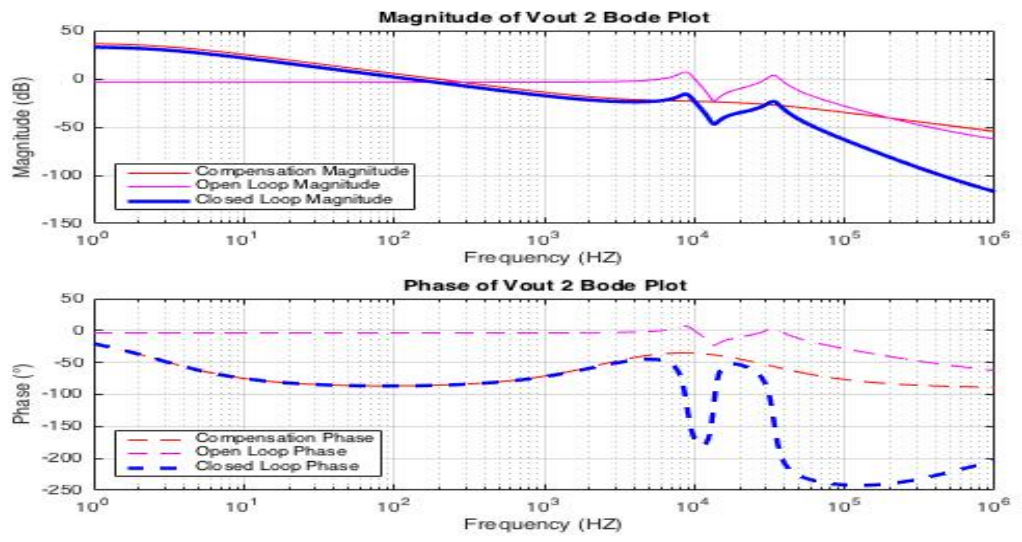

Figure 5-12. Mode 2 Bode Plot 

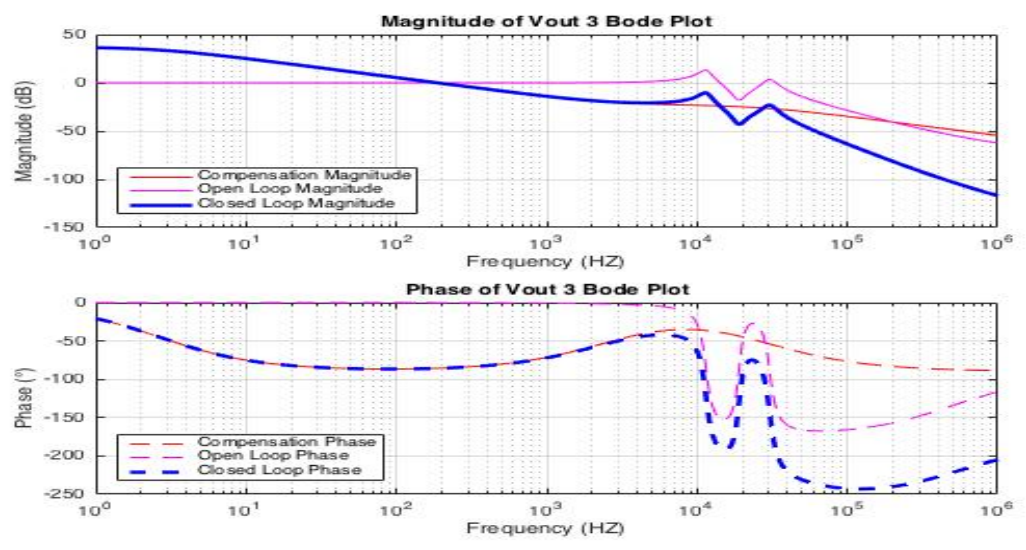

Figure 5-13. Mode 3 Bode Plot

As depicted in Figures 5-11 through 5-13, the resonance frequencies gain is negative. System stability is defined by positive gain margin and phase margin. The following equations describe those criteria for stability, where gain margin is calculated at the frequency at which the phase equals $180^{\circ}\left(w_{m c}\right)$. The phase margin is evaluated at the frequency when the gain plot is equal to $0 \mathrm{~dB}\left(w_{p c}\right)$.

$$
\begin{gathered}
G M=\text { Gain Margin }=-G[d B] \\
P M=\text { Phase Margin }=180^{\circ}+\angle G\left(w_{p c}\right)
\end{gathered}
$$

Based on above equations, gain margin for the system is $19.19 \mathrm{~dB}$ and phase margin is $94.31^{\circ}$ indicating that the system is stable.

\subsection{Power Dissipation}

While in simulations all components are ideal, this section evaluates the loss across the major components based on equations given by the LT3782A datasheet. The components' power dissipations and equations used are listed in Table 5-6. 
Table 5-6. Topology Power Dissipation [32]

\begin{tabular}{|c|c|c|c|}
\hline Component & Quantity & Power Dissipation Equation & $\begin{array}{c}\text { Power } \\
\text { Dissipation } \\
{[\mathrm{W}]}\end{array}$ \\
\hline IC & 1 & $\begin{array}{c}I_{Q(\text { TOT })} \approx I_{Q}=f \cdot Q_{G}, \text { where } f=200 \mathrm{kHz}, Q_{G} \\
=44 n C \\
P_{I C}=V_{\text {in }} \cdot\left(I_{Q}+f \cdot Q_{G}\right) \\
P_{I C}=V_{\text {in }} \cdot\left(2 \cdot f \cdot Q_{G}\right)\end{array}$ & 0.2112 \\
\hline MOSFET & 2 & $\begin{array}{c}P_{F E T}=\left(\frac{\frac{I_{o(\mathrm{MAX})}}{2}}{1-D_{M A X}}\right)^{2} \cdot R_{D S(o n)} \cdot D_{M A X} \cdot \rho_{T} \\
+k \cdot V_{o}^{2} \cdot \frac{\frac{I_{o(\mathrm{MAX})}}{2}}{1-D_{M A X}} \cdot C_{R S S} \cdot f \\
\text { where } \rho_{T}=0.4 \frac{\%}{{ }^{\circ} C}, k=1.7, C_{R S S} \\
=140 p F, R_{D S(o n)}=7.3 \mathrm{~m} \Omega\end{array}$ & 0.225 \\
\hline $\begin{array}{l}\text { Sense } \\
\text { Resistor }\end{array}$ & 2 & $\begin{aligned} P_{R(S E N S E)}= & \left(\frac{\frac{I_{o(\mathrm{MAX})}}{2}}{1-D_{M A X}}\right)^{2} \cdot R_{S E N S E} \cdot D_{M A X} \\
& R_{S E N S E}=5 m \Omega\end{aligned}$ & 0.0919 \\
\hline Inductor & 4 & $\begin{aligned} P_{L}= & \left(\frac{\frac{I_{o(\mathrm{MAX})}}{2}}{1-D_{M A X}}\right)^{2} \cdot R_{D S R} \\
& R_{D S R}=7.25 \mathrm{~m} \Omega\end{aligned}$ & 0.7237 \\
\hline Diode & 2 & $\begin{array}{c}P_{D I O D E}=\frac{I_{O(\mathrm{MAX})}}{2} \cdot V_{D} \\
V_{D}=0.8 \mathrm{~V}\end{array}$ & 5.048 \\
\hline & & Total Power Dissipation: & 6.2998 \\
\hline
\end{tabular}

In ideal situation, the circuit has an equivalent input and output power yielding a hundred percent efficiency. Using the losses calculated above, this ideal model could be reformed to calculate a more practical efficiency. That efficiency is determined based on the output power divided by the output power plus the losses. This produces an efficiency of $93.78 \%$. 


\subsection{Implementation and Testing}

After choosing components, the next step involves building a PCB and testing the two topologies. The schematic from LTspice was recreated in Altium in order to generate the PCB. The PCB design was fabricated according to the modified topology with the flexibility to test the standard topology. This simplified the PCB design process and allowed for consistent power path for both topologies. The PCB design provides the ideal testing optionality for both topologies and proves the benefits of the modified topology.

\subsubsection{PCB Layout}

Altium layout software was used to create the PCB. It possesses an easy user interface and provides variety of footprints while having vast open source guides for operation. Altium can also produce a 3D model of the design once completed. Overall, the Altium software allows for ease of layout design.

The LT3782A provides few guidelines for PCB layout design. Moreover many other layout decisions considered signal versus power traces' placements will be discussed in this section.

Few traces lengths were kept to minimum. The MOSFETs' gate signals require short trace as it is driving sensitive signals to turn on and off the MOSFETs. Any noise that accumulates on such signal can cause a change in duty cycle and thus can affect the output voltage. Same theory is applied to the input bypass capacitor, as the capacitor is responsible to maintain and supply the input voltage.

As result of keeping the gate drive signals to a minimum; the MOSFETs and IC need to be in close proximity of each other. Moreover, output voltage feedback signal is recommended to have a short trace. However, the IC pin configuration does not permit 
short traces for both the feedback and gate drivers' signals. A RC low pass filter connected to the output feedback signal solves this issue. It eliminates any noise accumulating on signal while not disturbing the switching behavior. Therefore the RC filter is stationed as close to chip while the voltage divider trace extends all the way around to get to the sense pins.

In terms of power board layout, it is important to segregate power versus signal traces. All power components (i.e. inductor, MOSFETs, Diodes) have high frequency content embedded in their signal, while many components connected to the chip run on very low clean voltages that could easily be affected by such noise. Thus in orders to separate the two, different grounds are used. Moreover, in order to even simplify the layout design, a ground layer was implemented where eventually all the grounds are connected. While this helps, it is also necessary to have different paths for power and signals. Therefore as can be seen in Figure 5-14, power moves from top to bottom from both directions. The chip orientation conflicts with completely separating the signal and power sections, therefore the chip is located in the middle of the board with effortless access to both phases of the multiphase boost. Power signals traces are wider to help with carrying high currents while the low voltage control signals are substantially smaller.

Since inductor current ripples are the prime performance criteria of comparison between the standard and modified topologies, current loops using 12 gauge wire are inserted before each inductor. This allows the use of current scope probe to inspect the current waveforms. 
Top

Bottom

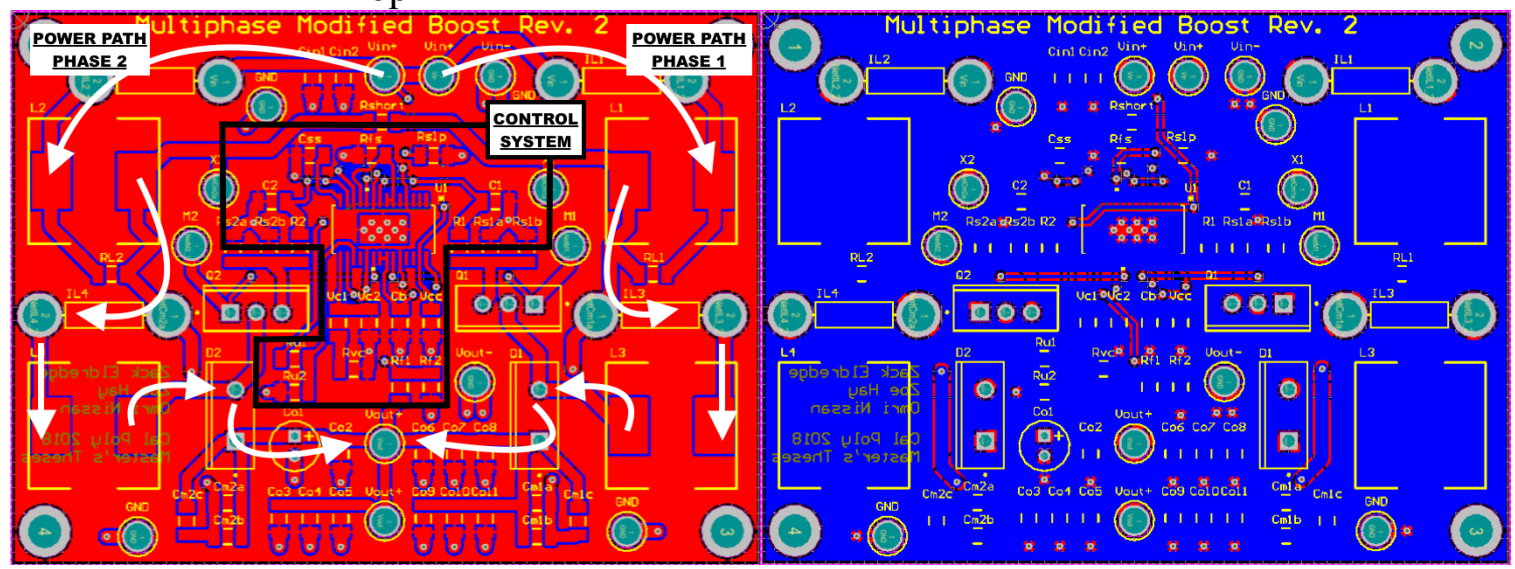

Figure 5-14. Top and Bottom Sides of the PCB with Highlighted Power Path and Control System

Figure 5-15 to 5-16 show the final assembly for the standard and modified multiphase boost converters. As can be seen the standard has two less inductors then the modified. APPENDIX - IV includes enlarged images of the top and bottom layers with the bill of material.

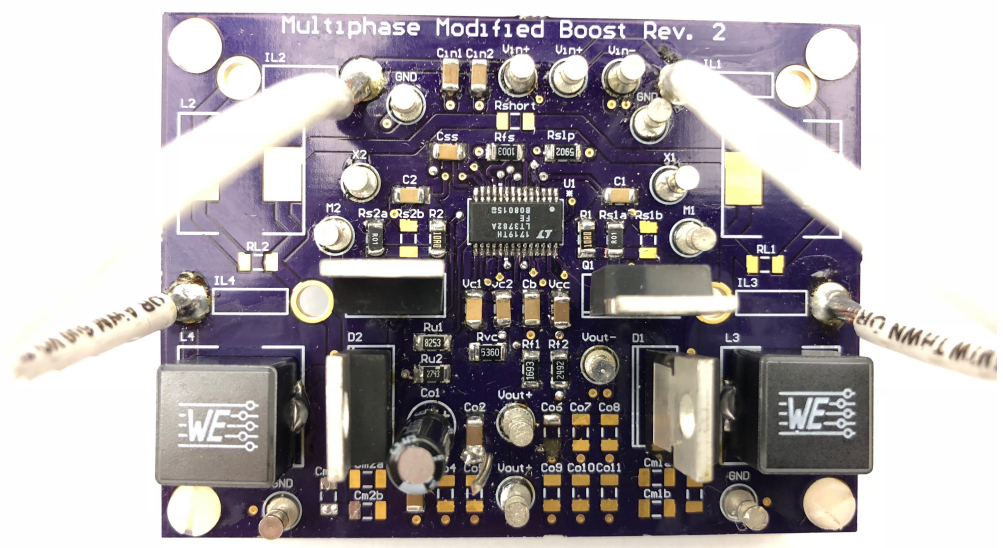

Figure 5-15. Assembled Standard PCB (Top View) 


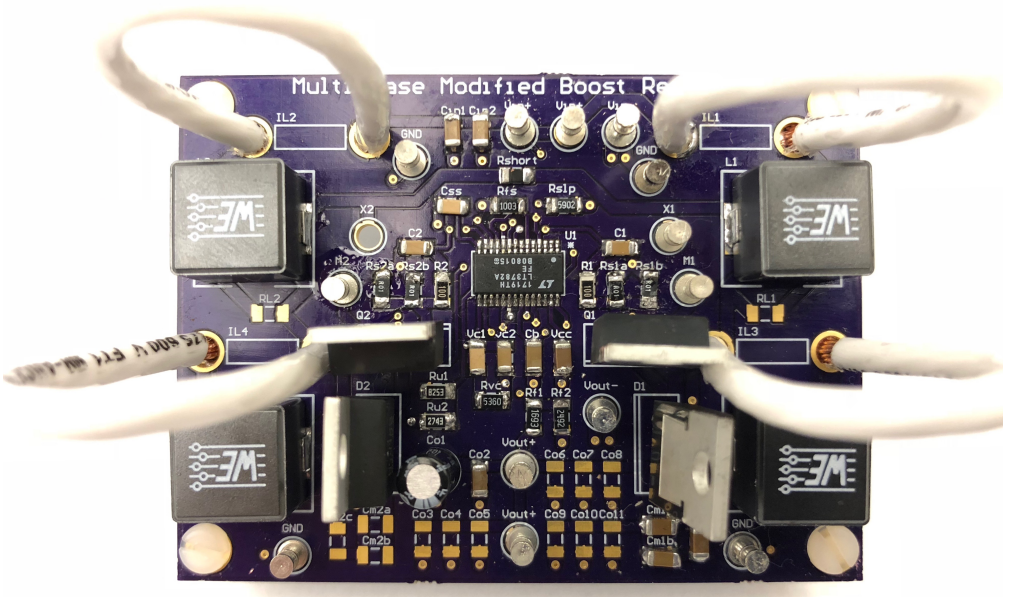

Figure 5-16. Assembled Modified PCB (Top View)

\subsubsection{Test Setup and Results}

Consistent PCB layout for both standard and modified boost topologies allowed for the identical test bench setup. After the initial testing, modifications/additions to the PCB shown above were made. The original design of the sense resistors prohibited the converters to regulate at full load. Thus decreasing the sense resistors to $5 \mathrm{~m} \Omega$ was necessary for proper working of the circuits. By treating the system as ideal, the peak current was minimized. Treating the system with minimum efficiency of $90 \%$, current peak seen by the switch is $10.977 \mathrm{~A}$. The lower sense resistor minimized peak voltage for current sensing, which enables output regulation.

$$
\begin{gathered}
I_{o(M A X)}=\hat{I}_{s w}=\frac{\bar{I}_{\text {in }}}{2}+\frac{\Delta I_{\text {in }}}{2}=\frac{P_{\text {out }}}{2 \cdot \eta_{\text {min }} \cdot V_{\text {in }}}+\frac{V_{\text {in }} \cdot D}{2 f_{s} \cdot L} \\
=\frac{95 \mathrm{~W}}{2 \cdot 0.9 \cdot 12 \mathrm{~V}}+\frac{12 \mathrm{~V} \cdot 0.368}{2 \cdot 200 \mathrm{kHz} \cdot 4.7 \mathrm{uH}}=10.977 \mathrm{~A}
\end{gathered}
$$

Measurements of the voltages using a probe scope showcased exceeding amount of noise. In order to avoid this issue, the probe and ground must create a smaller loop. 
This is achievable by soldering ground pins closer to the measured voltages' pins. This substantially reduced noise seen on the oscilloscope. Figure 5-17 demonstrates this contraption.

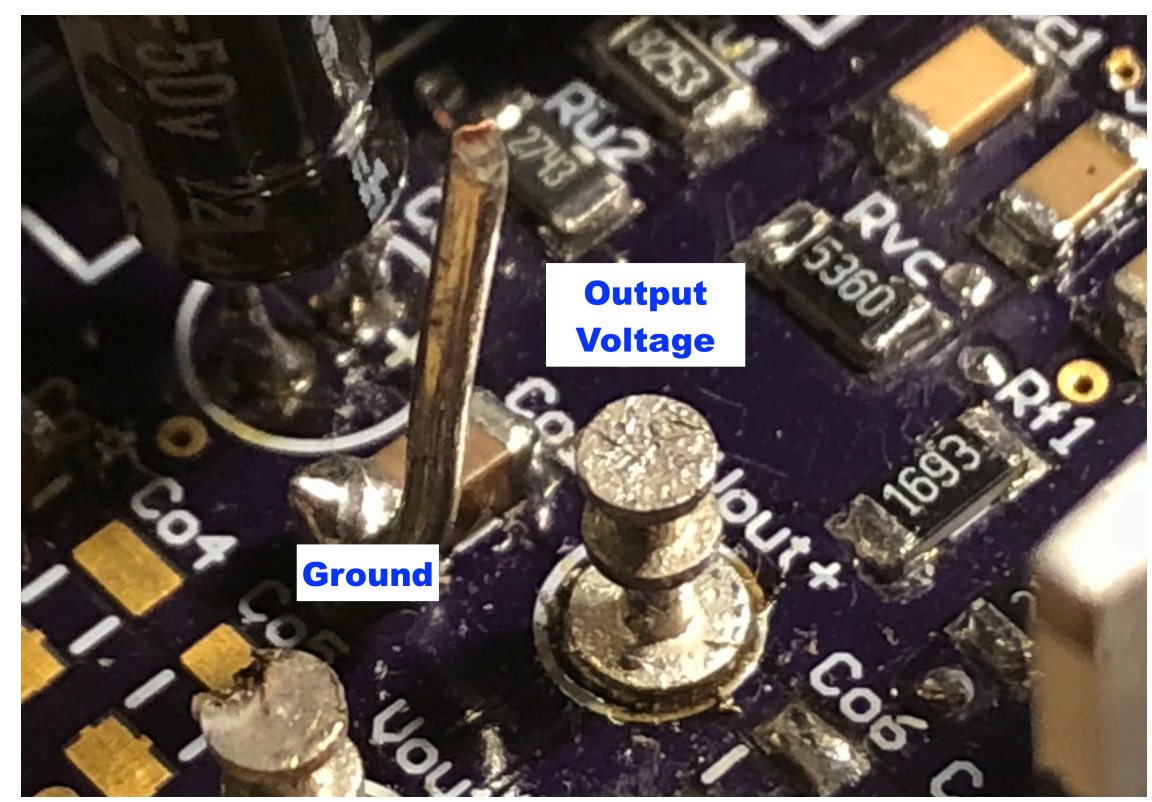

Figure 5-17. Ground Pin Contraption for Voltage Scope Captures

\subsubsection{Equipment and Lab Bench Setup}

Figure 5-17 displays the connection between all the equipment.

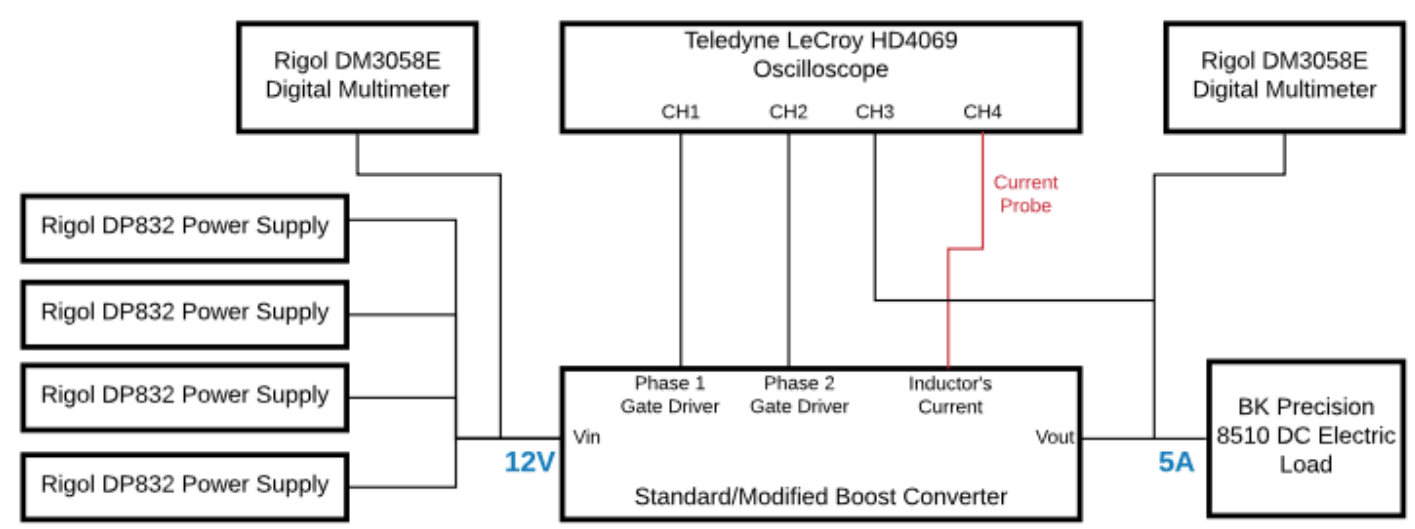

Figure 5-18. Hardware Test Connections 
Input current is a higher for a boost converter than the output current due to the stepping up voltage function of the boost converter. No access to a minimum 12A DC power supply required the use of four channels of the Rigol DP832, which correlates to two power supplies. Moreover, one BK Precision 8510 DC electronic load handled the necessary output current. Two Rigol DM3058 measured the input and output voltages as the power supplies and electronic load provide inaccurate readings. The Teledyne LeCroy HD4069 Oscilloscope has multiple channels, where channel $1(\mathrm{CH} 1)$ and $2(\mathrm{CH} 2)$ show phase one and phase two gate drives respectively. Channel $3(\mathrm{CH} 3)$ alternates between output voltage and positive terminal voltage of the feedback capacitor. Channel 4 (CH4) records all current measurements with the use of the oscilloscope's memory function in order to observe both inductor currents' phases.

Figure 5-18 exhibits an image of the lab bench setup used for testing. As mentioned there are two multimeters, two power supplies with 4 channels being used, one electronic load, and one oscilloscope with four channels capturing data. 


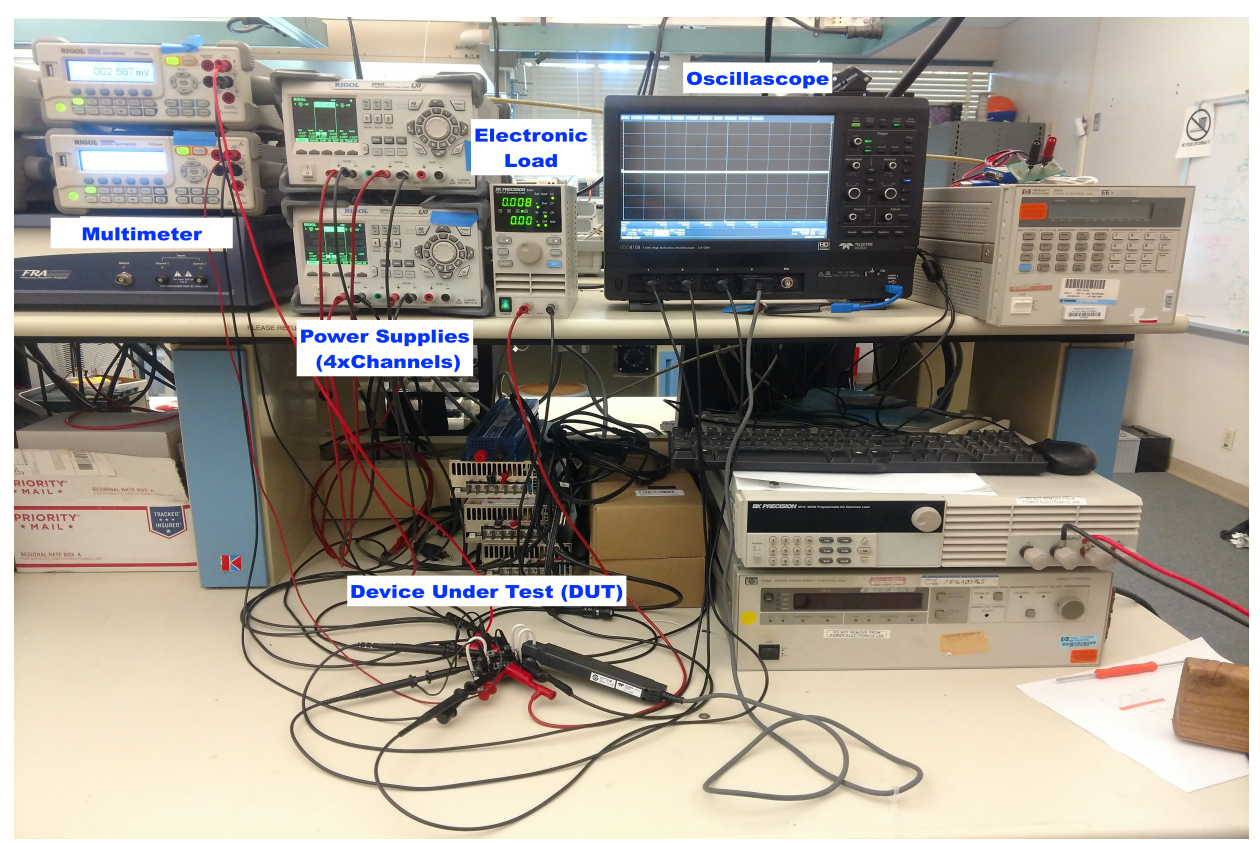

Figure 5-19. Laboratory Test Configuration

\subsubsection{Standard Boost Performance Results}

Figure 5-19 presents the output voltage while Figure 5-20 presents the interleaved inductor currents of the standard boost topology. The inductor currents are perfectly triangular as expected. However, the voltage waveform observes noise spikes around the time switches turn on and off. This is due to the inductor currents not wanting to change instantaneously. By toggling the switch, inductor current is forced to stop thus compensated by a voltage spike. Simulation does not show those switching noise, as the models for all the components were ideal. Moreover, the existence of parasitic extends the severity of switching noises. 


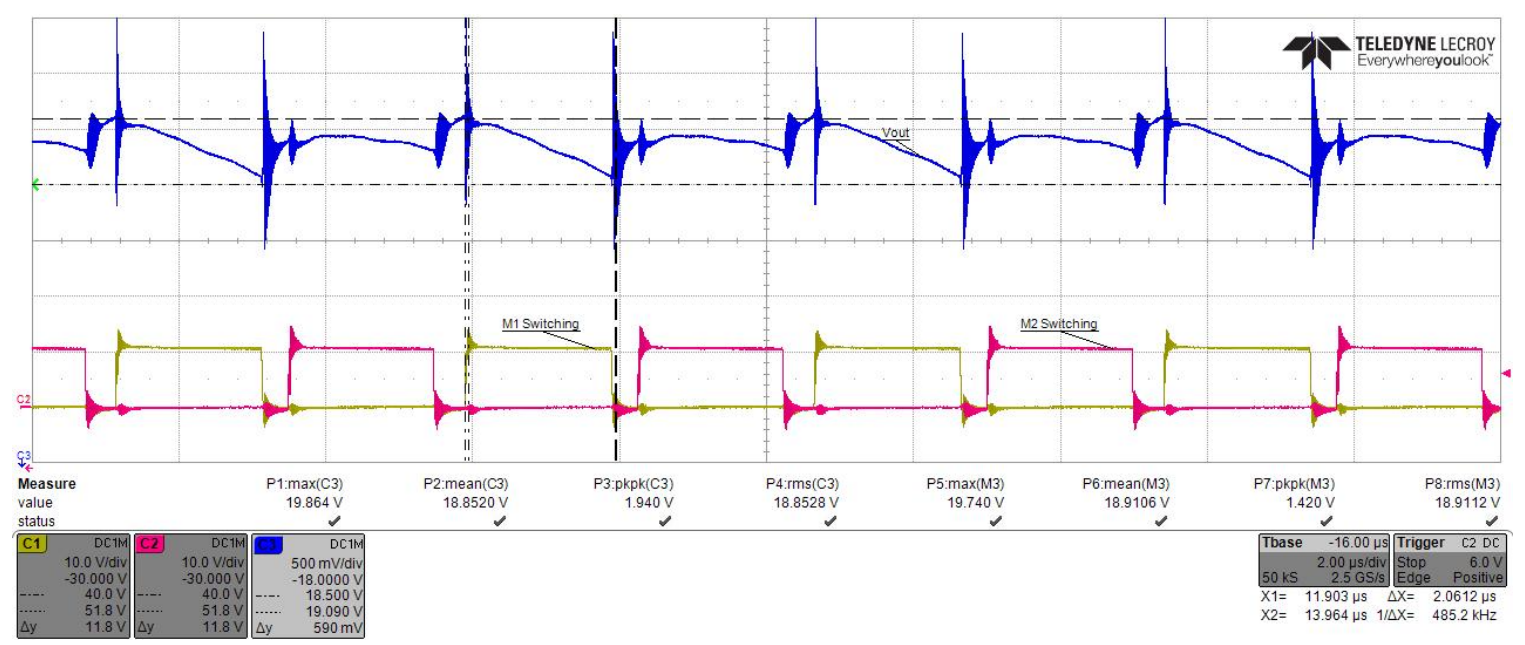

Figure 5-20. Standard Multiphase Boost Hardware Output Voltage and Gate Drives

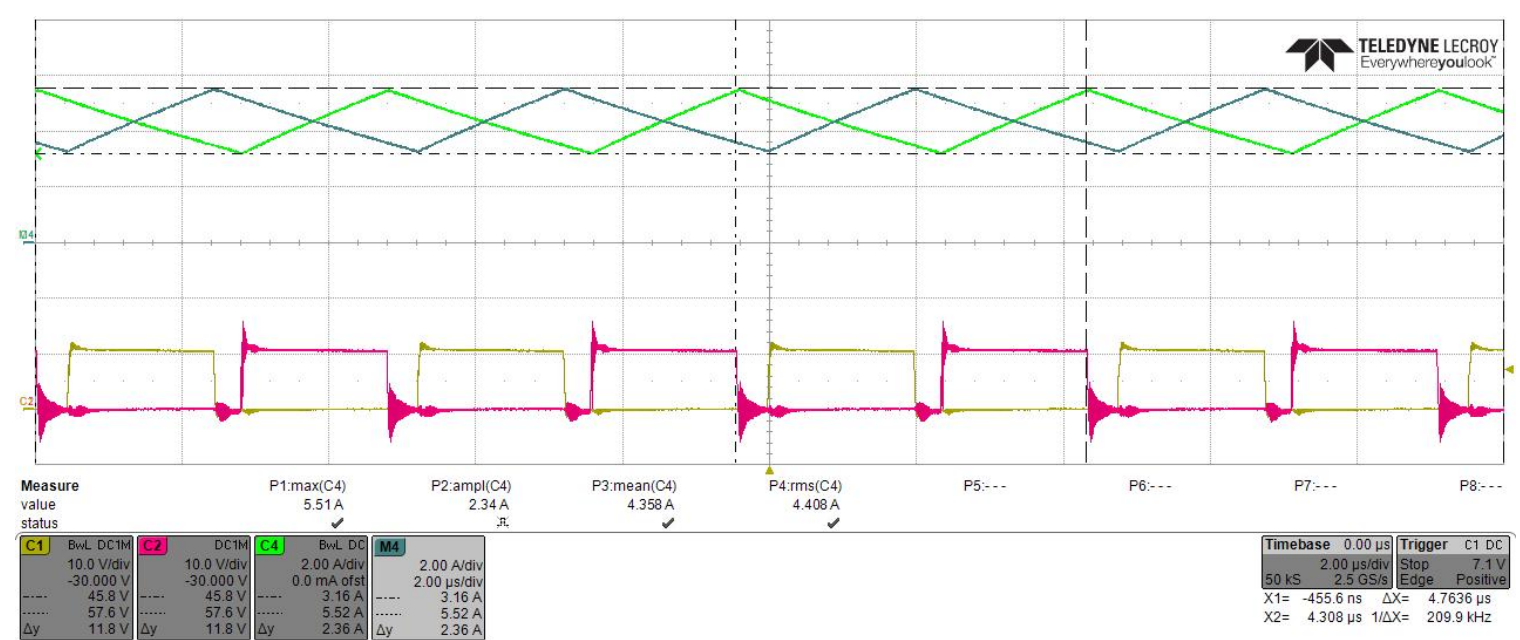

Figure 5-21. Standard Multiphase Boost Hardware Inductors' Current $(\mathrm{C} 4=$ phase 1, M4 = Phase 2) and Gate Drives

Using the math function of the oscilloscope generates an inappropriate input current waveform, therefore importing the inductor current waveforms into Matlab and combining them results in more appropriate current ripple waveform as can be seen from Figure 5-22. APPENDIX - V carries the code to generate Figure 5-22. 


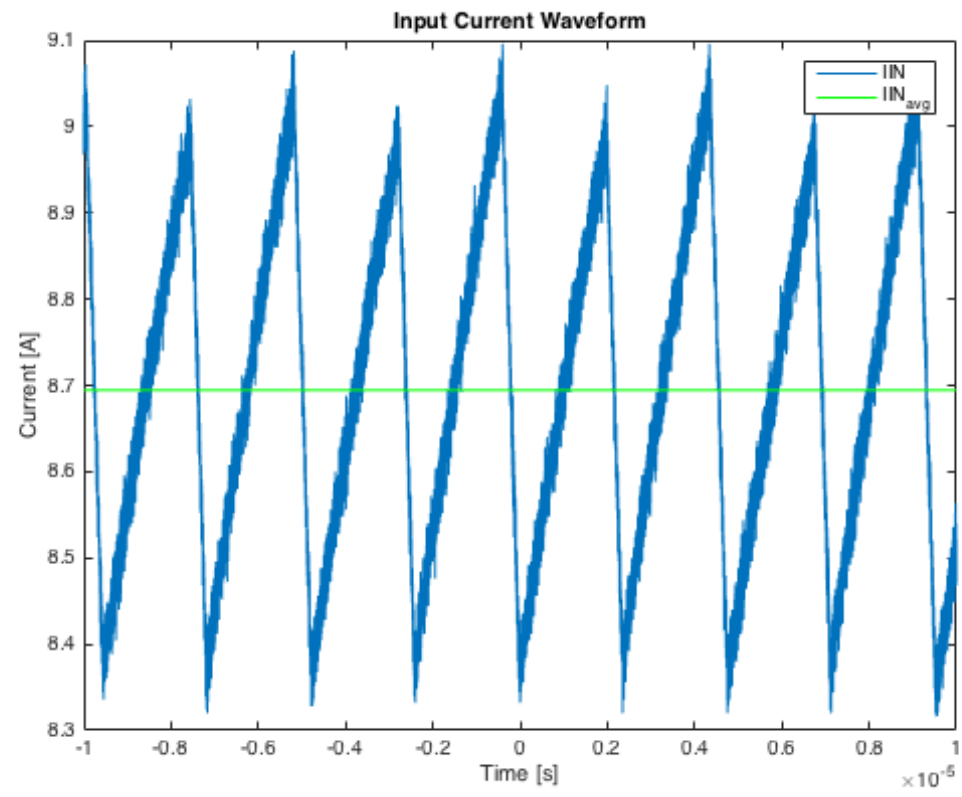

Figure 5-22. Standard Multiphase Boost Hardware Input Current

The summary of inductor currents and output voltage waveforms are listed in Table 5-7. The ripple seen by each inductor current is slightly smaller with respect to simulation while output voltage cannot reach $19 \mathrm{~V}$ exactly due to the parasitic of each component.

Table 5-7. Standard Multiphase Boost Hardware Results

\begin{tabular}{|c|c|c|c|}
\hline & $\begin{array}{c}\text { Inductor Current } \mathbf{L}_{\mathbf{1 T}} \\
(\mathbf{A})\end{array}$ & $\begin{array}{c}\text { Inductor Current } \mathbf{L}_{\mathbf{1 B}} \\
(\mathbf{A})\end{array}$ & $\begin{array}{c}\text { Capacitor Voltage } \mathbf{C}_{\mathbf{2}} \\
(\mathbf{V})\end{array}$ \\
\hline Average & 4.337 & 4.358 & 18.795 \\
\hline Peak-Peak & 2.324 & 2.344 & 0.590 \\
\hline \%Ripple & 53.591 & 53.786 & 3.139 \\
\hline
\end{tabular}

The efficiency measurements were conducted every $0.5 \mathrm{~A}$ until $80 \%$ of the load was achieved. The data from 4A until full load (5A) was collected every 0.2A. Figure 523 displays the efficiency plot graphed based on the data collected at each load condition. 


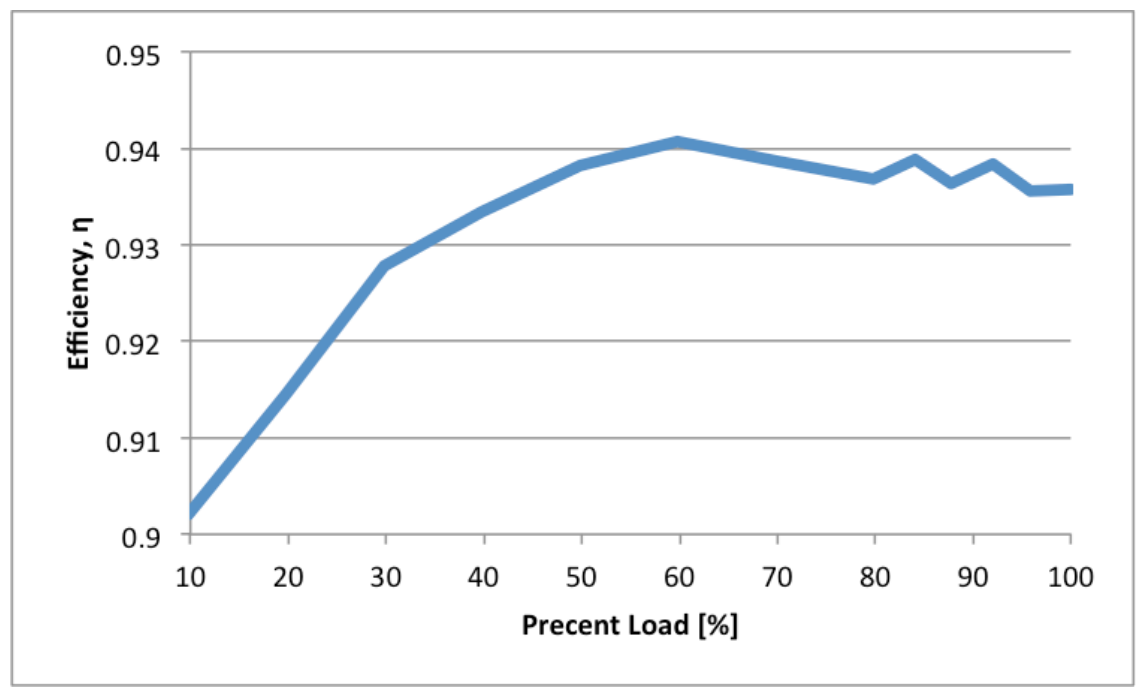

Figure 5-23. Standard Multiphase Boost Hardware Efficiency Versus Load Percentage Plot

Load regulation for the standard topology is calculated below:

$$
\begin{gathered}
\% \text { Load Regulation }==\frac{\bar{V}_{\text {out }(\text { low-load })}-\bar{V}_{\text {out }(\text { high-load })}}{\bar{V}_{\text {out }(\text { high-load })}} \cdot 100 \% \\
\% \text { Load Regulation }==\frac{18.935-18.906 \mathrm{~V}}{18.906 \mathrm{~V}} \cdot 100 \%=0.156 \%
\end{gathered}
$$

Calculation of line regulation uses $10 \%$ input voltage deviation, which corresponds to input voltages $10.8 \mathrm{~V}$ and $13.2 \mathrm{~V}$.

$$
\begin{gathered}
\% \text { Line Regulation }=\frac{\bar{V}_{\text {out }(\text { high-input })}-\bar{V}_{\text {out }(\text { low-input })}}{\bar{V}_{\text {out }(\text { nominal-input })}} \cdot 100 \% \\
\% \text { Line Regulation }=\frac{18.906 \mathrm{~V}-18.901 \mathrm{~V}}{18.9056 \mathrm{~V}} \cdot 100 \%=0.03 \%
\end{gathered}
$$

\subsubsection{Modified Boost Performance Results}

Below are the waveforms for the major voltages and currents for the modified multiphase boost converter. Figure 5-24 shows the output voltage of the converter. 


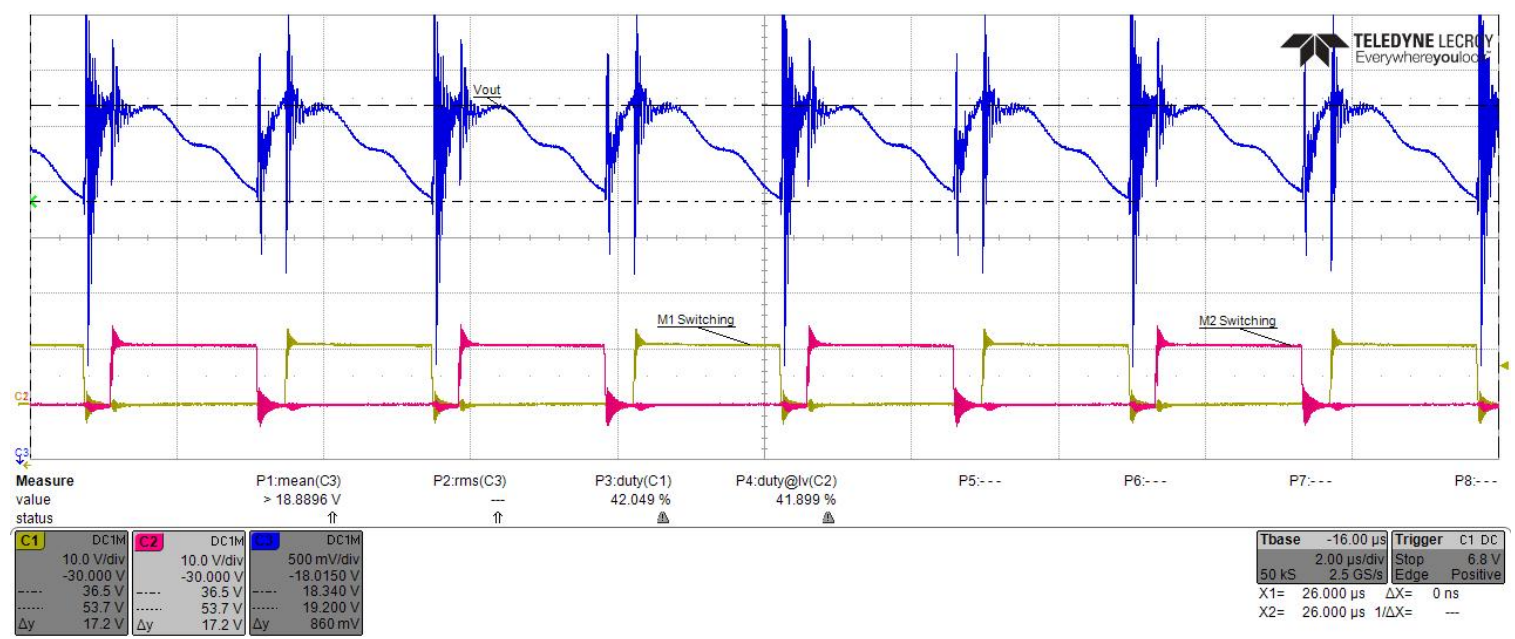

Figure 5-24. Modified Multiphase Boost Hardware Output Voltage and Gate Drives

Figure 5-25 captures the voltage at the positive node of the feedback capacitor, which is the intersection of the inner and outer inductors.

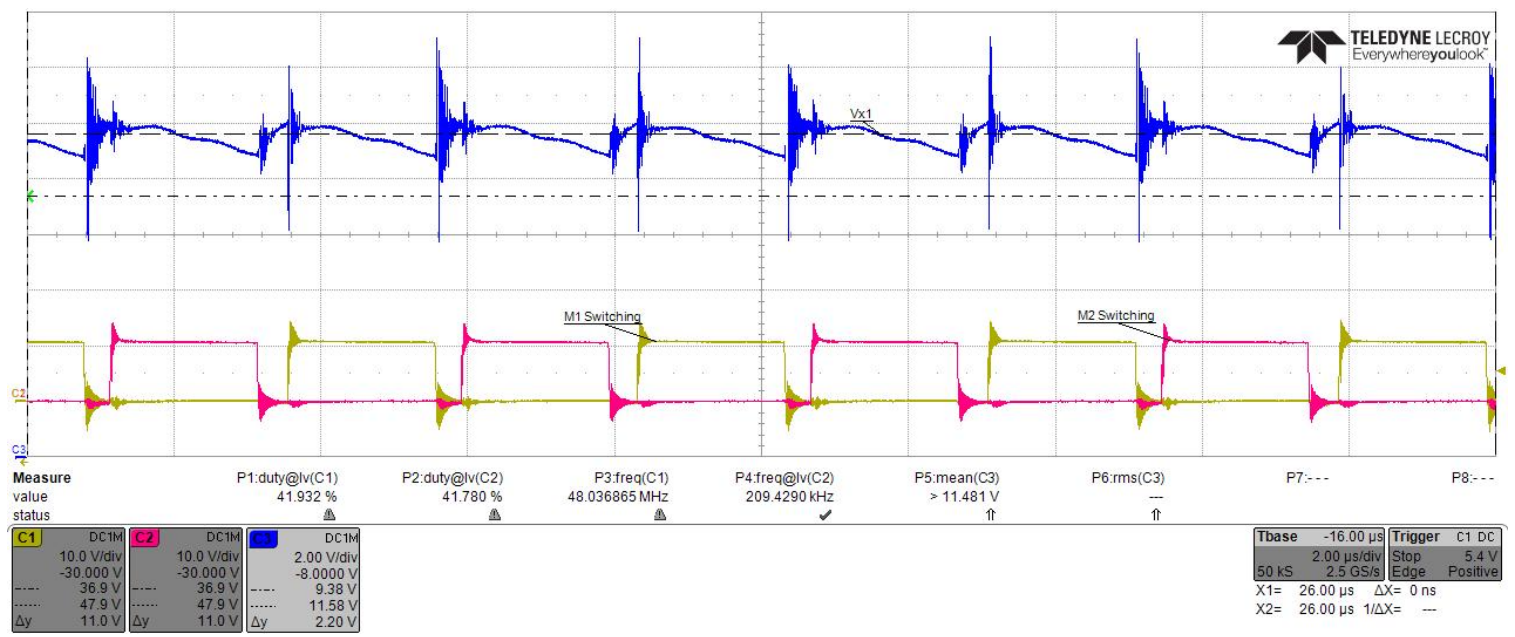

Figure 5-25. Modified Multiphase Boost Hardware Vx Voltage (Positive Node of Feedback Capacitor) and Gate Drives

Similar to the input current calculation, exporting the scope waveform as a csv format allows for more accurate calculation of feedback capacitor voltage. Moreover, voltages observed on the scope are plagued with noise. This noise complicates calculations since the minimum and maximum are false values. Thus a FIR Kaiser filter 
with clipping limits was applied to the feedback capacitor voltage as shown in Figure 525. APPENDIX - VI carries the code to generate Figure 5-25.

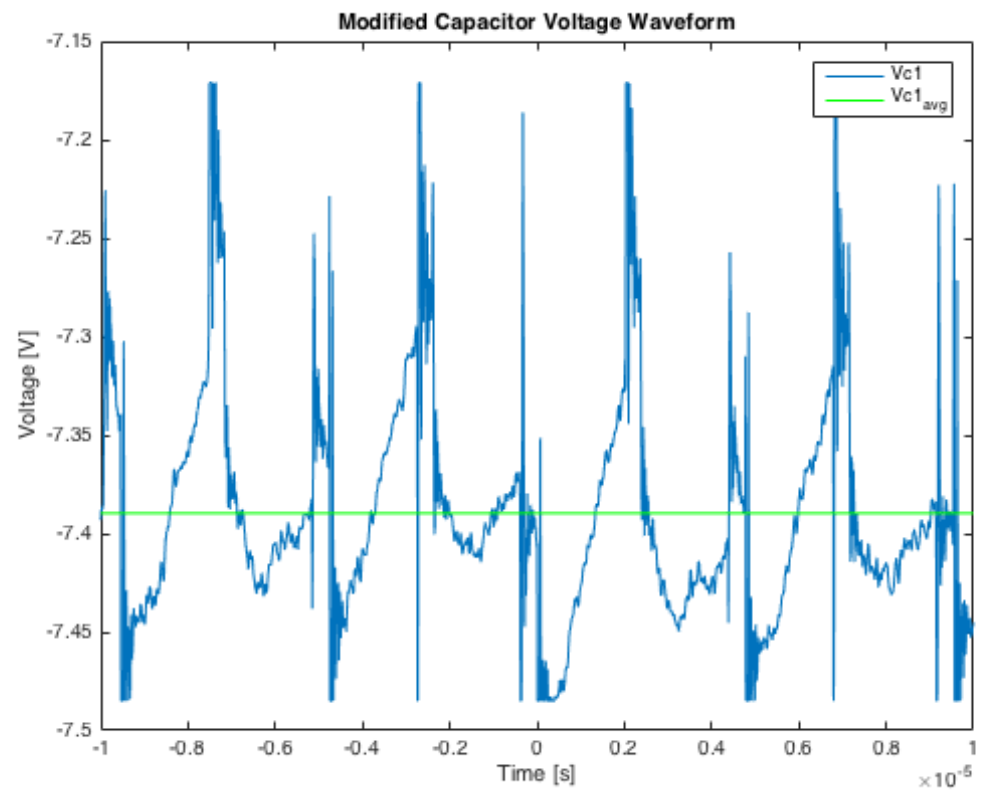

Figure 5-26. Modified Multiphase Boost Hardware Feedback Capacitor Voltage

Figure 5-27 and 5-28 show the inductor current waveforms for both inner and outer inductors. The duty cycle slightly deviates from the standard as the $\mathrm{L}_{2 \mathrm{~T}}$ and $\mathrm{L}_{2 \mathrm{~B}}$ have duty cycle of 0.420 and 0.418 . As can be seen the input inductors have the same shape and almost overlay each other perfectly. 


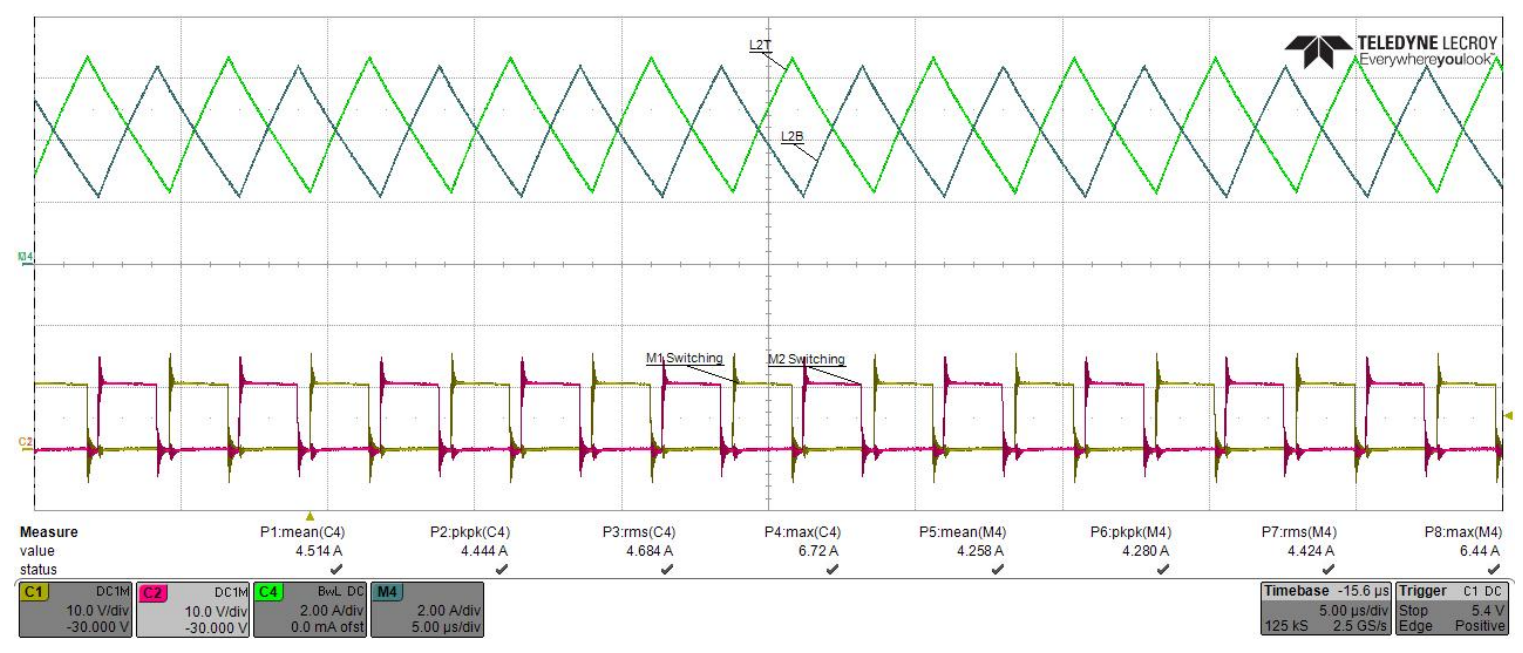

Figure 5-27. Modified Multiphase Boost Hardware Inner Inductors' $\left(\mathrm{L}_{2 \mathrm{~T}}\right.$ and $\mathrm{L}_{2 \mathrm{~B}}$ ) Current and Gate Drives

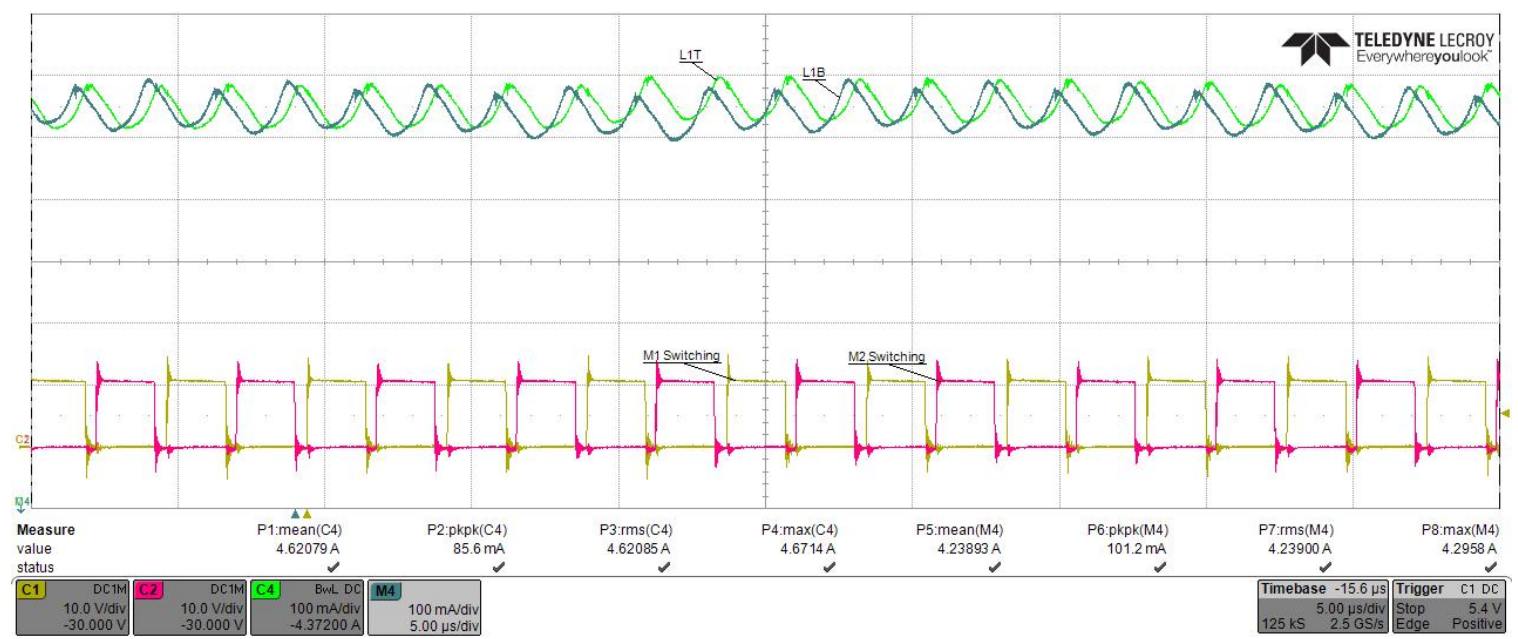

Figure 5-28. Modified Multiphase Boost Hardware Outer Inductors' $\left(\mathrm{L}_{1 \mathrm{~T}}\right.$ and $\mathrm{L}_{1 \mathrm{~B}}$ ) Current and Gate Drives

Matlab code from APPENDIX - V is applied again to generate the input current waveform seen in Figure 5-29. 


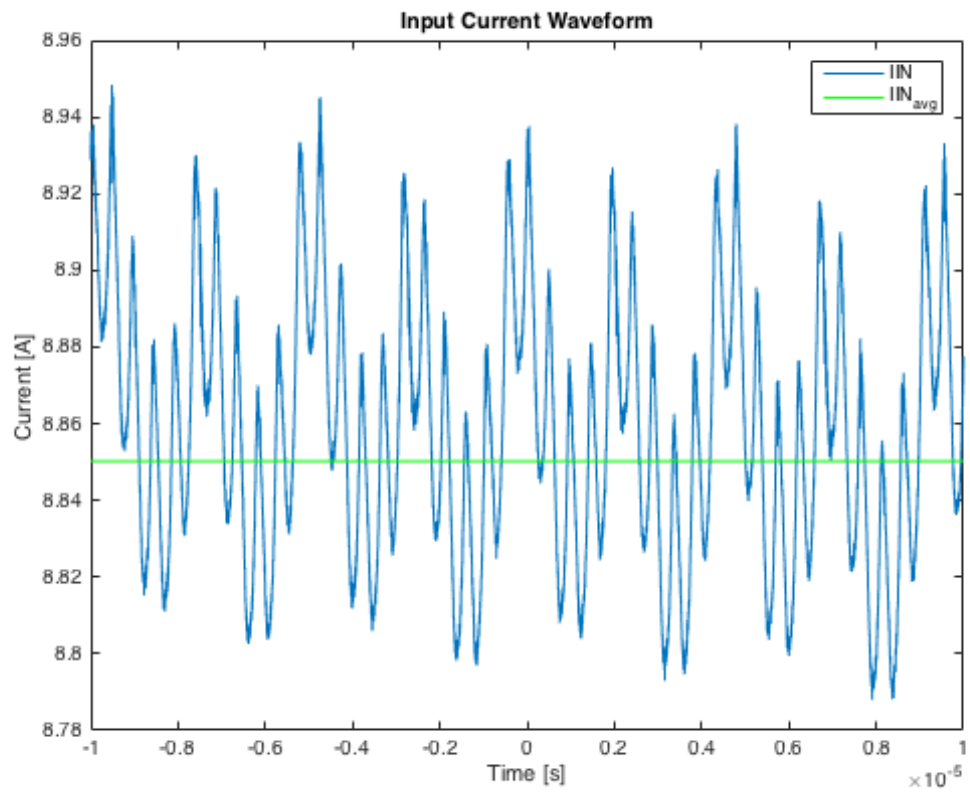

Figure 5-29. Modified Multiphase Boost Hardware Input Current

The waveforms' key characteristics are analyzed in Table 5-8. The average and ripple for the outer inductors are substantially higher. This is due to unaccountable losses through the system like capacitor's ESR or MOSFET's $\mathrm{R}_{\mathrm{ds}(\mathrm{on})}$. The inner inductors are affected positively by parasitic, as the ripple is smaller than the simulation.

One noticeable difference between hardware and simulation is the misalignment of current waveforms, both in ripple and in time. The outer inductors have different averages and are not perfectly aligned as expected. The inner inductors only experience different DC offsets. This is due to the tolerance of the inductors and current sense resistors. There is not balancing circuitry to solve this issue. The more additional components added to a multiphase topology the higher the probability of such occurrence. 
Table 5-8. Modified Multiphase Boost Hardware Results

\begin{tabular}{|c|c|c|}
\hline & L $_{\mathbf{1 T}}$ Current (A) & L $_{\mathbf{1 T}}$ Current (A) \\
\hline Average & 4.616 & 4.234 \\
\hline $\begin{array}{c}\text { Peak- } \\
\text { Peak }\end{array}$ & 0.1102 & 0.130 \\
\hline \%Ripple & 2.387 & 3.061 \\
\hline Average & $\mathbf{L}_{\mathbf{2}}$ Current (A) & $\mathbf{L}_{\mathbf{2 B}}$ Current (A) \\
\hline $\begin{array}{c}\text { Peak- } \\
\text { Peak }\end{array}$ & 4.514 & 4.258 \\
\hline \%Ripple & 4.444 & 4.280 \\
\hline Average & 98.449 & 100.517 \\
\hline $\begin{array}{c}\text { Peak- } \\
\text { Peak }\end{array}$ & -7.3805 & $\mathbf{C}_{2}$ Voltage (V) \\
\hline \%Ripple & 0.314 & 18.770 \\
\hline
\end{tabular}

The efficiency is measured exactly the same as the standard topology. Figure 5-30

displays the efficiency plot graphed based on the data collected at each load condition.

The converter performs very well under both high and low loads with above $90 \%$

efficiency. 


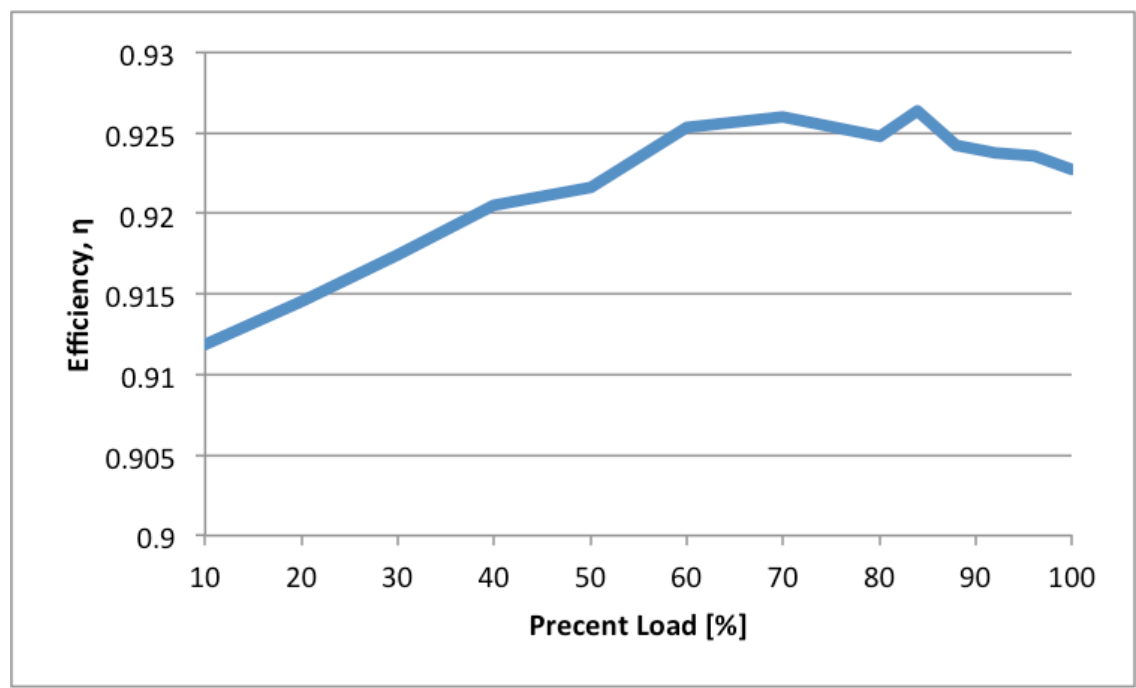

Figure 5-30. Modified Multiphase Boost Hardware Efficiency Versus Load Percentage Plot

The load and line regulation calculations are presented below. The modified topology performs slightly worse than the standard; however, it is still below $0.5 \%$ load regulation and below $0.1 \%$ line regulation.

$$
\begin{gathered}
\% \text { Load Regulation }=\frac{18.935-18.906 \mathrm{~V}}{18.906 \mathrm{~V}} \cdot 100 \%=0.253 \% \\
\% \text { Line Regulation }=\frac{18.906 \mathrm{~V}-18.901 \mathrm{~V}}{18.9056 \mathrm{~V}} \cdot 100 \%=0.08 \%
\end{gathered}
$$

\subsection{Performance Comparison}

While both the standard and modified topologies have very good results the overall behaviors of the circuits are not exactly the same. Table 5-9 compares the standard and modified boosts' performances at full load. Due to higher frequency operation, the current ripple has been affected positively. The ratio of the current ripple between the nominal and the measured is 1.049 . Moreover, the duty cycle measured was $13-14 \%$ more than the calculated theoretical value presented in Chapter 4 . Since ripple is directly affected by those two quantities, the hardware lower ripple is understandable. 
The observed ripple is $80 \%$ of the simulated value, whereas based on the numerical calculation using the new duty cycle and frequency the number is $76 \%$.

Comparing the two topologies, the modified topology adds more components thus resulting in slightly lower ripple. The voltage at full load is only slightly different while output voltage ripple is still maintained under $5 \%$.

Table 5-9. Hardware Performance Comparison

\begin{tabular}{|c|c|c|}
\hline & Standard Multiphase Boost & Modified Multiphase Boost \\
\hline Efficiency & $93.580 \%$ & $92.274 \%$ \\
\hline $\begin{array}{c}\text { Average Output } \\
\text { Voltage }\end{array}$ & $18.795 \mathrm{~V}$ & $18.770 \mathrm{~V}$ \\
\hline $\begin{array}{c}\text { \%Ripple } \\
\text { Output Voltage }\end{array}$ & $3.139 \%$ & $4.58 \%$ \\
\hline $\begin{array}{c}\text { Gate 1 Duty } \\
\text { Cycle }\end{array}$ & $41.706 \%$ & $41.934 \%$ \\
\hline $\begin{array}{c}\text { Gate 2 Duty } \\
\text { Cycle }\end{array}$ & $41.851 \%$ & $41.798 \%$ \\
\hline Frequency & $209.8386 \mathrm{kHz}$ & $209.6552 \mathrm{kHz}$ \\
\hline
\end{tabular}

Based on the Matlab code in APPEDIX E, the input current ripple is recorded in Table 5-10. Even with the interleaved cancellation the standard boost was unable to match the ripple generated by the modified topology. The modified multiphase topology ripple is almost $25 \%$ times smaller than then the standard multiphase topology. With respect to simulations, the standard performed about $2 \%$ better than expected while the modified missed the simulated value by almost $1 \%$. This may be caused due to the misalignment of the inductor currents' waveforms or the data manipulations since the oscilloscope math function was unreliable. 
Table 5-10. Hardware Input Current Ripple

\begin{tabular}{|c|c|c|}
\hline Input Current & Standard Multiphase Boost & Modified Multiphase Boost \\
\hline Average (A) & 8.6946 & 8.8503 \\
\hline Peak-Peak (A) & 0.78 & 0.2006 \\
\hline \%Ripple (\%) & 8.9711 & 2.2666 \\
\hline
\end{tabular}




\section{CONCLUSION}

The operations of standard and modified multiphase boost topologies were observed under continuous conduction mode during steady state operations. Results from theoretical calculations, computer simulations using LTSpice, and hardware implementation were obtained and compared. Multiple extended volt-second balance analysis yields the equations defining the behavior seen in hardware. Also the key highlight and thus benefit of the modified topology was noted in which the modified multiphase topology demonstrated a ripple of about $2 \%$, compared to the $6 \%$ obtained by the standard topology.

The modified topology behaved slightly different from the specified theoretical equations. The overall addition of four inductors compared to two for the standard topology resulted in higher susceptibility to tolerance, thus affecting the input current ripple. The tolerances increase the probability of unbalanced DC averages for each inner inductor. Moreover, derivations presumed 100\% efficiency, thus originally currents simulated indicated lower maxima. Based on the $93 \%$ efficiency calculated in Chapter 5, inductor current peaks extend by as high as $11 \mathrm{~A}$. Thus, duty cycles elongate, inductor current ripples increase, and sense resistances decrease in order to regulate the output voltage.

The hardware revealed substantially higher output voltage ripple compared to the simulations due to the reasons mentioned above. The input current ripple was lower for the standard and higher for the modified with respect to simulation results. Multiple reasons such as different ripple averages or the ripple combination process can cause the 
discrepancy. However, the modified topology performed $6 \%$ better in input current ripple than that of the standard, which proves the value of the modified topology.

This topology integrates well with renewable energy technology. The boost converter will inflict very minor noise into the solar panel voltage, thus allowing for ideal operation around the maximum power point of the solar panel. This is done with minimal capacitance on the input, which shrinks the converter package drastically. Moreover the modified topology provides high power transmission with no transformer, which integrates really well with inverters. For this thesis, inductor footprints were chosen to be the same for both the standard inductors $(10 \mu \mathrm{H})$ and modified inductors $(4.7 \mu \mathrm{H})$ for ease of layout design. In the future, inductor package can be minimized with respect to a package of a standard topology, thus shrinking the board size.

The modified topology performed phenomenally; however, few modifications are interesting to investigate in the future. The test setup required two power supplies and four channels each set to $12 \mathrm{~V}$ with maximum current sourcing of $3 \mathrm{~A}$. One power supply could have reduced the issues with input current measurements. Also, since each channel was connected to the input of the converter with different length wires, the current seen per channel was different as well as the overall voltage on the input due to power dissipation. The drop across the input affected the overall performance (especially duty cycle) of the both topologies as the input linearly decreased from $12 \mathrm{~V}$ to $11.55 \mathrm{~V}$ at full load.

The control theory to stabilize the system was complicated to design based on the Linear Technology IC. It required iterative methodology during simulation to ensure stability. The design for the compensation can be simplified by operating the topology in 
discontinuous conduction mode (DCM). This eliminates the right half plane zero of the boost appearing during CCM. Also, the DCM operation allows for zero-crossing switching, which improves efficiency. However, high average output current can cause large peaks during inductor's conduction, thus high voltage and low current applications may be a good testing condition for such operation.

Lastly, the diodes experienced significant thermal stress due to high peak current produced by the inner inductors. According to analytical calculation and touching the thermal pad, the diodes are the major components affecting efficiency droop. The calculated power drop across the diodes is $5 \mathrm{~W}$. This can be either solved with bigger inductors (lower peak to peak ripple), lower forward diode drop (by selecting new diode), or utilizing synchronous topology. If MOSFETs (IRF60B217) replace the diodes, the power loss across them would reduce to $1.33 \mathrm{~W}$. 


\section{BIOGRAPHY}

[1] E. I. Administration, "How much electricity does an American home use?," How much electricity does an American home use?, 2016. [Online]. Available: https://www.eia.gov/tools/faqs/faq.php?id=97\&t=3.

[2] M. T. Thompson and D. Ph, "Notes 01 Introduction to Power Electronics Introduction to Power Electronics," pp. 1-138, 2007.

[3] J. X. Chen, “The Evolution of Computing: AlphaGo," Comput. Sci. Eng., vol. 18, no. 4, pp. 4-7, 2016.

[4] Solar Energy Industries Association (SEIA), "Solar Market Insight Report 2017 Q2," U.S. Solar Market Insight Report, 2017.

[5] N. Sriraam and V. Lakshminarayanan, "The effect of temperature on the reliability of electronic components," in IEEE International Conference on Electronics, Computing and Communication Technologies, 2014, pp. 1-6.

[6] B. W. Williams, "DC-to-DC converters with continuous input and output power," IEEE Trans. Power Electron., vol. 28, no. 5, pp. 2307-2316, 2013.

[7] N. D. Benavides and P. L. Chapman, "Modeling the effect of voltage ripple on the power output of photovoltaic modules," IEEE Trans. Ind. Electron., vol. 55, no. 7, pp. 2638-2643, 2008.

[8] M. Terasaki, Y. Oohashi, Y. Masuyama, and T. Sudo, "Design and Analysis for Noise Suppression of DC / DC Converter," 2014.

[9] K. Kam, D. Pommerenke, F. Centola, C. Lam, and R. Steinfeld, "Method to Suppress the Parasitic Resonance Using Parallel Resistor and Inductor Combination To Reduce Broadband Noise from DC / DC Converter,' EMC '09 Kyoto, vol. 22, no. 4, pp. 353-356, 2009.

[10] M. Score, "Ceramic or electrolytic output capacitors in DC / DC converters Why not both?," Analog Appl. J., pp. 1-7, 2015.

[11] N. H. Lentz, "A MODIFIED BOOST CONVERTER WITH REDUCED INPUT CURRENT RIPPLE,” California Polytechnic State University, San Luis Obispo, 2017.

[12] K. Wong and D. Evans, "Merits of multiphase buck DC / DC converters in small form factor applications," p. 6.

[13] K. Al-hosani and V. I. Utkin, "Multiphase Power Boost Converters with Sliding Mode," vol. IEEE Inter, no. 18, pp. 1541-1544, 2009.

[14] D. J. S. Newlin, R. Ramalakshmi, and S. Rajasekaran, "A Performance Comparison of Interleaved Boost Converter and Conventional Boost Converter for Renewable Energy Application," 2013 Int. Conf. Green High Perform. Comput., no. Ccm, pp. 1-6, 2013.

[15] F. Saleemi, "Analysis and Design of Multiphase Multi-Interleave DC-DC Converter with Input-Output Bypass Capacitor," California Polytechnic State 
University, San Luis Obispo, 2008.

[16] T. Taufik, T. Gunawan, D. Dolan, and M. Anwari, "Design and Analysis of TwoPhase Boost DC-DC Converter," vol. 4, no. 7, pp. 1065-1069, 2010.

[17] D. J. Perreault and J. G. Kassakian, "Distributed Interleaving of Paralleled Power Converters," IEEE Trans. Circuits Syst. I Fundam. Theory Appl., vol. 44, no. 8, pp. 728-734, 1997.

[18] T. Kohama and T. Ninomiya, "Automatic interleaving control for paralleled converter system and its ripple estimation with simplified circuit model," 7th Internatonal Conf. Power Electron. ICPE'07, pp. 238-242, 2008.

[19] M. Schuck and R. C. N. Pilawa-Podgurski, "Ripple Minimization Through Harmonic Elimination in Asymmetric Interleaved Multiphase DC-DC Converters," IEEE Trans. Power Electron., vol. 30, no. 12, pp. 7202-7214, 2015.

[20] F. Renken, I. M. Pop-Calimanu, and U. Schurmann, "Novel multiphase hybrid boost converter with wide conversion ratio," 2014 16th Eur. Conf. Power Electron. Appl. EPE-ECCE Eur. 2014, 2014.

[21] G. Kishor, D. Subbarayudu, and S. Sivanagaraju, "Multiphase Boost Converter with Reduced Input Current Ripple Using Direct Coupled Inductors," vol. 4, no. 2, pp. 274-279, 2014.

[22] Q. Hu and L. Zhengyu, "A Novel Step-up VRM - Two-phase Interleaved Coupled-Boost Converter," pp. 1-5.

[23] P. Musznicki, M. Rucinski, M. Turzynski, and S. Abramik, "Prediction of ringing frequencies in DC-DC boost converter," IEEE Int. Symp. Electromagn. Compat., vol. 2016-Novem, pp. 672-675, 2016.

[24] K. P. Engineering, "Analysis of Multiphase Boost Converter for High Power Application," vol. 1, no. 7, pp. 1-6, 2012.

[25] Y. Dong, "Investigation of Multiphase Coupled-Inductor Buck Converters in Point-of-Load Applications Investigation of Multiphase Coupled-Inductor Buck Converters in Point-of-Load Applications," Virginia Polytechnic Institute and State University, 2009.

[26] Y. M. Y. Buswig, W. M. Utomo, A. A. Bakar, and Z. A. Haron, "State-Space Derivation of an Interleaved Boost Converter," 2nd Power Energy Convers. Symp., no. May, pp. 259-262, 2014.

[27] J. Nn and M. Q. Nn, "WE-HCC High Current 10UH Inductor Datasheet." [Online]. Available: http://katalog.we-online.de/pbs/datasheet/7443321000.pdf.

[28] I. Solutions, "WE-HCC High Current 4.7UH Inductor Datasheet," 2013. [Online]. Available: http://katalog.we-online.de/pbs/datasheet/7443320470.pdf.

[29] A. Masuda, "Multi Layer Ceramic Capacitor Datasheet," 2001. [Online]. Available: http://www.samsungsem.com/kr/support/productsearch $/ \mathrm{mlcc} /$ icsFiles/afieldfile/2016/12/27/Data sheet_CL31B106KBHNFNE.pdf. 
[30] Infineon Technologies, "IR MOSFET Strong IR FET TM IRF60B217." [Online]. Available:

https://www.infineon.com/dgdl/irf60b217.pdf?fileId=5546d462533600a4015355e $42 \mathrm{~b} 3719 \mathrm{c} 8$.

[31] O. Semiconductor, "MBR10100GOS-ND Diode Datasheet." [Online]. Available: http://www.onsemi.com/pub/Collateral/MBR1080-D.PDF.

[32] L. T. Corporation, "LT3782A - 2-Phase Step-Up DC/DC Controller." [Online]. Available: http://www.analog.com/media/en/technical-documentation/datasheets/3782afc.pdf.

[33] N. Tang, "Designing Ultrafast Loop Response With Type-III Compensation for Current Mode Step-Down Converters," 2010. [Online]. Available: http://www.ti.com/lit/an/slva352a/slva352a.pdf.

[34] H. J. Zhang, "Modeling and Loop Compensation Design of Switching Mode Power Supplies," 2015. [Online]. Available: http://www.analog.com/media/en/technical-documentation/applicationnotes/AN149fa.pdf.

[35] T. I. Incorporated, "AN-1286 Compensation For The LM3478 Boost Controller," 2013. [Online]. Available: http://www.ti.com/lit/an/snva067c/snva067c.pdf. 


\section{APPENDIX - A}

\section{A. Matlab State Variable Simulation}

multiphase_boost_mod_cycle.m

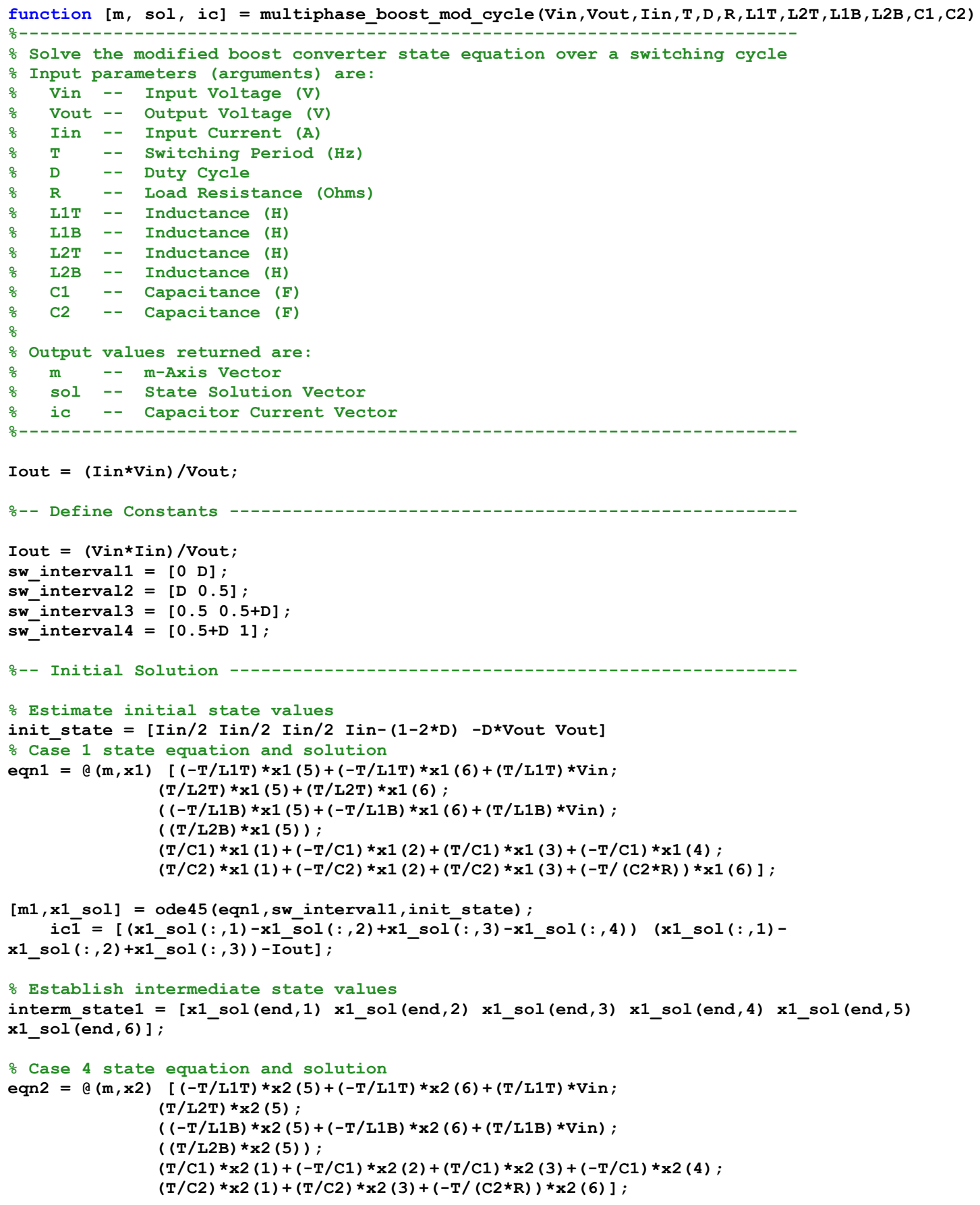




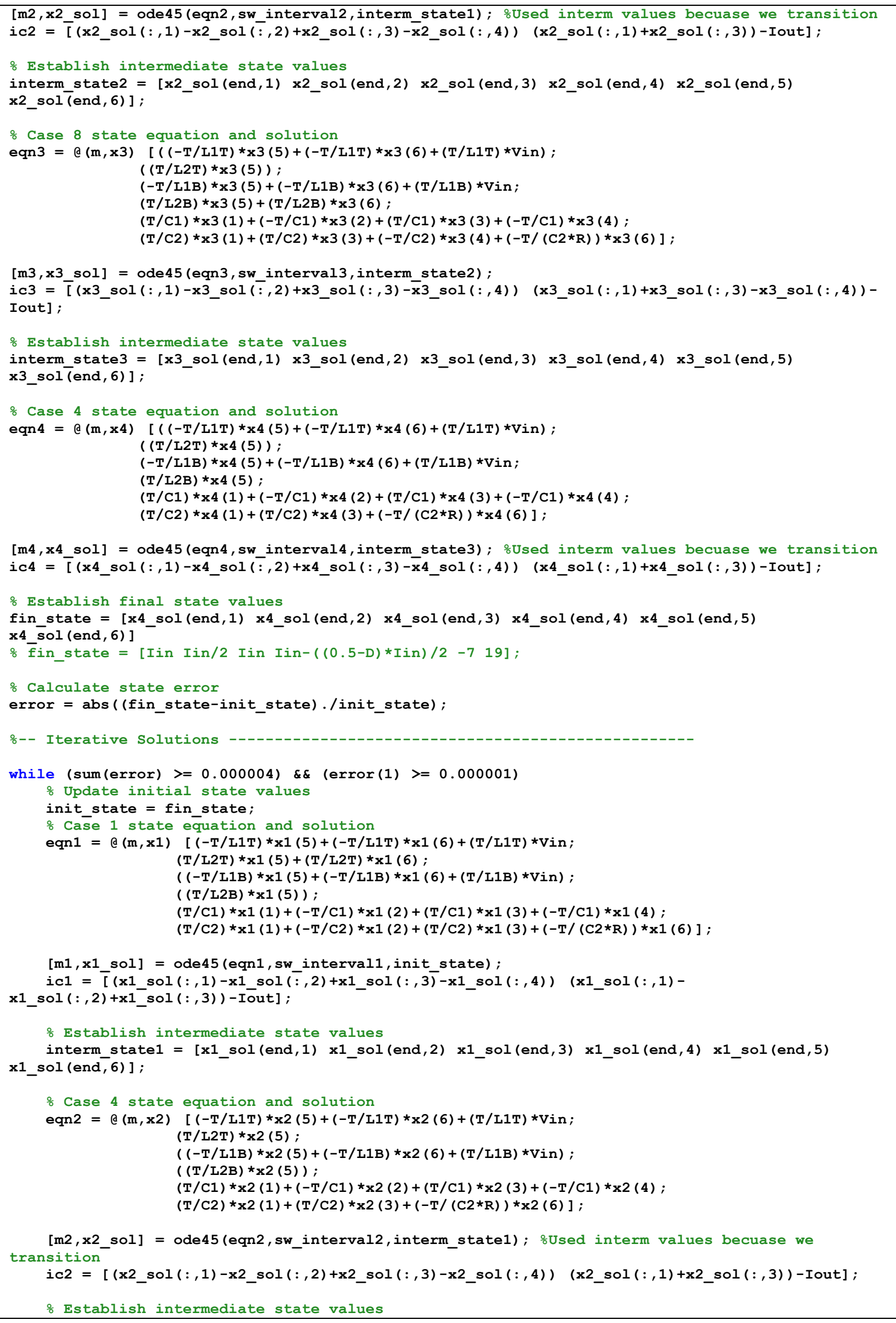




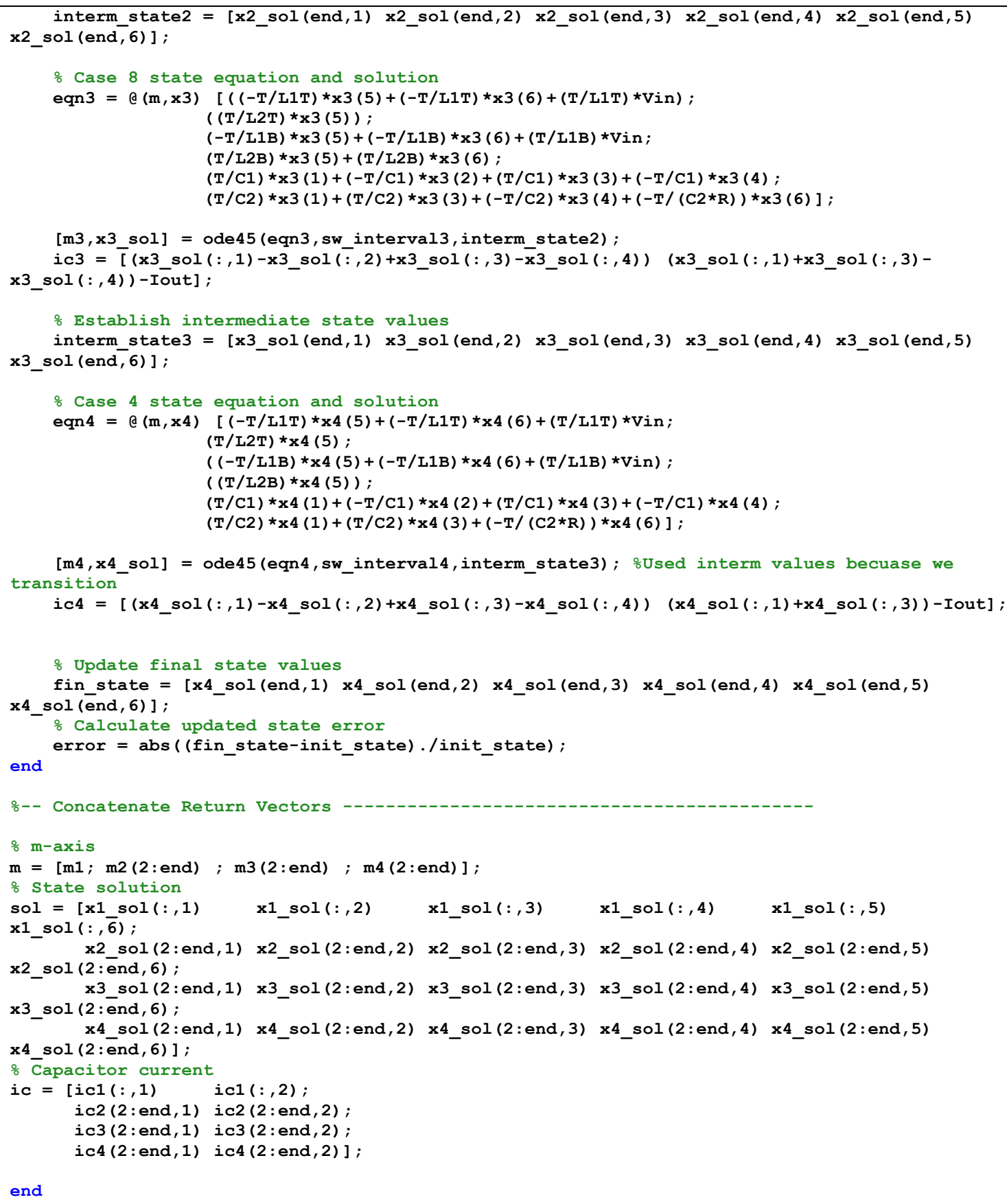

[m4, x4_sol] = ode45 (eqn4, sw_interval4, interm_state3); oUsed interm values becuase we transition

ic4 $=\left[\left(x 4 \_s o l(:, 1)-x 4 \_\operatorname{sol}(:, 2)+x 4 \_\operatorname{sol}(:, 3)-x 4 \_\operatorname{sol}(:, 4)\right)\left(x 4\right.\right.$ sol $\left.\left.(:, 1)+x 4 \_\operatorname{sol}(:, 3)\right)-I o u t\right]$;

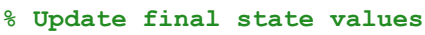

fin_state $=\left[x_{4}\right.$ _sol $($ end, 1$) \times 4$ _sol (end, 2) $\times 4$ _sol (end, 3) $\times 4$ _sol (end, 4) $\times 4$ _sol (end, 5)

multiphase_boost_mod_sim.m

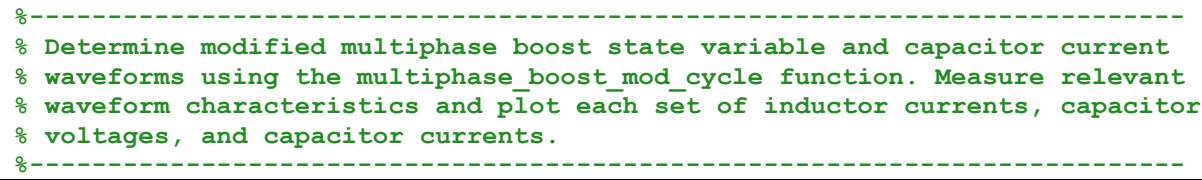




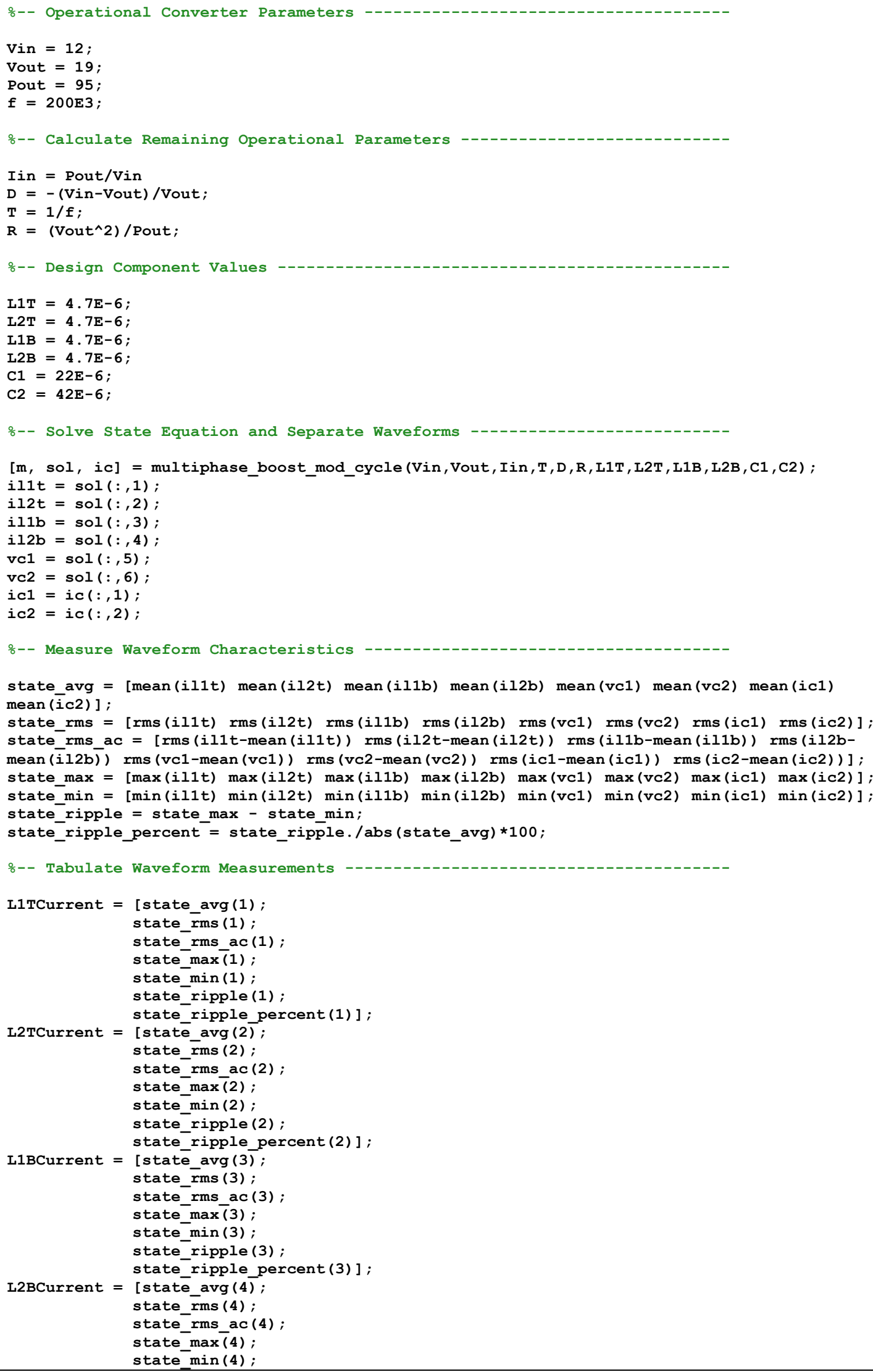




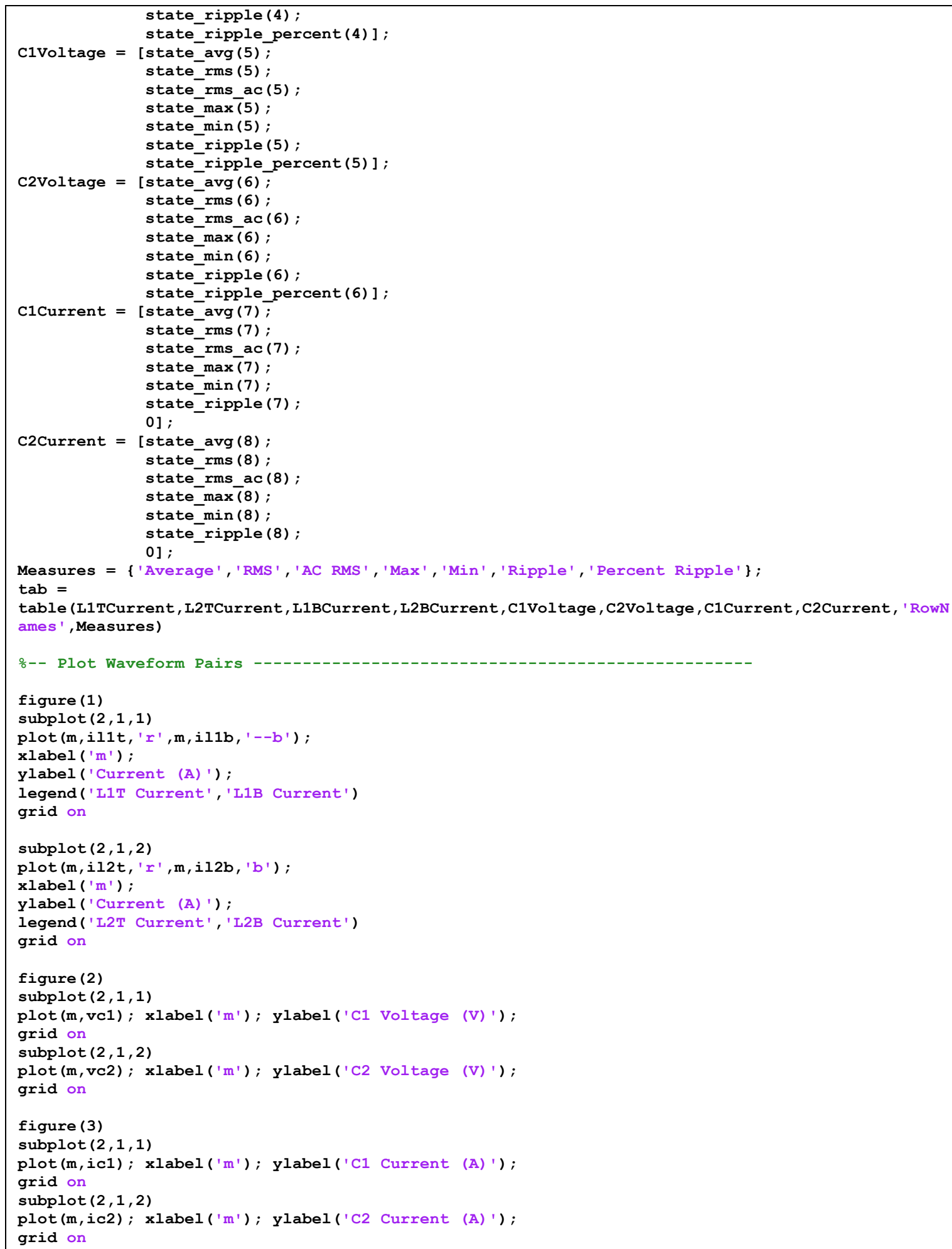




\section{APPENDIX - B}

\section{B. Data Extraction from LTspice - Bode}

The extraction process for waveforms from LTspice is fairly easy. The LTspice simulation must run first before attempting to extract the data. Once the simulation is done, view the plot. Press the setting button as seen in Figure II-1 to access the setting command window.

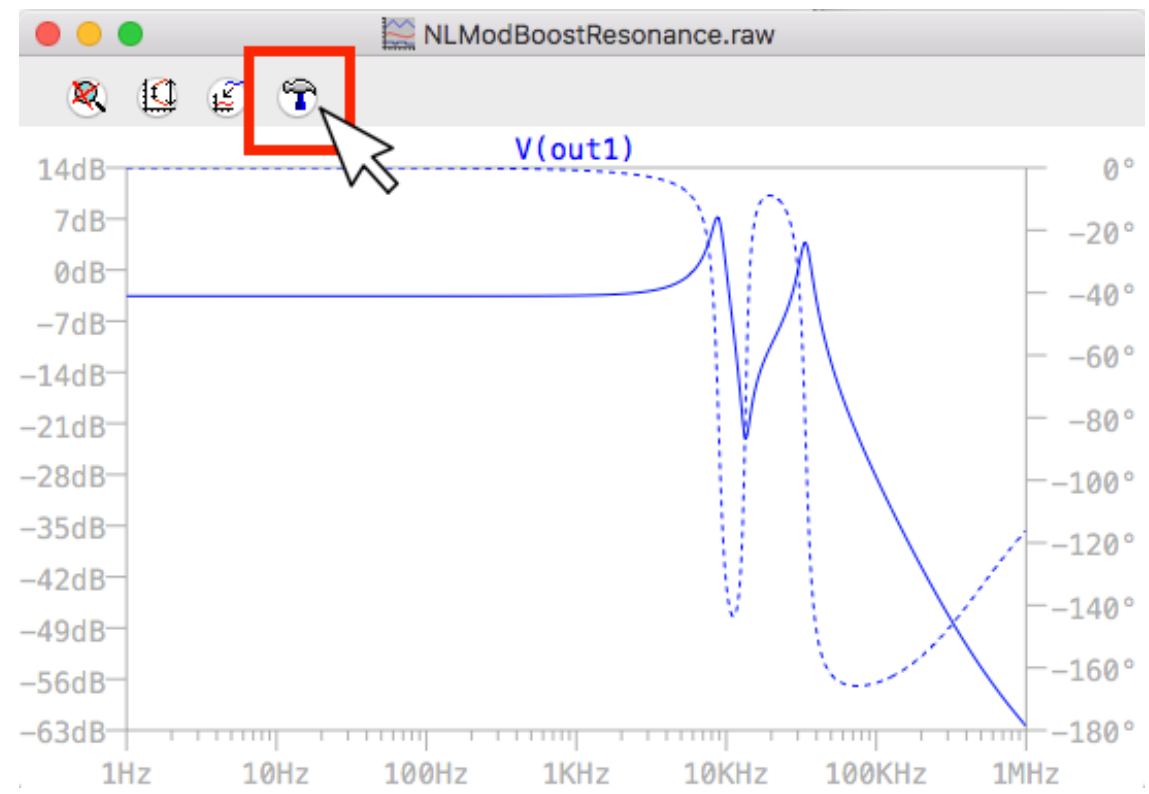

Figure B-1. Window Showing Setting Access from Simulation Plot

After accessing the command line, under the waveform tab there is an option for exporting data as seen in Figure II-2. 


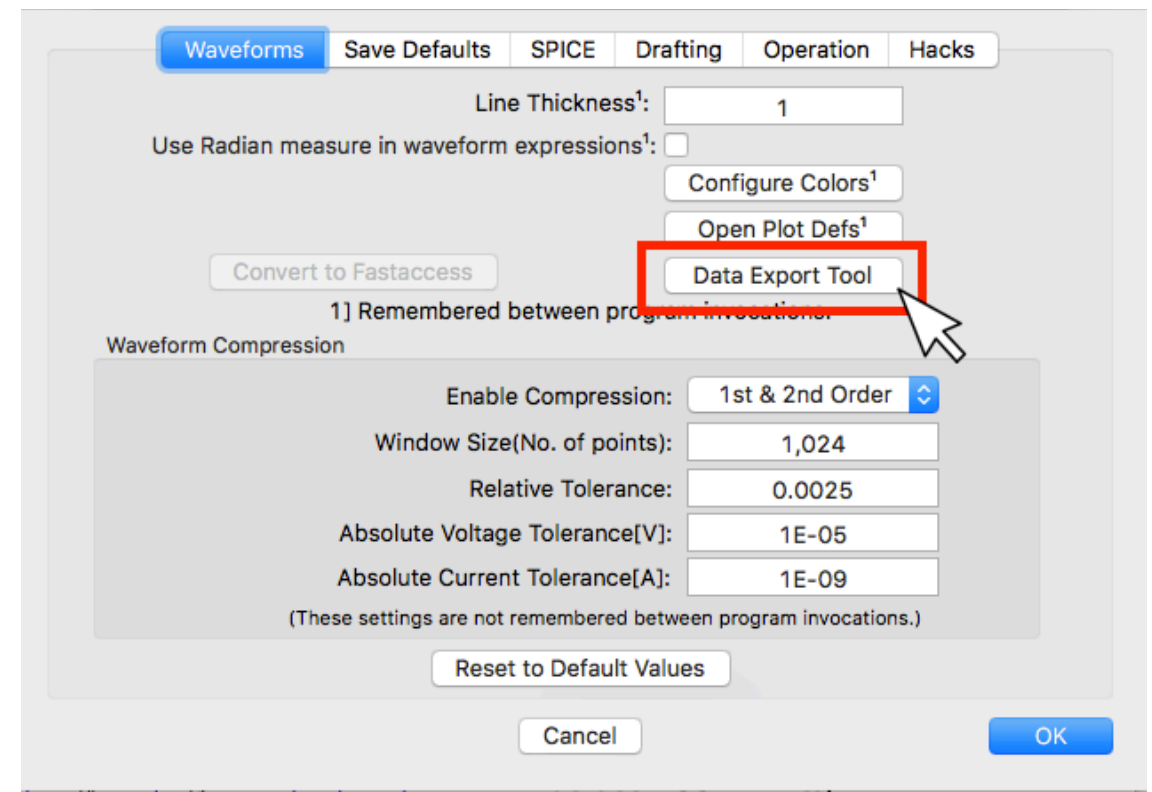

Figure B-2. Window Showing Data Exporting Option

After pressing the "Data Export Tool" a trace needs to be chosen for export. The location of the file can be adjusted as well as the format. Since the data is used for bode plot algebra, the appropriate format is Polar. Once the okay button is pressed, a file containing the data will be located in your chosen location. The file contains as many data points as specified under the Waveforms tab of the setting window.

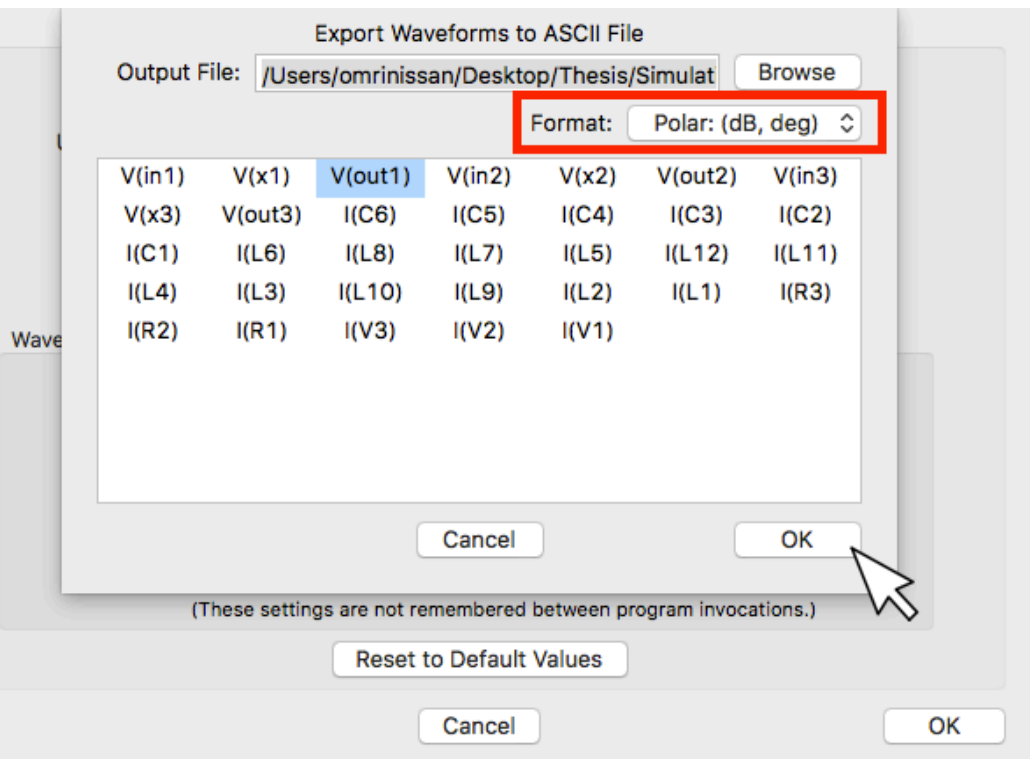

Figure B-3. Window Showing Choosing Data and Exporting 


\section{APPENDIX - C}

\section{Matlab Compensation Design}

\section{Compensation_Design.m}

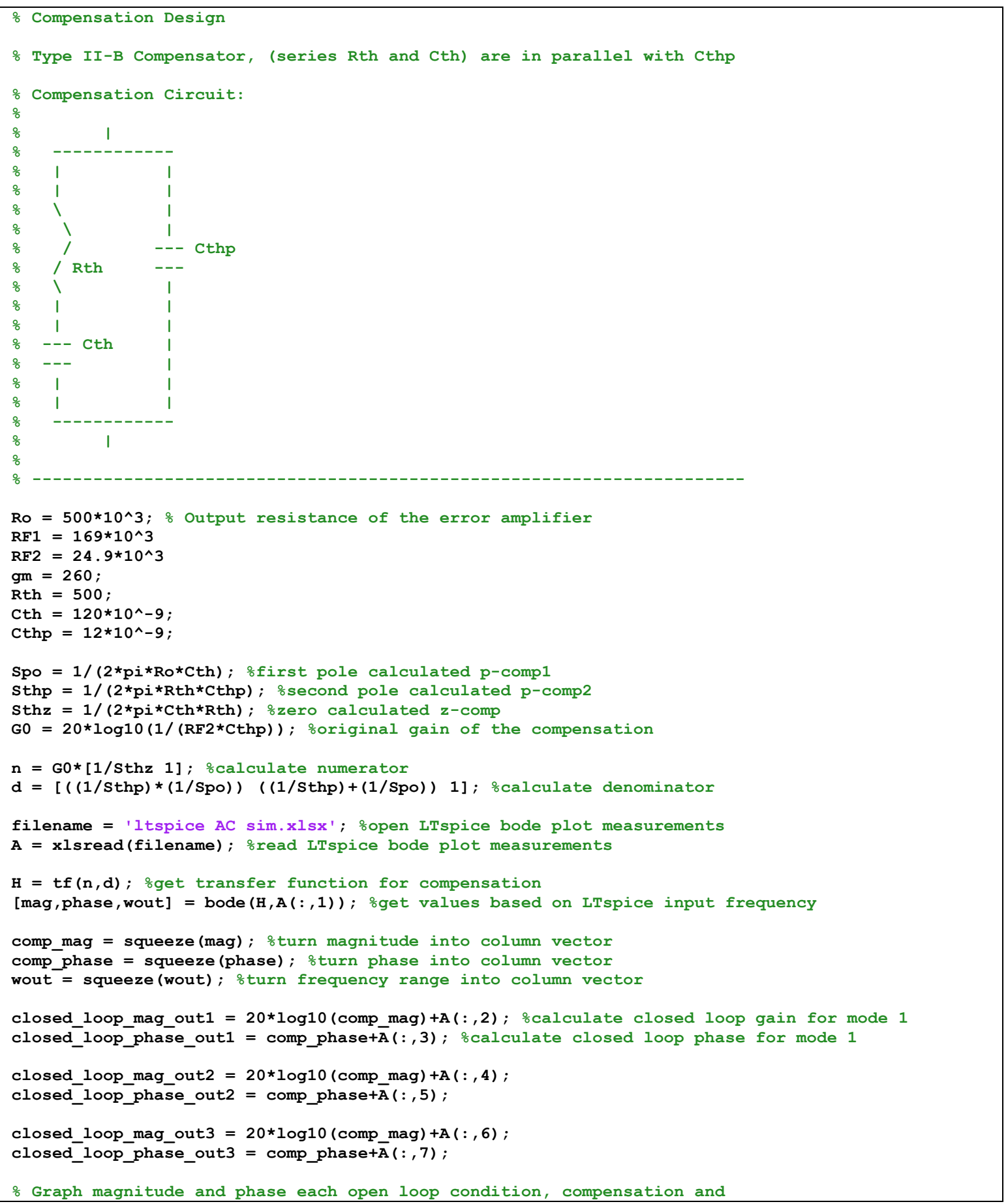




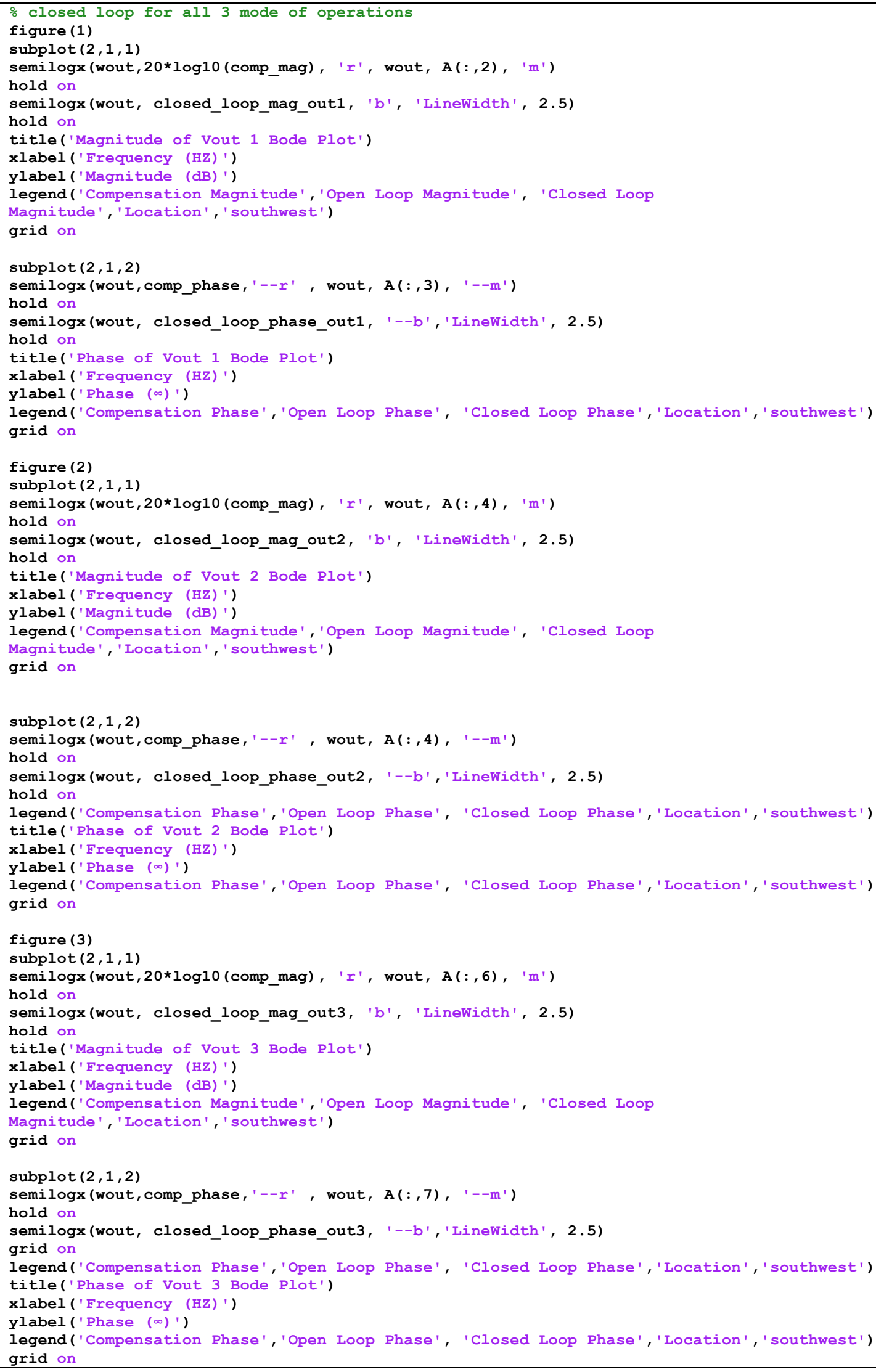


APPENDIX - D

\section{Bill of Material}

\begin{tabular}{|c|c|c|c|}
\hline Designator & Description & Part Number & $\begin{array}{c}\text { Total } \\
\text { Quantity }\end{array}$ \\
\hline $\mathrm{C} 1, \mathrm{C} 2$ & \begin{tabular}{|c|} 
CAP CER 10000PF 100V X7R \\
1206
\end{tabular} & 490-10753-1-ND & 4 \\
\hline $\mathrm{Cb}$ & CAP CER 2.2UF 16V X7R 1206 & 490-1799-1-ND & 2 \\
\hline $\begin{array}{c}\text { Cin1, }{ }_{\mathrm{Cm}} \text { 1 } 2, \mathrm{Co} 2, \\
\end{array}$ & CAP CER 10UF 50V X7R 1206 & 1276-6767-1-ND & 9 \\
\hline Css & $\begin{array}{l}\text { CAP CER 6800PF 100V X7R } \\
1206\end{array}$ & 490-11619-1-ND & 2 \\
\hline D1, D2 & $\begin{array}{l}\text { Diode Schottky 100V 10A } \\
\text { Through Hole TO-220-2 }\end{array}$ & MBR10100GOS-ND & 4 \\
\hline $\begin{array}{l}\text { GND, M1, M2, } \\
\text { Vin+, Vin-, X1, } \\
\text { X2 }\end{array}$ & $\begin{array}{l}\text { TERM TURRET SINGLE } \\
\text { L=5.56MM TIN }\end{array}$ & 36-1502-2-ND & 24 \\
\hline L1, L2 & $\begin{array}{c}10 \mu \mathrm{H} \text { Shielded Wirewound } \\
\text { Inductor } 9 \mathrm{~A} 16.7 \mathrm{mOhm} \text { Max } \\
\text { Nonstandard }\end{array}$ & 732-2145-1-ND & 2 \\
\hline L1, L2, L3, L4 & \begin{tabular}{|c|}
$4.7 \mu \mathrm{H}$ Shielded Wirewound \\
Inductor 15.5A $7.9 \mathrm{mOhm}$ Max \\
Nonstandard
\end{tabular} & 732-2142-1-ND & 4 \\
\hline Q1, Q2 & $\begin{array}{l}\text { N-Channel 60V 60A (Tc) 83W } \\
(\mathrm{Tc}) \text { Through Hole TO-220AB }\end{array}$ & IRF60B217-ND & 4 \\
\hline $\mathrm{R} 1, \mathrm{R} 2$ & $\begin{array}{c}\text { RES SMD } 10 \text { OHM 1\% 1/4W } \\
1206\end{array}$ & 1276-3513-1-ND & 4 \\
\hline Rf1 & $\begin{array}{c}\text { RES SMD } 169 \mathrm{~K} \text { OHM } 1 \% 1 / 4 \mathrm{~W} \\
1206\end{array}$ & 541-169KFCT-ND & 2 \\
\hline Rf2 & $\begin{array}{l}\text { RES SMD 24.9K OHM 1\% } \\
\text { 1/4W } 1206\end{array}$ & 541-24.9KFCT-ND & 2 \\
\hline Rfs & $\begin{array}{c}\text { RES SMD } 100 \mathrm{~K} \text { OHM } 1 \% 1 / 4 \mathrm{~W} \\
1206\end{array}$ & 541-100KFCT-ND & 2 \\
\hline RL1, RL2, Rshort & RES SMD 0 OHM JUMPER & HCJ1206ZT0R00CT- & 1 \\
\hline
\end{tabular}




\begin{tabular}{|c|c|c|c|}
\hline $\begin{array}{c}\text { Rs1a, Rs1b, Rs2a, } \\
\text { Rs2b }\end{array}$ & RES 0.01 OHM 1\% 1/2W 1206 & ND & 8 \\
\hline Rslp & $\begin{array}{c}\text { RES SMD 59K OHM 1\% 1/4W } \\
1206\end{array}$ & $541-59.0$ KFCT-ND & 2 \\
\hline Rvc & $\begin{array}{c}\text { RES SMD 536 OHM 1\% 1/4W } \\
1206\end{array}$ & $541-536$ FCT-ND & 2 \\
\hline U1 & $\begin{array}{c}\text { Boost Regulator Positive Output } \\
\text { Step-Up DC-DC Controller IC } \\
28-T S S O P-E P\end{array}$ & $\begin{array}{c}\text { LT3782AEFE\#PBF- } \\
\text { ND }\end{array}$ & 2 \\
\hline Vc1 & $\begin{array}{c}\text { CAP CER 0.012UF 100V X7R } \\
1206\end{array}$ & $490-16825-1-N D$ & 2 \\
\hline Vc2 & $\begin{array}{c}\text { CAP CER 0.12UF 50V X7R } \\
1206\end{array}$ & $478-1557-1-N D$ & 2 \\
\hline Vcc & CAP CER 1UF 50V X7R 1206 & $490-3908-1-N D$ & 2 \\
\hline Ru1 & $\begin{array}{c}\text { RES SMD 825K OHM 1\% 1/4W } \\
1206\end{array}$ & P825KFCT-ND & 2 \\
\hline Ru2 & $\begin{array}{c}\text { RES SMD 274K OHM 1\% 1/4W } \\
1206\end{array}$ & P274KFCT-ND & 2 \\
\hline $\mathrm{n} / \mathrm{a}$ & Standoffs \& Spacers HEX \\
SPACER 4-40 1/2" & $\begin{array}{c}534-1902 \mathrm{C} \\
\mathrm{n} / \mathrm{a}\end{array}$ & $\begin{array}{c}\text { Screws \& Fasteners 1/4 4-40 } \\
\text { NYLON PAN }\end{array}$ & $834-9327$ \\
\hline
\end{tabular}




\section{E. Altium PCB Layout}

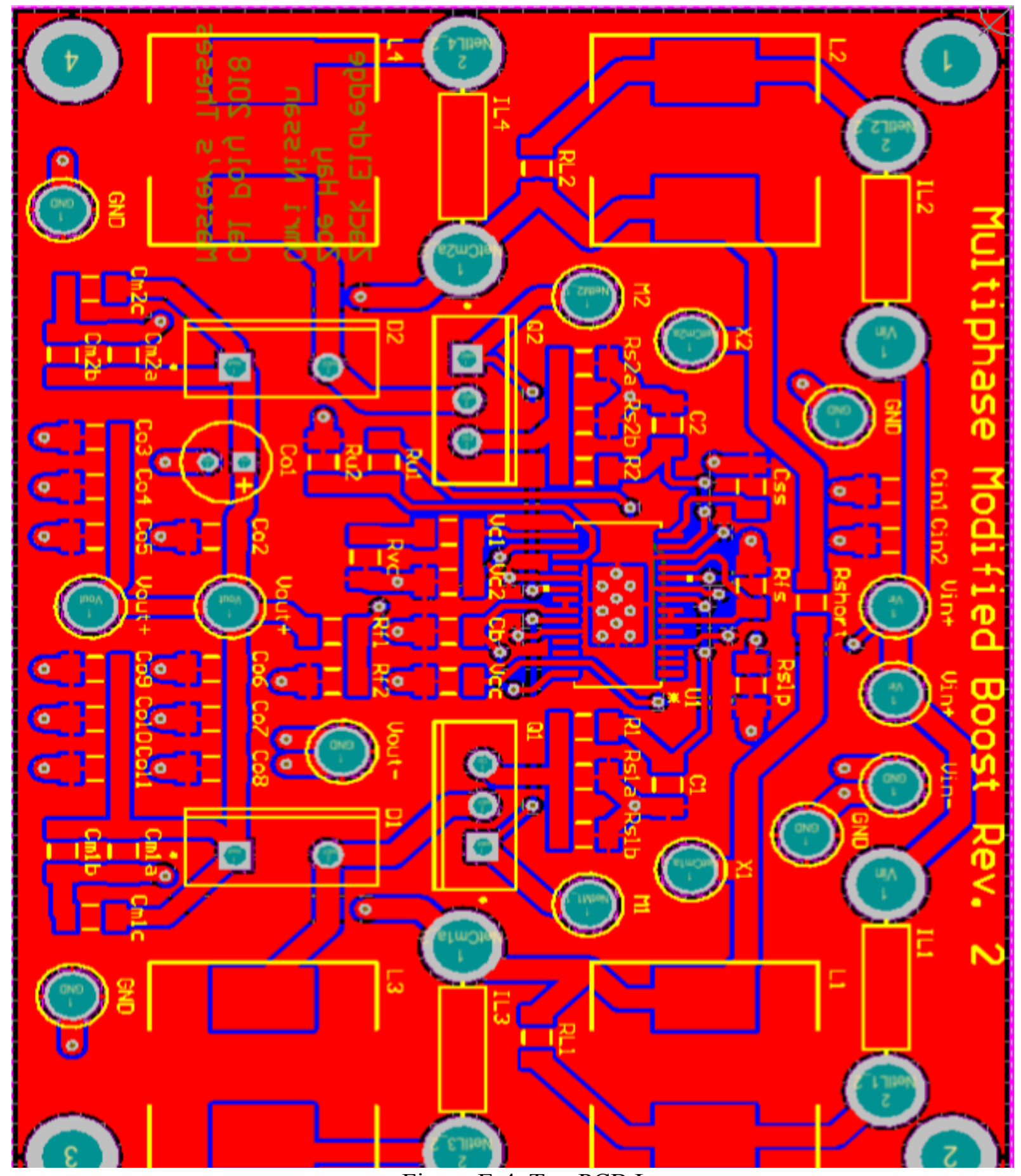

Figure E-4. Top PCB Layer 


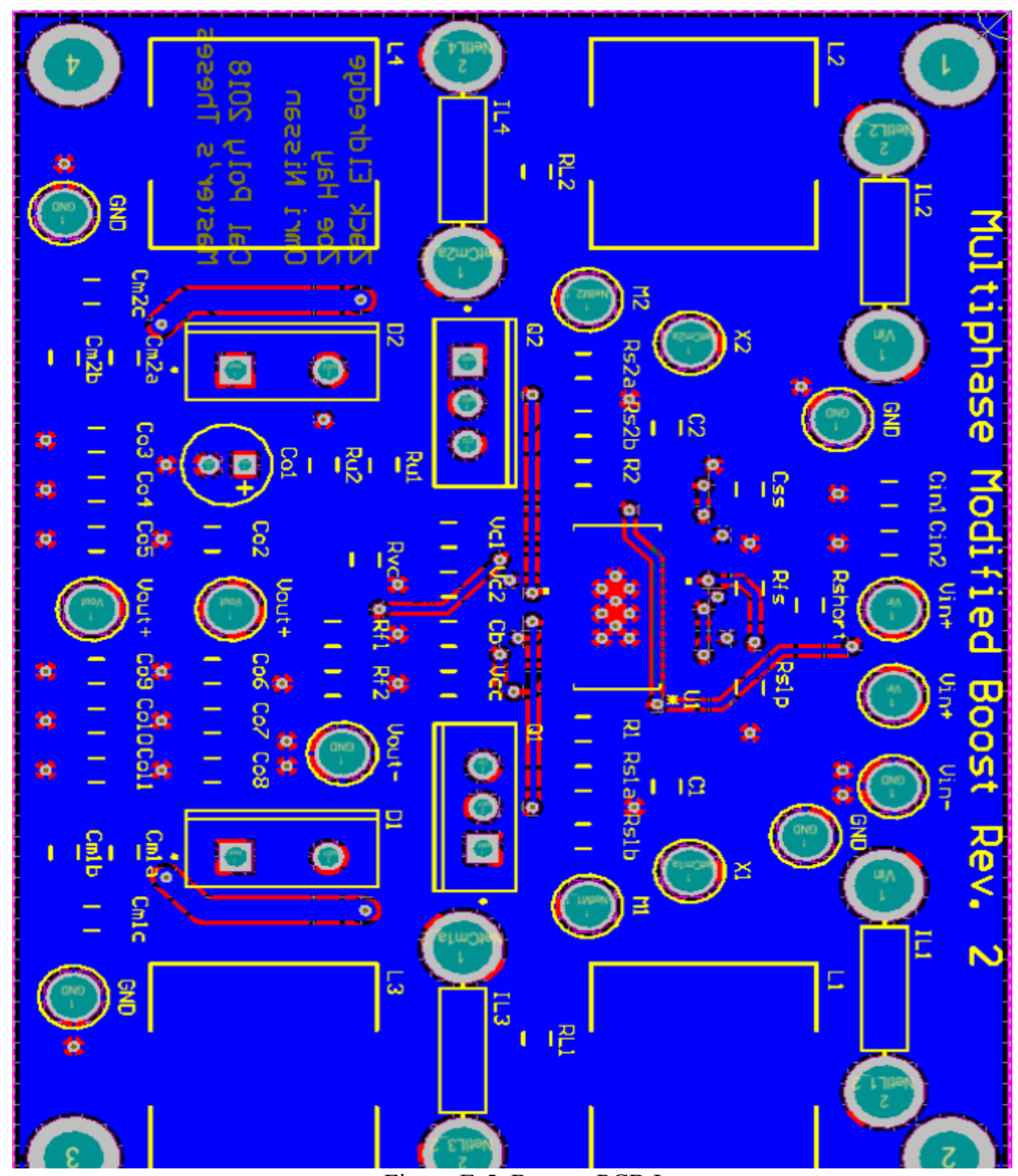

Figure E-5. Bottom PCB Layer 


\section{APPENDIX - F}

\section{F. current_adder.m}

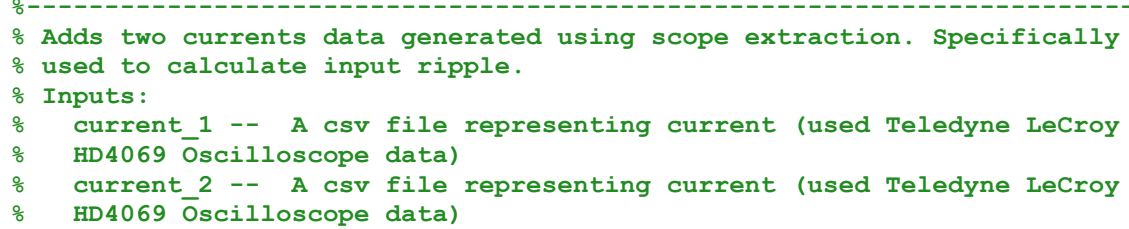




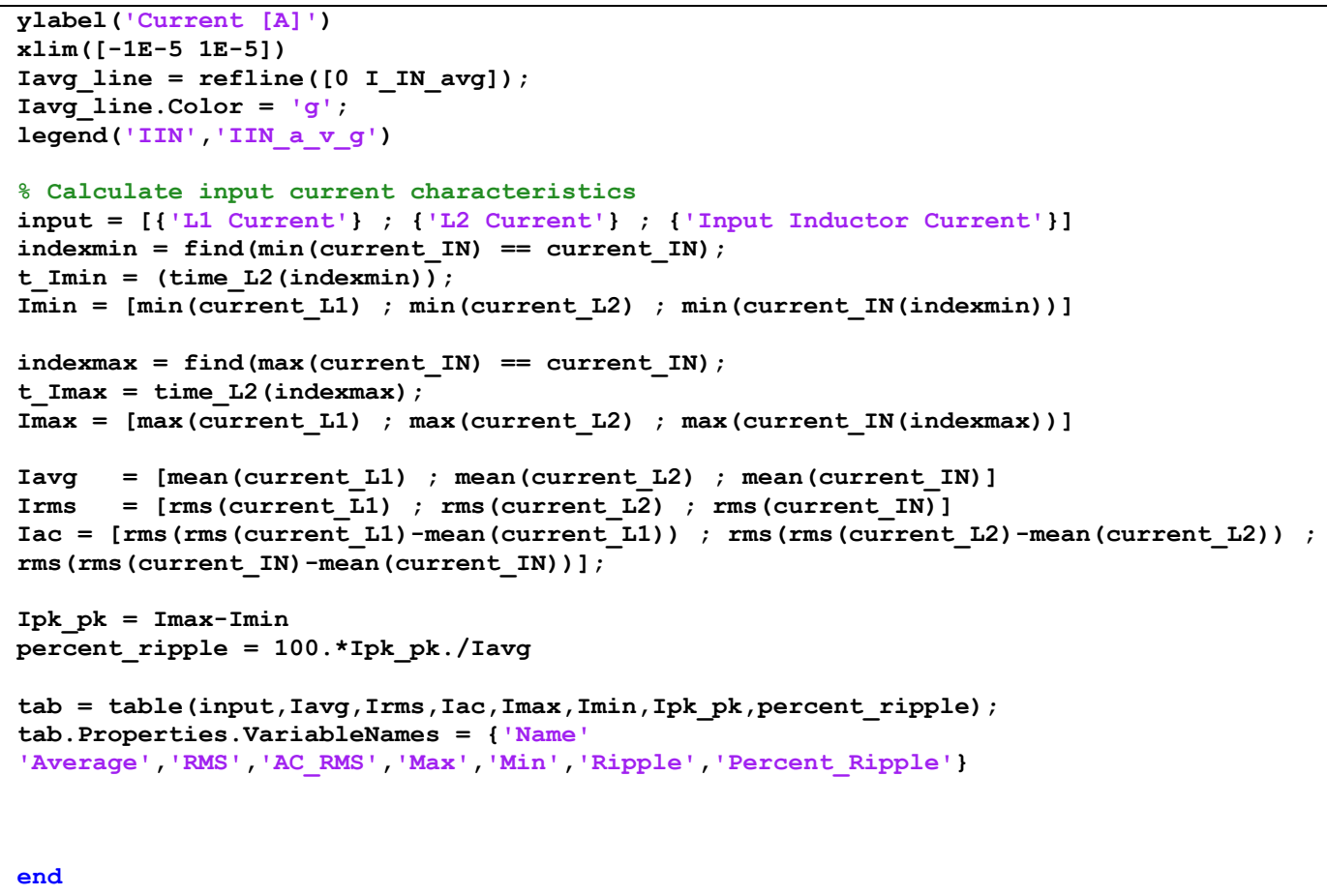




\section{APPENDIX - G}

\section{G. voltage_subtruct.m}

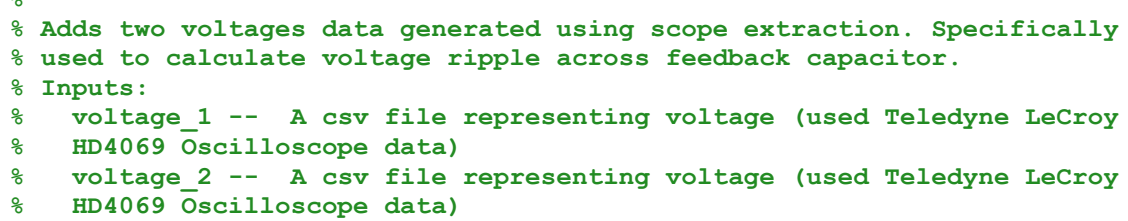




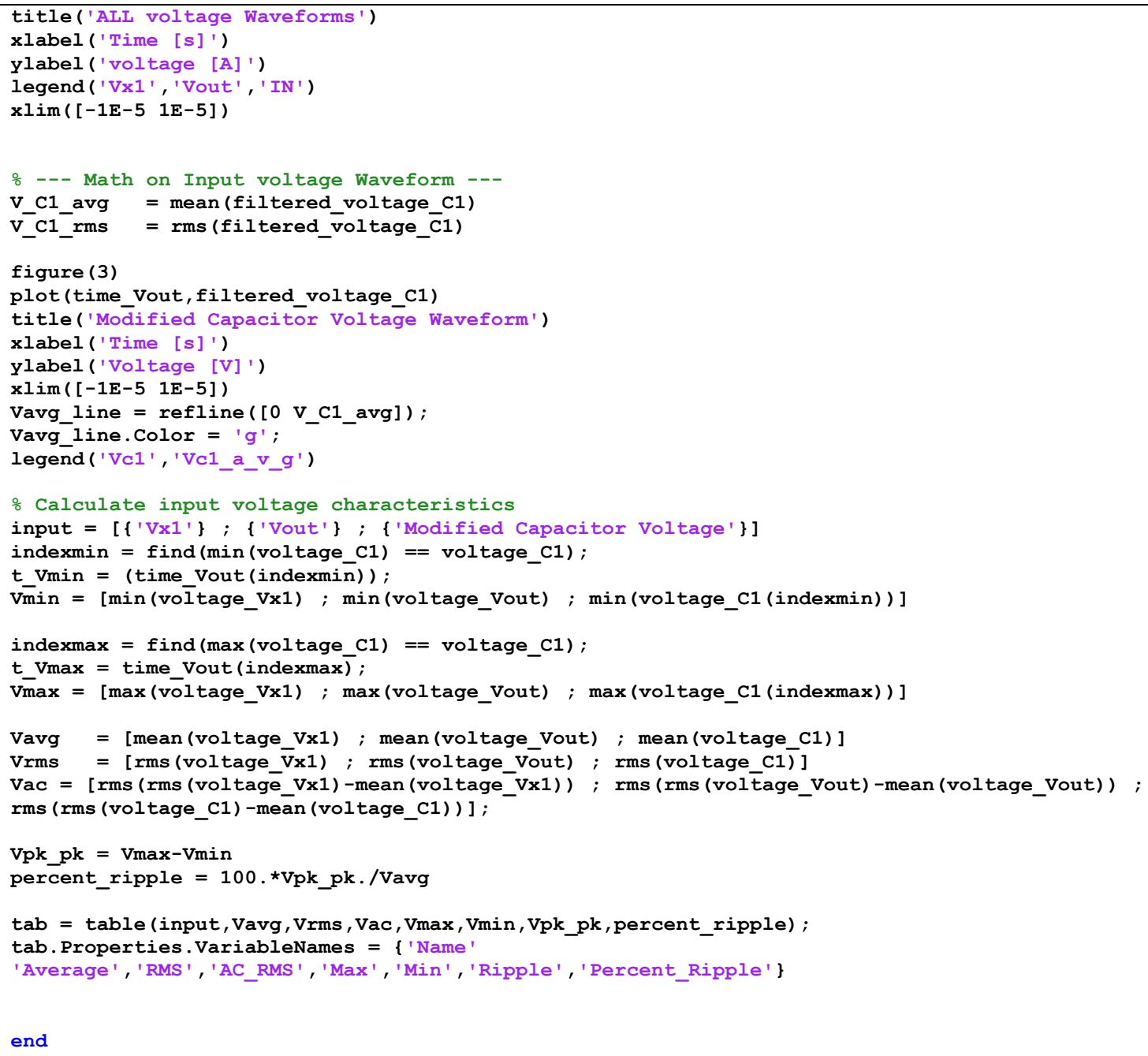




\section{APPENDIX - H}

\section{H. Analysis of Senior Project}

1. Summary of Functional Requirements

The purpose of this design was to create a topology that acts as the middle ground between solar panels and an inverter. With the growth of renewable technology, a solution that accommodates the requirements of solar is necessary. The topology allows for maximum power out of solar panel by limiting the input current ripple while demonstrating minimal losses as it converts the solar cell voltage into an acceptable higher voltage for the inverter.

2. Primary Constraints

The topology has to demonstrate improvement in input ripple while maintaining above $90 \%$ efficiency. The topology should also be easily reproducible and well documented for future research.

3. Economic

a. What economic impacts result?

i. Human Capital: The topology permits the expansion of solar around the globe. The integration of solar will create new jobs for design and integration. Implementation of the solar structures will also help countries that suffer from energy poverty and provide them with potential careers maintaining these infrastructures.

ii. Financial Capital: 
Increased standard of living will potentially foster economic development. The topology will allow for transfer of larger sums of solar energy, as it is more efficiency for packets of high packets.

iii. Natural Capital:

The electrical components ( 2 more inductors and 1 capacitor with respect to multiphase boost) of the system will add material costs. The topology will increase integration of renewable energy. The adoption of more DC systems could allow transition away from nonrenewable energy resource.

iv. Costs/Timing:

The cost of this project is proving the design and then the addition of components with respect to a standard multiphase converter.

4. If Manufactured on a Commercial Basis

In the initial of implementation for the converter, small private solar farms will be used. After proof of concept the topology could be integrated in large scale. The total cost of the topology, including independent $\mathrm{PCB}$, is in the $\$ 100$ range without labor. For future implementation, the converter could be integrated into the inverter, therefore it would not need to be externally connected between the two technologies.

5. Environmental

a. What environmental impacts are associated with manufacturing or use? Environmental impacts may be associated with the manufacturing of converter in this project. 
b. Which natural resources and ecosystem services does the project use (directly and indirectly), improve, or harm?

The converter purpose is to spread the use of renewable energy while improving the energy delivered by solar energy. The converter will use common resources for PCB manufacturing, hopefully complying with ROHS standards (which depends on the designer).

c. How does the project impact other species?

Indirectly, as the converter integrates with future renewable energy, it could reduce environmental damage and threat to species from other nonrenewable energy sources. It could help renewable energy become the standard for energy generation.

6. Manufacturability

a. Describe any issues or challenges associated with manufacturing.

The design will need to be surface mount soldered. For testing and initial use, this will be done by hand. The project will be designed with the goal of affordable manufacturability.

7. Sustainability

a. Describe any issues or challenges associated with maintaining the completed device.

The converter should maintain the efficiency standards for at least 10 years. Evaluating the technology after 10 years is necessary to integrate 
new industry findings. Care should be taken to select components that handle the proper ratings to ensure longevity of the converter.

b. Describe how the product impacts the sustainable use of resources.

The development of the converter can encourage the use of sustainable sources of energy.

c. Describe any upgrades that would improve the design of the project.

Future development should focus on decreasing the ripple on the inner inductors thus improving efficiency of the design and directly decreasing the inductors size.

d. Describe any issues or challenges associated with upgrading the design. As renewable technology improves, adjusting to solar panels' new standard voltage levels or any other characteristics is necessary to improve interaction between renewable energy and the power grid.

\section{Ethical}

a. Ethical implications relating to the design, manufacture, use, or misuse of the project:

i. The converter overall design has impressive positive ethical implication as it supports the use of renewable energy. It permits more efficient use of solar with relatively minor changes to the current topology used for such purpose. Misuse of the product could result system failure and overall fault in the grid. Necessary protocols and protection circuitry will be implemented to prevent accidents from misuse. Per the IEEE code of ethics, 
our product will be tested to guarantee that performance specifications are met with absolute certainty, under both ideal and non-ideal conditions.

9. Health and Safety

a. Health and safety concerns associated with design, manufacture or use of the project.

The implementation of the system can result in more conducive environment that allows for healthier living. Since it is connected to solar power, the power transmission could be high and pose a safety risk. The high voltage nature of the project indicates safety and fault protection should be a key concern.

10. Societal and Political

a. Social and political issues associated with design, manufacture and use: The purpose of the topology is to expand the benefits of solar, thus it has positive social intentions to protect the environment. The spread of renewable energy associated with this new topology in general will have wider positive social and political effects.

b. Who does the project impact? Who are the direct and indirect stakeholders? How are they affected?

The topology should help government meet sustainable initiatives as it provides better efficiency than the currently used converter. In terms of government installation, the development will depend on budget. On the 
flip side, privately owned renewable energy has been increasing year after year, thus this converter is ideal integration for those owners.

\section{Development}

a. New tools or techniques, used for either development or analysis that were learned during the course of this project:

The completion of this project will require an understanding of fundamental knowledge of multiphase and boost topology.

Implementation will also require knowledge of PCB design, layout, and tiny surface mount soldering. 